\title{
Cytoprotective approaches to protect myocardium against ischemia/reperfusion injury
}

\author{
Ph.D. Thesis \\ János Pálóczi MSc \\ Cardiovascular Research Group \\ Department of Biochemistry \\ Doctoral School of Multidisciplinary Medicine \\ Faculty of Medicine \\ University of Szeged
}

Supervisors: $\quad$ Anikó Görbe MD, Ph.D.

Péter Bencsik MD, Ph.D.

Szeged

2015 


\section{LIST OF PUBLICATIONS}

1. List of full papers directly related to the subject of the thesis:

I. Bencsik P*, Pálóczi J*, Kocsis GF, Pipis J, Belecz I, Varga ZV, Csonka C, Görbe A, Csont T, Ferdinandy P. Moderate inhibition of myocardial matrix metalloproteinase-2 by ilomastat is cardioprotective. Pharmacol Res. 2014; 80:36-42. IF.: 3.976

*these authors contributed equally to the work.

II. Görbe A, Varga ZV, Pálóczi J, Rungarunlert S, Klincumhom N, Pirity MK, Madonna R, Eschenhagen T, Dinnyés A, Csont T, Ferdinand P. Cytoprotection by NO-donor SNAP against ischemia/reoxygenation injury in mouse embryonic stem cell-derived cardiomyocytes. Mol Biotechnol. 2014; 56:258-64. IF.: 2.275

Cumulative impact factor of papers directly related to the thesis: 6.251

\section{List of full papers indirectly related to the subject of the thesis:}

III. Csonka C, Kupai K, Bencsik P, Görbe A, Pálóczi J, Zvara A, Puskás LG, Csont T, Ferdinandy P. Cholesterol-enriched diet inhibits cardioprotection by ATP-sensitive $\mathrm{K}^{+}$ channel activators cromakalim and diazoxide. Am J Physiol Heart Circ Physiol. 2014; 306:H405-13. IF.: $\mathbf{4 . 0 1 2}$

IV. Monostori P, Kocsis GF, Ökrös Z, Bencsik P, Czétényi O, Kiss Z, Gellén B, Bereczki, C, Ocsovszki I, Pipis J, Pálóczi J, Sárközy M, Török S, Varga IS, Kiss I, Fodor E, Csont T, Ferdinandy P, Túri S. Different administration schedules of darbepoetin alfa affect oxidized and reduced glutathione levels to a similar extent in $5 / 6$ nephrectomized rats. Clin Exp Nephrol. 2013; 17:569-74. IF.: 1.708

V. Szücs G, Murlasits Z, Török S, Kocsis GF, Pálóczi J, Görbe A, Csont T, Csonka C, Ferdinandy P. Cardioprotection by Farnesol: Role of the Mevalonate Pathway. Cardiovasc Drugs Ther. 2013; 27:269-77. IF.: 2.952

VI. Varga ZV, Kupai K, Szücs G, Gáspár R, Pálóczi J, Faragó N, Zvara A, Puskás LG, Rázga Z, Tiszlavicz L, Bencsik P, Görbe A, Csonka C, Ferdinandy P, Csont T. MicroRNA-25-dependent up-regulation of NADPH oxidase 4 (NOX4) mediates hypercholesterolemia-induced oxidative/nitrative stress and subsequent dysfunction in the heart. J Mol Cell Cardiol. 2013; 62:111-21. IF.: 5.218

VII. Kocsis GF, Sárközy M, Bencsik P, Pipicz M, Varga ZV, Pálóczi J, Csonka C, Ferdinandy P, Csont T. Am J Physiol Heart Circ Physiol. 2012; 303:H1229-36.

IF.: 3.629

Cumulative impact factor of papers indirectly related to the thesis: 17.519 


\section{TABLE OF CONTENTS}

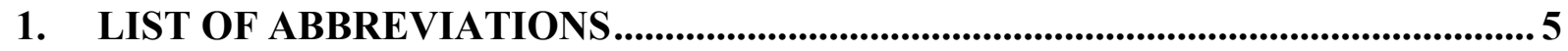

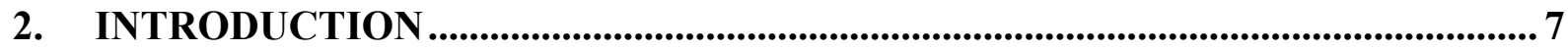

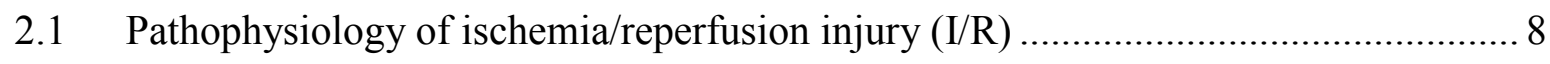

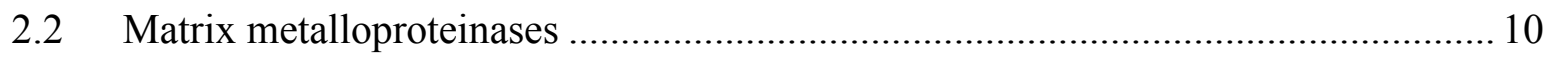

2.3 Stem cell-derived cardiomyocytes: a new therapeutic approach to treat myocardial

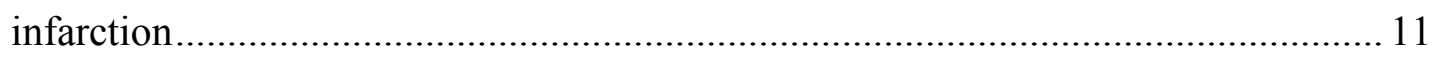

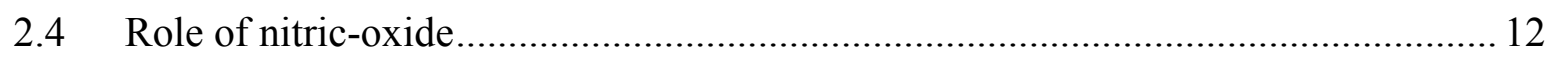

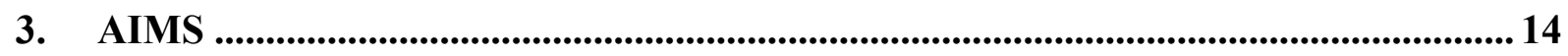

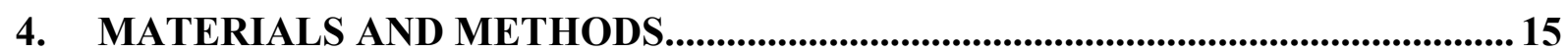

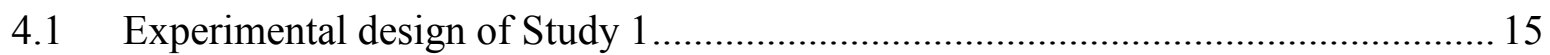

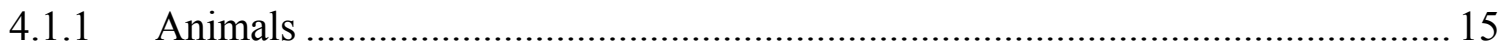

4.1.2 Experimental design of in vitro studies ........................................................ 15

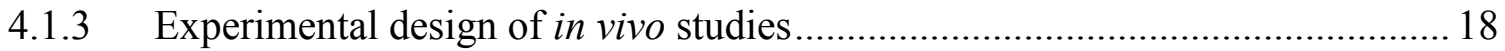

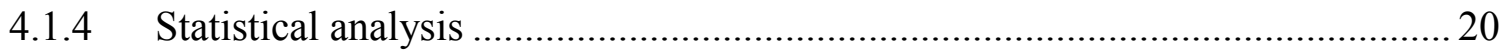

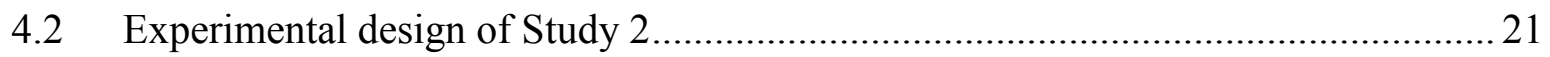

4.2.1 Mouse Embryonic Stem Cell Culture ….......................................................... 21

4.2.2 Embryoid Body (EB) Formation and Cardiomyocyte Differentiation............... 21

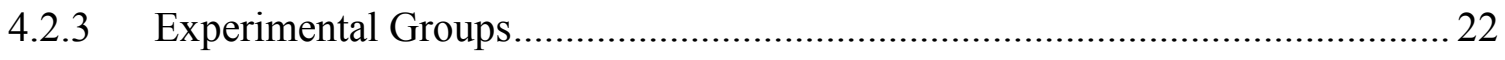

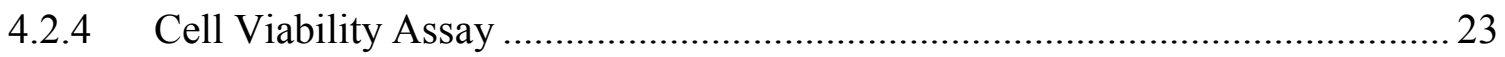

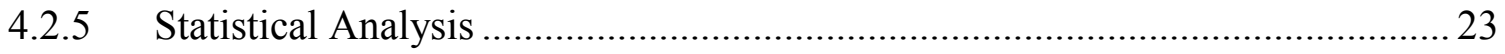

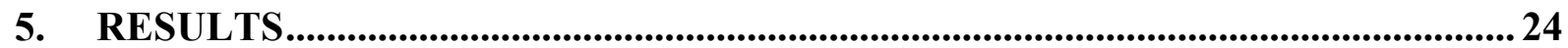

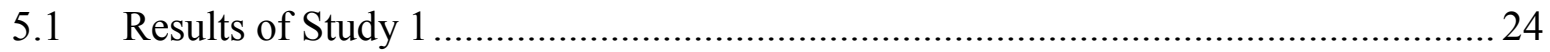

5.1.1 Effect of ilomastat on cardiac gelatinolytic activity....................................... 24

5.1.2 Effect of ilomastat on cardiomyocytes injured by ischemia/reoxygenation ...... 24 
5.1.3 In situ MMP-2 inhibition by ilomastat in cardiomyocytes injured by

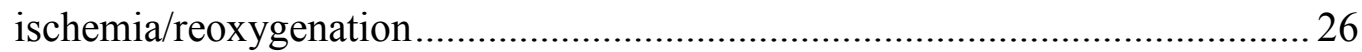

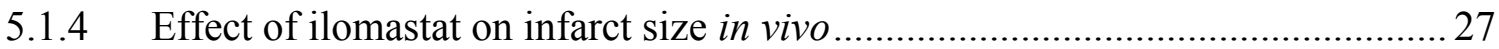

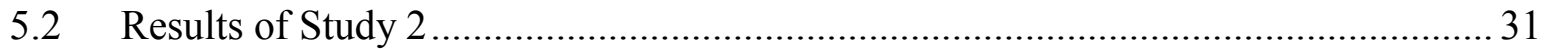

5.2.1 Cell Viability after SI/R treatment of mESC-derived cardiomyocytes ............... 31

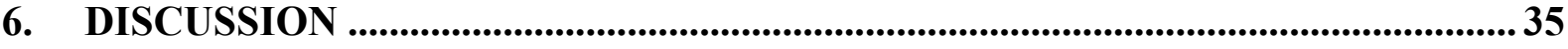

6.1 Study 1: MMP-2 inhibition by ilomasat exerts cardioprotection ............................ 35

6.2 Study 2: the NO donor SNAP has cytoprotective effect on mESC-derived

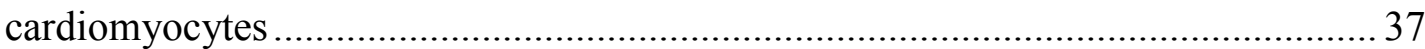

7. CONCLUSIONS AND FURTHER PERSPECTIVES .......................................... 40

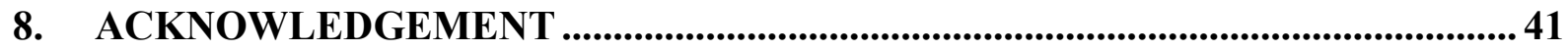

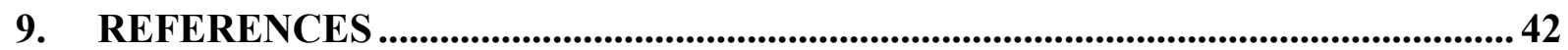

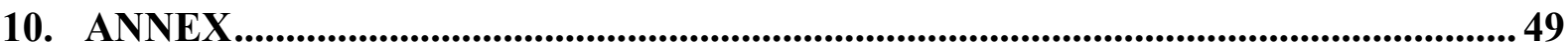




\section{LIST OF ABBREVIATIONS}

AMI

ANOVA

BNP

cGMP

DMEM

DMSO

EBs

ECG

EDTA

eGFP

FBS

Glib

$\mathrm{I} / \mathrm{R}$

IHD

ILO

$\mathrm{K}_{\mathrm{ATP}}$

LAD

LIF

L-NNA

MEFs

mESCs

MMP

mPTP

NEAA

$\mathrm{NF} \kappa \mathrm{B}$

$\mathrm{Nkx} 2.5$

$\mathrm{NO}$

NOS

NOS1 (or nNOS)

NOS2 (or iNOS)

NOS3 (or eNOS)

PBS acute myocardial infarction

analysis of variance

B-type natriuretic peptide

cyclic guanosine monophosphate

Dulbecco's Modified Eagle's Medium

dimethyl sulfoxide

embryonic bodies

electrocardiogram

ethylene-diamine-tetra-acetic acid

enhanced green fluorescent protein

fetal bovine serum

glibenclamide

ischemia/reperfusion

ischemic heart disease

ilomastat

ATP-sensitive potassium channel

left anterior descending coronary artery

leukemia inhibitory factor

N-Nitro-L-arginine

mouse embryonic fibroblasts

mouse embryonic stem cells

matrix metalloproteinase

mitochondrial permeability transition pore

nonessential amino acids

nuclear factor kappa-B

homeobox protein $\mathrm{Nkx} 2.5$

nitic oxide

nitric oxide synthase

neural nitric oxide synthase

inducible nitric oxide synthase

endothelial nitric oxide synthase

phosphate buffer solution 
PI

PKG

pro-MMP2

RISK

RNS

ROS

SAFE

SEM

$\mathrm{SI} / \mathrm{R}$

SNAP

SR propidium iodine

protein kinase $\mathrm{G}$

pro-form of matrix metalloproteinase type 2

reperfusion injury salvage kinase

reactive nitrogen species

reactive oxygen species

survivor activating factor enhancement

standard error of the mean

simulated ischemia/reoxygenation

s-nitroso-n-acetyl-penicillamine

sarcoplasmic reticulum 


\section{INTRODUCTION}

Ischemic heart disease (IHD) is one of the leading cause of death in the industrialized world. IHD by itself is the single most common cause of death in the European Union: accounting for over 681000 deaths in each year (according to the European Cardiovascular Disease Statistics, released in 2012) [1]. In Hungary, more than 6000 patients die due to the consequences of acute myocardial infarction (AMI) in each year (according to the official statement of the Hungarian Central Statistical Office, released in 2012) [2]. AMI leads to massive cardiac cell loss, rapid decline of cardiac contractility, occurrence of lethal arrhythmias, and in the long run to scar formation, structural and functional cardiac remodeling and eventually to the development of heart failure. Therefore, it is highly important to salvage the ischemic region of heart via its reperfusion as soon as possible to improve the clinical outcomes of myocardial infarction. In experimental studies, the rate of remodeling is highly affected by the extent of the infarcted area [3]. In humans, infarct size is a major determinant of mortality in myocardial infarction [4]. Therefore, limitation of infarct size by induction of reperfusion is an important therapeutic approach. However, reperfusion may lead to intense generation of reactive oxygen (ROS) and nitrogen species (RNS) and activation of numerous cascade mechanisms which may result in further myocardial damage [5]. Additionally, despite of a decade of intense research on the cellular mechanism of cardioprotective interventions aiming to reduce reperfusion injury, such as ischemic or pharmacological postconditioning, the underlying mechanisms of these protective pathways are still poorly understood. Therefore, no drug targets could be identified so far that would lead to the development of a cardioprotective compound until market launching. This fact urges to identify novel targets and to find effective drugs for cardioprotection.

Over the last decade, a novel therapeutic approach has been offered; stem cell derived cardiomyocytes may be used as a cell source for cardiac repair after myocardial infarction [69]. Despite the encouraging results and the enormous potential of human stem cell-derived cardiomyocytes, several complications and ethical concerns need to be overcome towards clinical translation. Therefore, the improvement of cell replacement therapy is one of the most important aims of further investigations. 


\subsection{Pathophysiology of ischemia/reperfusion injury (I/R)}

Ischemia is defined as an inadequate blood flow in the affected tissue or in an organ that is accompanied by the loss of oxygen and nutrients. It is well known that myocardial ischemia results in the impairment of contractile function and causes myocardial damage as a consequence of cell death from both necrosis and apoptosis [10]. Ischemia triggers the accumulation of intracellular sodium, hydrogen, and calcium ions, thereby facilitating tissue acidosis (Fig.1). The decline of $\mathrm{pH}$ stimulates $\mathrm{Na}^{+}-\mathrm{H}^{+}$exchange and $\mathrm{Na}^{+}-\mathrm{HCO}_{3}{ }^{-}$transporter, which leads to intracellular sodium accumulation and development of intracellular $\mathrm{Ca}^{2+}$ overload [11].

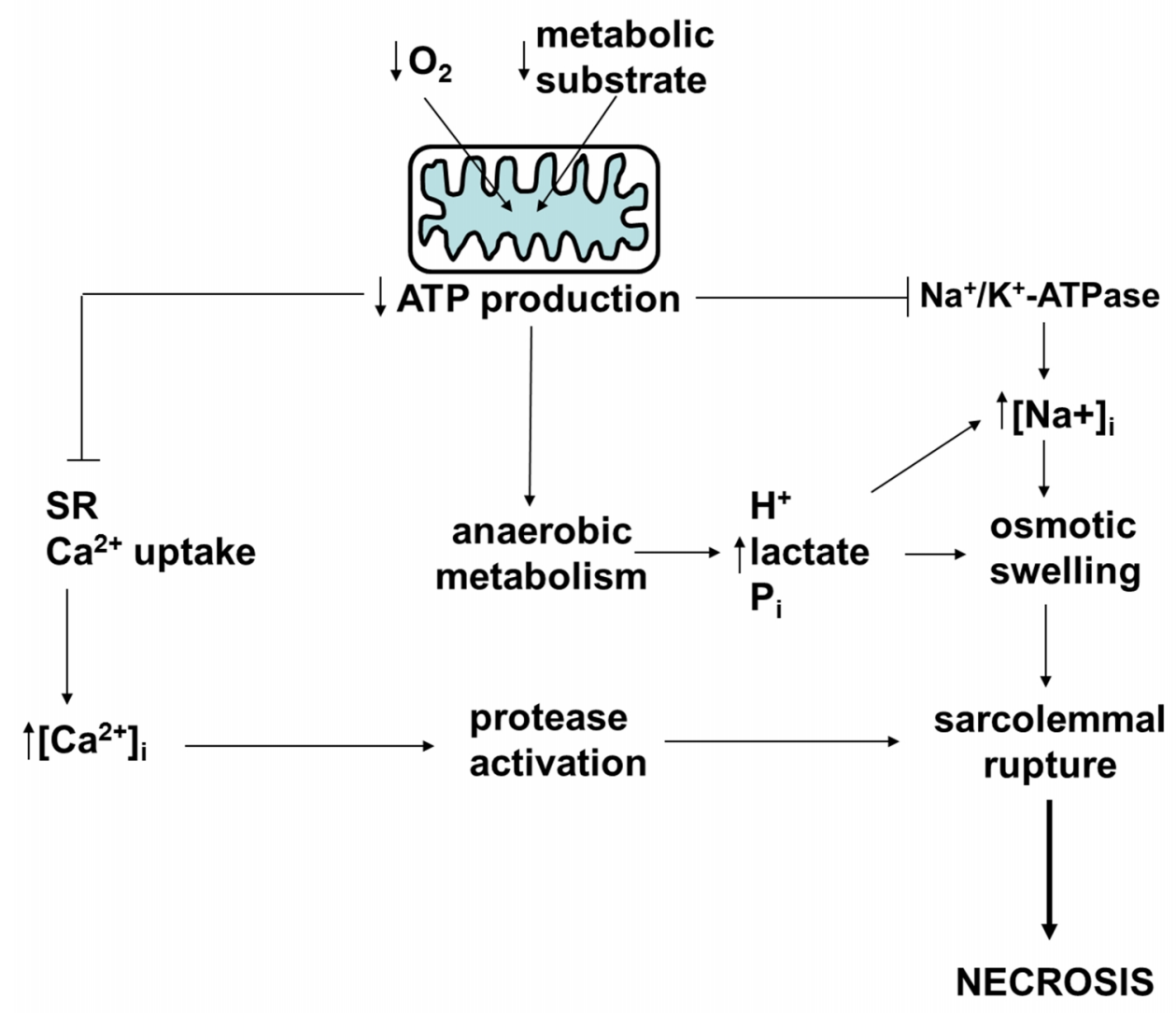

Fig.1: Ischemic injury of myocardium

(modified from Ferdinandy et al., Pharmacol Rev. 2007).

Due to the impaired calcium handling, numerous intracellular enzymes are activated including proteases and endonucleases, which are involved in proapoptotic signaling [12], activating plasma membrane phospholipase A2, which leads to the formation of arachidonic acid derivatives (e.g. leukotriene B4, thromboxane A2). This event then facilitates neutrophil infiltration and perpetuates the generation of reactive oxygen radicals via stimulation of neutrophil oxidative burst. In addition, the absence of oxygen causes cellular ATP-depletion 
that leads to mitochondrial dysfunction and initiates the translocation of Bax, a proapoptotic Bcl2 family member protein, from the cytosol to the outer mitochondrial membrane. This triggers mitochondrial swelling and induces the efflux of cytochrome $\mathrm{c}$ via opening of the permeability transition pore (mPTP) into the cytosol [13]. The intracellularly localized cytochrome c activates effector caspases and initiates apoptosis. The impairment of the mitochondrial electron transport chain stimulates the generation of ROS and development of oxidative stress in the ischemic heart. ROS react directly with cellular lipids, proteins and DNA exacerbating cell injury/death and leading to the activation of nuclear factor kappa-B (NFkB) [14]. Moreover, the excess of ROS impairs the antioxidant capacity of cell by depleting reduced glutathione. Additionally, it has been also reported that intracellular ROS (particularly peroxynitrite) are implicated with the activation of matrix metalloproteinases (MMPs), thereby playing a pivotal role in the progression of ischemic injury by contributing to the degradation of several extracellular matrix protein [15].

Although the re-establishment of adequate oxygen and nutrients supply is able to limit the extent of the infarction, restoration of normal blood flow results in a complex cascade of inflammation, sudden oxygen surplus and oxidative stress (Fig.2).

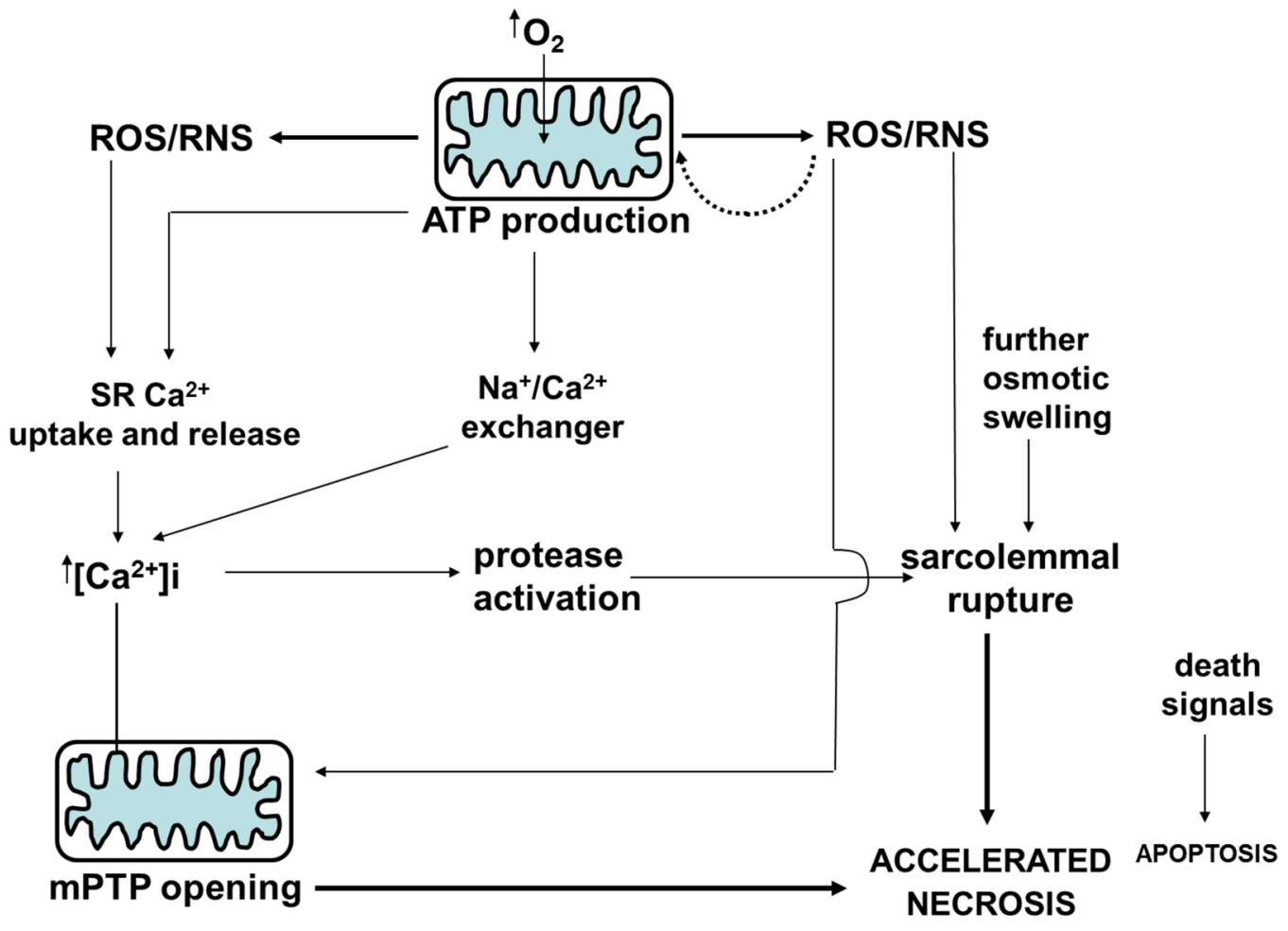

Fig.2: Reperfusion injury

(modified from Ferdinandy et al., Pharmacol Rev. 2007). 
Increasing evidence points to the fact that reperfusion injury can lead to a rapid rising of cell necrosis and apoptosis. At reperfusion; endothelial cells up regulate the expression of adhesive proteins and release leukocyte attractants. Activation and accumulation of leukocytes (primarily neutrophils and monocytes) triggers multiple mediator cascades leading to cytokine release, increased vascular permeability, generation of ROS and liberation of proteolytic enzymes from granulocytes [10].

Additionally, during ischemia, the hydrolysis of ATP to AMP leads to the accumulation of hypoxanthine. Increased intracellular calcium enhances the conversion of xanthine dehydrogenase to xanthine oxidase which may produce superoxide and xanthine from the accumulated hypoxanthine upon reintroduction of oxygen. This leads to further oxidative stress that can jeopardize cellular function and survival [16].

\subsection{Matrix metalloproteinases}

Matrix metalloproteinases (MMPs) are a large family of zinc dependent endopeptidases. They were firstly identified by Gross et al. and named according to their ability to remodel extracellular matrix [17]. MMPs are synthesized in an inactive form (zymogen or pro-MMP), and are activated by proteolytic cleavage of an N-terminal domain or by conformational changes induced by denaturing agents or ROS. Basically, MMPs are activated by the removal of the autoinhibitory propeptide domain resulting in an active truncated MMP. They are involved in the remodeling of extracellular matrix during various physiological processes including embryonic development [18], angiogenesis [19], wound healing and tissue repair [20]. On the other hand, MMPs have been shown to play a crucial role in several pathologies such as metastatic cancers [21], arthritis [22], inflammation [23] and diabetes [24]. Moreover, gelatinase types of MMPs, (MMP-2 and MMP-9) are implicated with numerous cardiovascular diseases such as ischemia/reperfusion injury [25,26]. It has been previously reported that MMP-2 is constitutively expressed in cardiomyocytes [27] and stored intracellularly in an inactive pro-MMP-2 (also referred as $72 \mathrm{kDa}$ MMP-2) form. Increasing evidences suggest that ischemic stimulus can activate the intracellular pro-MMP-2 which is able to proteolytically cleave several structural proteins including titin, alpha-actinin, or troponins (for recent review see ref. 28). Degradation of these proteins could lead to contractile dysfunction and cell death. The activation of pro-MMP-2 may be due to the increased peroxynitrite production [26]. Peroxynitrite has been shown to activate pro-MMP-2 via the redox modification of the regulatory site of this enzyme [29,30]. This redox 
modification leads to the undesired activation of 75 and $72 \mathrm{kDa}$ isoforms of MMP-2, besides that only the $64 \mathrm{kDa}$ isoform is active once MMP-2 is activated in the classical manner [31,32]. In addition, active MMP-2 is released from necrotic cells thereby exacerbating the outcome of ischemic injury [15]. Hence, the activation of MMP-2 during an ischemic insult is associated with decreased functional recovery and larger infarct size of the heart (for review see ref. 33).

We have previously reported that MMP-2 activity was moderately decreased during ischemic preconditioning [34] and that exogenous inhibition of MMPs by ilomastat, a nonselective MMP inhibitor diminished ischemia-induced MMP-2 activity in isolated rat hearts [35]. Furthermore, we have demonstrated that the activities of MMP-2 and MMP-9 were decreased significantly in an in vivo rat model of ischemic late preconditioning [36]. Moreover, we and others have shown that the non-selective MMP inhibitor ilomastat reduced infarct size in rats and mice [36,37]. Taken together, MMP-2 became a major target for drug development in acute cardiovascular pathologies including AMI $[38,39]$. However it is unknown whether ilomastat-induced cardioprotection is due to MMP-2 inhibition and what extent of this inhibition is required for sufficient cardioprotection. Moreover it is still unclear whether the ilomastat-iduced cardioprotection occurs via the inhibition of the intracellularly active MMP-2.

\subsection{Stem cell-derived cardiomyocytes: a new therapeutic approach to treat myocardial infarction}

Thrombolytic therapy and other coronary interventions are widely used clinical strategies to reduce infarct size and facilitate rapid recanalization of the occluded coronary artery after myocardial infarction to limit infarct size (for review see ref. 40). However, if there is no adequate intervention to minimize myocardial damage, the prolonged ischemic injury would increase the risk of mortality. Recently, an alternative approach has come into the focus of cardiovascular regenerative medicine. Over the last few years, various cell types such as fetal or neonatal cardiomyocytes, skeletal muscle myoblasts, mesenchymal stem cells, hematopoietic stem cells, adult cardiac resident stem cells, embryonic stem cell-derived

cardiomyocytes have been used in preclinical studies for cell replacement therapy following myocardial infarction (for review see ref. 41). Embryonic stem cells might be a promising cell source, because of their capability to provide unlimited expansion in undifferentiated state and 
their ability to undergo inducible differentiation into cardiomyocytes in vitro [6-9]. However, applications of embryonic stem cell-derived cardiomyocytes have ethical considerations; therefore, better potential of these cardiomyocytes is testing cardioprotective compounds in vitro. Moreover, a recently discovered technique [42] gives new insight into stem cell biology: reprogramming of adult somatic cells into pluripotent stem cell lines (generation of induced pluripotent stem cells) and their differentiation into functional cardiomyocytes provides new perspectives in personalized cell replacement therapy (for review see ref. 43 and ref. 44).

Despite the increasing number of promising results $[7,8,45]$, several complications need to be overcome towards clinical translation including the precise characterization of stem cell lines, such as the development of efficient protocols for proper cardiomyocyte differentiation, the establishment of strategies for cardiomyocyte selection, the development of scaling-up procedures to provide clinically-relevant number of cardiomyocytes, and the development of cell delivery strategies [43,44,46,47]. Another limitation regarding their clinical utilization is that the survival of implanted cells is reduced after transplantation $[6,8]$. Implanted cells undergo a significant cell death within the first 24 hours [48]. A plausible reason for this effect is the unfavorable microenvironment for the grafted cells when implanted into the ischemic myocardium. Thus, in vitro preconditioning strategies might be beneficial to improve and optimize long-term survival and maturation of the cell grafts $[49,50]$. Furthermore, characterization of these cells and their hypoxic tolerance in a simulated ischemia/reoxygenation test system would be important, since little is known about the ischemic tolerance of stem cell-derived cardiomyocytes.

\subsection{Role of nitric-oxide}

Nitric oxide (NO) is a gaseous substance that regulates a wide range of biological processes. It typically exerts its physiological functions by binding directly to ferrous iron of heme proteins or indirectly by S-nitrosylation of protein thiol groups [51]. NO is synthesized at low physiological levels by NO synthase (NOS) enzymes. In this reaction, L-arginine is oxidized with molecular oxygen to form L-citrulline and NO [52]. Three main isoforms of NOS are widely present and named according to the tissues where they were first identified or to their mode of expression: neural NOS (nNOS or NOS1) is expressed mainly in neurons; inducible NOS (iNOS or NOS2), the NOS isoform with the highest rate of NO synthesis expressed in cell types of the immune system in response to infection; and endothelial NOS 
(eNOS or NOS3) is presented in the vascular endothelium. NO has a well-known cardioprotective effect against ischemia/reperfusion injury that is conducted by activating the cyclic guanosine monophosphate (cGMP)/ protein kinase G (PKG) axes, as a key modulator of the RISK (reperfusion injury salvage kinase) and SAFE (survivor activating factor enhancement) pathways, and by inducing S-nitrosylation of proteins including sarco/endoplasmic reticulum $\mathrm{Ca}^{2+}$-ATPase and several mitochondrial proteins (for review see ref. 51,53-57). However, excess of NO in the presence of the co-existing free radicals have detrimental effect on cell survival.

We have previously shown that the exogenously administered NO donor S-nitroso-nacetyl-penicillamine (SNAP) and the particulate guanylate cyclase activator B-type natriuretic peptide (BNP) exert cytoprotective effect against simulated ischemia/reoxygenation (SI/R) injury in primary neonatal rat cardiomyocytes [58]. This protection acts via the activation of cGMP/PKG signaling pathway, thereby stimulating its multiple downstream signal transduction cascade which leads to increased cell viability against SI/R injury $[59,58,60]$. Moreover, our previous findings also suggest that the present screening platform is a useful tool for discovery of cardiocytoprotective molecules and investigate their cellular mechanisms. Nevertheless, the importance of the cardioprotective effect of the activation of cGMP-PKG axes in mouse ESC (mESC)-derived cardiomyocytes is still unknown. Thus, it would be beneficial to test this pathway in the previously established SI/R test system. 


\section{AIMS}

\section{Study 1}

We aimed to test whether ilomastat-induced cardioprotection is due to (and what extent of) MMP-2 inhibition, we performed gelatin zymography and in situ zymography followed by immunostaining of MMP-2 in primary neonatal rat cardiomyocytes exposed to SI/R injury. Furthermore, our goal was to investigate the dose-response effect of ilomastat administered before the onset of ischemia as well as before the onset of reperfusion in an in vivo rat model of myocardial infarction.

\section{Study 2}

The aim of the second study was to establish a mouse embryonic stem cell-derived cardiomyocyte-based drug screening platform by investigating whether the cytoprotective NO-donor SNAP and B-type natriuretic peptide is able to protect these cells against SI/R injury. We also investigated the downstream pathways of the protection in this platform. 


\section{MATERIALS AND METHODS}

Animal handling and the investigation was in conjunction with Guide for the Care and Use of Laboratory Animals published by the U.S. National Institutes of Health (National Institutes of Health publication 85-23, revised 1996), and it was approved by a local animal ethics committee.

\subsection{Experimental design of Study 1}

\subsubsection{Animals}

Male Wistar rats (Charles-River, Germany) weighing 280-370g were used in the experiments housed in individually ventilated cages. Animals were fed with standard murine chow and unlimited access to water was ensured prior to the surgical intervention. For the cell culture experiments, neonatal Wistar rats were purchased from the local live-stock of the University of Szeged.

\subsubsection{Experimental design of in vitro studies}

\subsubsection{Inhibition of gelatinase activity by ilomastat}

To determine the source of the gelatinolytic activity and its inhibition by ilomastat, gelatin zymography was performed on cardiac tissue homogenate of a non-treated control rat. Gelatinolytic activities of MMP-2 were examined as previously described in detail by Kupai et al. [31]. Briefly, $8 \%$ polyacrylamide gels were copolymerized with gelatin $(2 \mathrm{mg} / \mathrm{mL}$, type A from porcine skin, Sigma-Aldrich, Budapest, Hungary), and $50 \mu \mathrm{g}$ of protein per lane were loaded. After electrophoresis $(90 \mathrm{~V}, 1.5 \mathrm{~h})$, gels were washed with renaturation buffer (BioRad, Hercules, CA; containing $2.5 \%$ Triton $\mathrm{X}-100$ ) for $3 \times 15 \mathrm{~min}$ then incubated in development buffer (Bio-Rad, Hercules, CA) for $20 \mathrm{~min}$ to eliminate Triton-X-100. Gels were sliced according to the lanes and the slices were incubated separately for $20 \mathrm{~h}$ at $37^{\circ} \mathrm{C}(\mathrm{pH}$ 7.4) in development buffer in the presence of vehicle and/or different concentrations of ilomastat (0.5 nM and 5.0 nM). Recombinant, human MMP-2 was used as positive control. Gels were then stained with $0.05 \%$ Coomassie brilliant blue (G-250, Sigma-Aldrich, 
Budapest, Hungary). Gelatinolytic activities were detected as transparent bands against the dark-blue background. Band intensities were quantified (Quantity One software, Bio-Rad, Hercules, CA) and expressed in arbitrary units. The gelatin zymography protocol does not contain any component or step, which may inhibit proteases including other MMPs.

\subsubsection{Simulated ischemia/reoxygenation in cardiomyocytes}

Neonatal rat cardiomyocytes were cultured in 48-well plates. Neonatal cardiomyocytes were chosen for this study, as they can be harvested on culture dishes without coating. The lack of coating is important in the present study, as coating materials (e.g. laminin, collagen, etc.) could influence the action of matrix metalloproteinases [61,62]. Cell isolation, culturing method and the SI/R drug screening platform were described before in detail $[58,63]$. Briefly, neonatal rats were sacrificed by cervical dislocation and hearts were placed into ice cold PBS solution. Ventricles were digested in $0.25 \%$ trypsin (Invitrogen, Life Technologies Hungary, Budapest, Hungary) solution and cell suspension was centrifuged at $400 \times \mathrm{g}$, for $15 \mathrm{~min}$ at $4^{\circ} \mathrm{C}$. Cell pellet was re-suspended in Dulbecco's Modified Eagle Medium (DMEM, Sigma-Aldrich, Budapest, Hungary) supplemented with L-glutamine (Sigma-Aldrich, Budapest, Hungary), Antibiotic-antimycotic solution (Sigma-Aldrich, Budapest, Hungary) and 10\% fetal bovine serum (FBS, Gibco, Life Technologies Hungary Ltd, Budapest, Hungary). Cells were counted in a hemocytometer, and seeded into 48-well plates at a density of $5 \times 10^{4}$ cell/well. After 24 hours, the growth medium was replaced with differentiation medium containing $1 \%$ fetal bovine serum. Cardiomyocytes were kept under normoxic conditions $\left(95 \%\right.$ air and $5 \% \mathrm{CO}_{2}$ at $37^{\circ} \mathrm{C}$ ) for three days prior to $\mathrm{SI} / \mathrm{R}$ experiments. We used a combination of hypoxic chamber and hypoxic solution to simulate tissue ischemia [58]. In the simulated ischemic group, the medium of the cultures were replaced with a hypoxic solution $[58,64]$ and plates were kept in a hypoxic chamber (gassed with $95 \% \mathrm{~N}_{2}$ and $5 \% \mathrm{CO}_{2}$ at $37^{\circ} \mathrm{C}$ ) for $240 \mathrm{~min}$ in the presence or absence of ilomastat ( $5 \mathrm{nM}, 50 \mathrm{nM} 500 \mathrm{nM}$ and $5 \mu \mathrm{M}$ ). The vehicle group was treated only with $0.2 \%$ DMSO. During reoxygenation, cells were covered with differentiation medium (containing 1\% fetal bovine serum) and kept in a normoxic incubator for $120 \mathrm{~min}$ (Fig.3). 


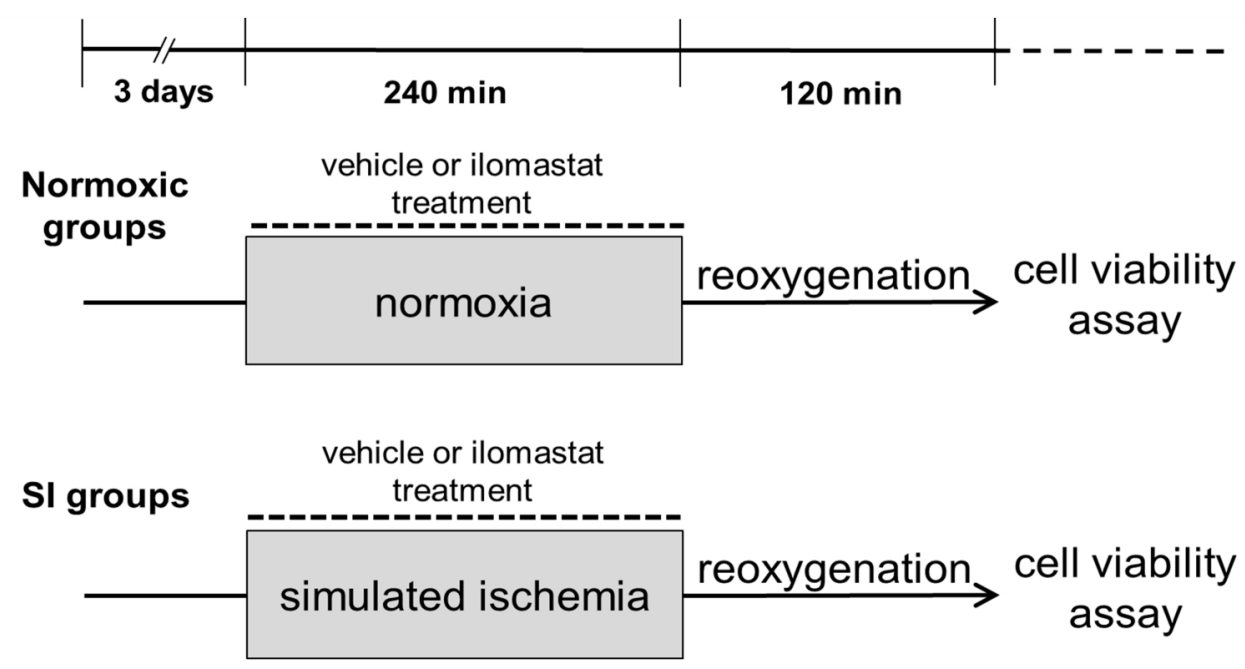

Fig.3: Experimental protocol for testing the direct cardioprotective effect of ilomastat in isolated neonatal rat cardiomyocytes exposed to SI/R injury.

\subsubsection{Cell viability assay}

Cell viability was assessed by a calcein and propidium iodine (PI) assay performed in each group after $2 \mathrm{~h}$ simulated reperfusion. Briefly, the growth medium was removed; cells were washed with PBS twice and incubated with calcein $(1 \mu \mathrm{M})$ for $30 \mathrm{~min}$. Then calcein solution was replaced with fresh PBS and fluorescence intensity of each well was detected by fluorescent plate reader (FluoStar Optima, BMG Labtech, Auro-Science Consulting Ltd, Budapest, Hungary; scan matrix: 10×10; scan diameter: $10 \mathrm{~mm}$; bottom optic; number of flashes/scan point: 3 ; temp: $37^{\circ} \mathrm{C}$; excitation wavelength: $488 \mathrm{~nm}$; emission wavelength: 520 $\mathrm{nm})$. Then to assess total cell count in each well, PI (50 $\mu \mathrm{M})$ and digitonin (100 $\mu \mathrm{M})$ (SigmaAldrich, St. Louis, MO) were dissolved in PBS and cells were incubated in this solution for 7 minutes. Then PI solution was replaced with fresh PBS and fluorescent intensity was detected with same settings (excitation wavelength: $544 \mathrm{~nm}$; emission wavelength: $610 \mathrm{~nm}$ ). Calcein data were normalized to total cell count obtained by PI+ digitonin treatment.

\subsubsection{In situ zymography and MMP-2 co-localization}

To detect in situ MMP-2 activity [65], neonatal rat cardiomyocytes were cultured in 24-well tissue culture plate at the density of $10^{5}$ cells/well for 3 days. The medium of cells was replaced with hypoxic solution supplemented with $\mathrm{DQ}^{\mathrm{TM}}$ gelatin (Invitrogen, Life Technologies Hungary Ltd, Budapest, Hungary) at $40 \mu \mathrm{g} / \mathrm{mL}$ concentration. Cells were then subjected to $240 \mathrm{~min}$ simulated ischemia in the presence of ilomastat (at $500 \mathrm{nM}$ 
concentration) or its vehicle. Other series of cells were covered with normoxic solution and kept in normoxic incubator for $240 \mathrm{~min}$. Subsequently, all groups were subjected to reoxygenation: the hypoxic, or normoxic solution of the cells was replaced with differentiation medium supplemented with $\mathrm{DQ}^{\mathrm{TM}}$ gelatin and cells were placed into a normoxic incubator for $120 \mathrm{~min}$. Finally cells were washed with PBS, and fixed in $3.7 \%$ paraformaldehyde dissolved in PBS for 15 min. MMP-2 fluorescent immunostaining using anti-proMMP-2 antibody (Chemicon, MAB3308; Merck Ltd, Budapest, Hungary; secondary antibody: rhodamine-labeled goat anti-mouse antibody; Abcam, AB5885, Cambridge, UK) was assessed to detect co-localization of MMP-2 with gelatinolytic activity. Nuclei of the cells were stained with Hoechst 33342 (Invitrogen, Life Technologies Hungary Ltd, Budapest, Hungary). After the subsequent washing steps, cells were covered with fluorescent mounting medium (Dako, Frank Diagnosztika Ltd, Budapest, Hungary), and fluorescence was detected with a confocal laser microscope in sequential scanning mode (Olympus Fluoview 1000, Olympus Hungary Ltd, Budapest, Hungary). Assessment of the gelatinolytic activity was carried out by quantifying different parameters of fluorescent particles from 10 fields selected randomly on each coverslip. Four coverslips were analyzed in each group. The number, total area, and area fraction of fluorescent signal, and the analyses of co-localization were quantified on images by ImageJ 1.45 software (National Institutes of Health, Bethesda, MD).

\subsubsection{Experimental design of in vivo studies}

\subsubsection{Surgical procedure of coronary occlusion}

Rats were anesthetized by intraperitoneal injection of $60 \mathrm{mg} / \mathrm{kg}$ sodium pentobarbital (Euthasol, Produlab Pharma b.v., Raamsdonksveer, The Netherlands). Animals were then intubated and mechanically ventilated (Model 683, Harvard Apparatus, Holliston, MA) with room air in a volume of $6.2 \mathrm{~mL} / \mathrm{kg}$ and a frequency of $55 \pm 5$ breath $/ \mathrm{min}$ according to their body weight. Rats were placed in supine position on a heating pad to maintain body core temperature in physiological range $\left(37.0^{\circ} \mathrm{C} \pm 1.0^{\circ} \mathrm{C}\right)$. Right carotid artery was cannulated to measure mean arterial blood pressure by a pressure transducer (Experimetria Inc., Budapest, Hungary). Mean arterial blood pressure and electrocardiogram (ECG) was continuously monitored throughout the experiments (Haemosys, Experimetria Inc., Budapest, Hungary). 
Right jugular vein was also cannulated for fluid substitution and drug administration. Left anterior descending coronary artery (LAD) occlusion was induced by left thoracotomy. A 5-0 Prolene suture (Ethicon, Johnson \& Johnson, Budapest, Hungary) was placed around LAD artery and a small plastic knob, which was threaded through the ligature and placed onto the heart, was used for making occlusion for 30 minutes. Appearance of ischemia was confirmed by ST segment elevation and arrhythmias. After 30-min ischemia, hearts were reperfused for 120 min by releasing the ligature. Restoration of blood flow was confirmed by arrhythmias observed in the first minutes of reperfusion.

\subsubsection{Experimental groups}

In first series of in vivo experiments, ilomastat was administered before the onset and during the 30-min ischemia. Animals were divided into five groups. Dimethyl sulfoxide (DMSO), $11.6 \mathrm{w} / \mathrm{v} \%$ solution diluted with physiological saline) as vehicle or $0.3,0.75,1.5$, and $3.0 \mu \mathrm{mol} / \mathrm{kg}$ ilomastat were administered intravenously in slow bolus 5 minutes before ischemia (Fig.4, shaded arrow). To maintain serum level of ilomastat, additional 3 boluses of vehicle (5.8\% DMSO solution) or ilomastat with half dose $(0.15,0.375,0.75$; and 1.5 $\mu \mathrm{mol} / \mathrm{kg}$, respectively), were given at the 10th, 25th min of ischemia and at the 10th min of reperfusion (Fig.4, open arrows). We estimated the maintaining doses of ilomastat according to its half-life based on pharmacokinetic data described previously in rodents after a single intravenous bolus injection [66].

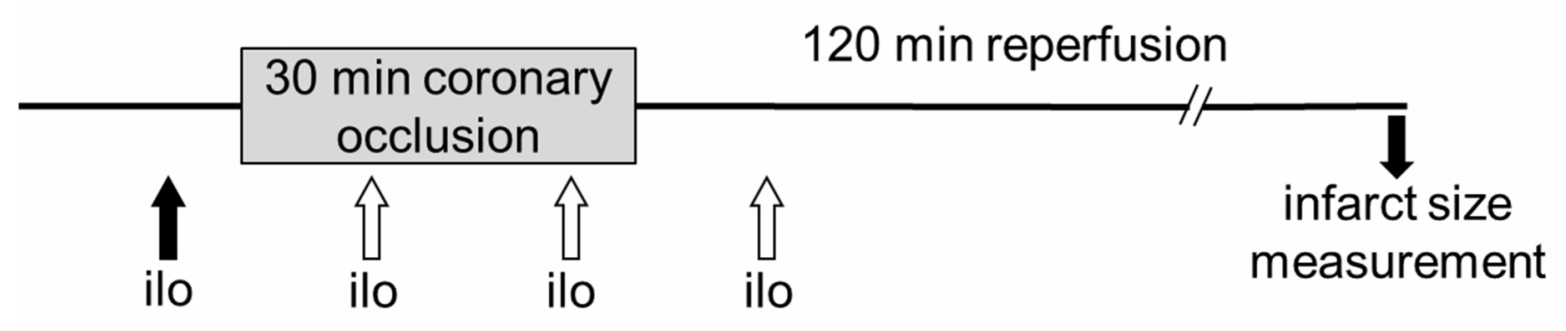

Fig.4: In vivo experimental protocol for testing the cardioprotective effect of ilomastat when administered before ischemia. Shaded arrow indicates the loading dose of ilomastat, whereas open arrows show the maintaining doses. 
In the second series of in vivo experiments DMSO (11.6 m/v\% solution) or ilomastat $(0.75,1.5,3.0$, and $6.0 \mu \mathrm{mol} / \mathrm{kg}$ ) bolus was injected at the 25 th $\min$ of ischemia (Fig.5). Maintaining boluses $(5.8 \%$ DMSO or $0.375,0.75,1.5$, and $3.0 \mu \mathrm{mol} / \mathrm{kg}$, respectively) were administered at the 10th, 25th and 40th min of reperfusion (Fig.5) to maintain constant ilomastat concentration in blood during the early phase of reperfusion.

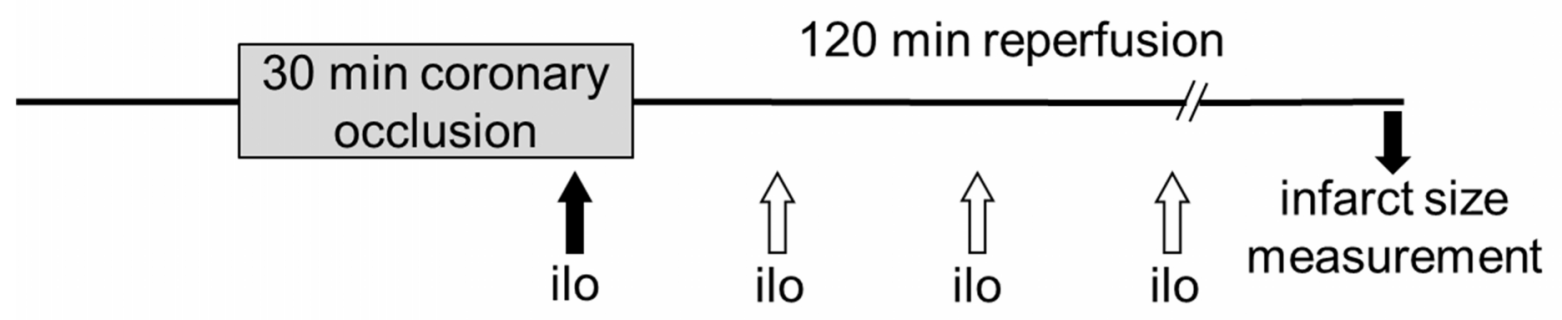

Fig.5: In vivo experimental protocol for testing the cardioprotective effect of ilomastat when administered before reperfusion. Shaded arrow indicates the loading dose of ilomastat, whereas open arrows show the maintaining doses.

\subsubsection{Determination of infarct size}

At the end of reperfusion hearts were isolated for infarct size measurements. Hearts were retrogradely perfused in a Langendorff perfusion system with $37^{\circ} \mathrm{C}$ Krebs-Henseleit buffer [67] to remove blood from the coronary vessels. After 5 min of perfusion, risk area was re-occluded, and hearts were perfused with $4 \mathrm{~mL}$ of $0.1 \%$ Evans blue dye through the ascending aorta. Following Evans staining, hearts were cut into 5 transversal slices and incubated in $1 \%$ triphenyl-tetrazolium-chloride for $10 \mathrm{~min}$ at $37^{\circ} \mathrm{C}$ followed by formalin fixation for $10 \mathrm{~min}$. Planimetric evaluation was carried out to determine infarct size using InfarctSize ${ }^{\mathrm{TM}}$ software, [68].

\subsubsection{Statistical analysis}

Statistical analysis was performed using Sigmaplot 11.0 software. All data were given as mean \pm standard error of the mean (SEM). One-way ANOVA followed by Fisher-LSD post hoc tests were performed to show differences among groups. P values of $\leq 0.05$ were accepted as statistically significant difference compared to vehicle control. 


\subsection{Experimental design of Study 2}

\subsubsection{Mouse Embryonic Stem Cell Culture}

Undifferentiated mouse embryonic stem cells (mESCs) (Nkx2.5/EGFP transgenic C57BL/6 mouse ES cell line; $\mathrm{Tg}^{\text {Nkx2.5/EGFP }}$ C57BL/6; passages 10-12) were cultured on feeder layers of mitomycin C-inactivated mouse embryonic fibroblasts (MEFs) which were obtained from 13.5 days postcoitus mouse embryos as described earlier [69]. mESCs were maintained in ES medium (DMEM) supplemented with 15\% (v/v) FBS (Sera Laboratories International, West Sussex, RH17 5PB, UK), 1000 U/mL mouse leukemia inhibitory factor (LIF, ESGRO, Chemicon International, Budapest, Hungary), $0.1 \mathrm{mM}$ nonessential amino acids (NEAA), 0.1 $\mathrm{mM} \beta$-mercaptoethanol ( $\beta$-ME) and $50 \mathrm{U} / \mathrm{mL}$ penicillin / $50 \mu \mathrm{g} / \mathrm{mL}$ streptomycin. mESCs were cultured on feeder layers for at least two passages after thawing and subsequently were cultured without feeder cells on $0.1 \%$ gelatin-coated tissue culture plates in the presence of LIF (2000 U/mL). Medium was changed daily for standards maintenance. mESCs were usually passaged every 1-2 days prior reaching 70\% confluences.

\subsubsection{Embryoid Body (EB) Formation and Cardiomyocyte Differentiation}

mESCs were dissociated from monolayer culture with $0.05 \%$ trypsin-EDTA into a single cell suspension. EBs were produced by using the hanging drop method [70]; Briefly, mESCs were resuspended at the density of $4 \times 10^{4}$ cells $/ \mathrm{mL}$ in differentiation medium (regular DMEM without LIF) resulting in 800 cells/drop. Two days later, the EBs were transferred and seeded into 24 well plates on gelatin coated coverslips. $0.1 \mathrm{mg} / \mathrm{ml}$ ascorbic acid was presented in the medium to induce cardiac differentiation. mESC-derived cardiomyocytes were used at 6-8 day-old stage for simulated ischemia/reoxygenation experiments. At this stage, the ratio of Nkx2.5-eGFP positive cells, an early marker for cardiac differentiation, exhibited $52.5 \pm 10 \%$ eGFP positivity $(\mathrm{n}=30)$. The cells were fluorescently imaged and analyzed by using Digital Image Processing Software (AxioVision 4.8.1, Carl Zeiss MicroImaging GmbH, Germany). 


\subsubsection{Experimental Groups}

For cell SI/R experiments, mESC-derived cardiomyocytes were tested under normoxic condition or were subjected to SI (Fig.6).
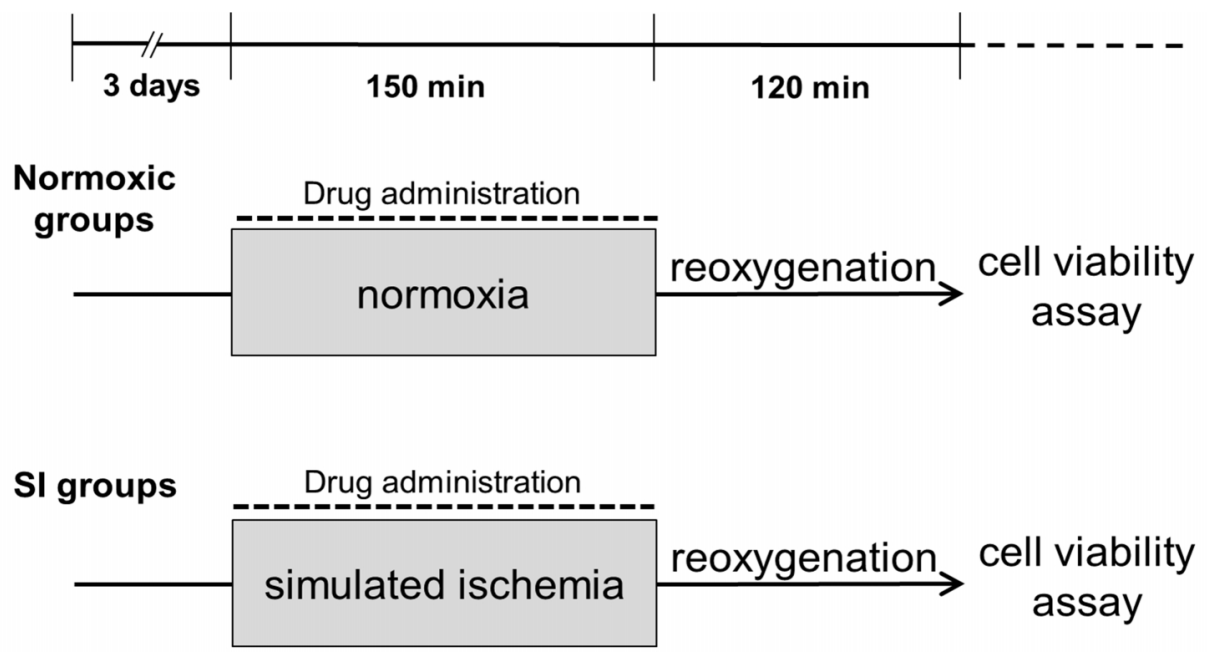

Fig.6: Experimental protocol for testing cardioprotective compounds in a stem-cell-based a drug screening.

The normoxic mESC-derived cardiomyocytes were kept under normoxic conditions; the growth medium was changed to a normoxic solution $[58,64]$ and the cells were incubated under $95 \%$ air and $5 \% \mathrm{CO}_{2}$ at $37{ }^{\circ} \mathrm{C}$ for $150 \mathrm{~min}$. In the second series of experiments, $\mathrm{mESC}$ derived cardiomyocytes were subjected to SI by incubating cells in hypoxic solution $[58,64]$ and placing the plates in a humidified $37^{\circ} \mathrm{C}$ hypoxic chamber exposed to a constant flow of a mixture of $95 \% \mathrm{~N}_{2}$ and $5 \% \mathrm{CO}_{2}$ for $150 \mathrm{~min}$. The cells were then subjected to the following treatments during SI or normoxic condition: (1) untreated control; (2) SNAP $(0.1 \mu \mathrm{M}, 1 \mu \mathrm{M}$, $10 \mu \mathrm{M}$; Sigma;St. Louis, MO) [58]; (3) selective PKG inhibitor KT-5823 (60 nM, an effective concentration that does not affect cell viability alone; Sigma, St. Louis, MO) [58]; (4) SNAP ( $1 \mu \mathrm{M}$, a concentration found here protective) in combination with KT-5823 (60 nM); (5) the particulate guanylate cyclase activator BNP (1 nM, $10 \mathrm{nM}, 100 \mathrm{nM}$; American Peptides, Sunnyvale, CA) [71]; (6) the nitric oxide synthase (NOS) inhibitor N-Nitro-L-arginine (LNNA; $100 \mu \mathrm{M}, 10 \mu \mathrm{M}$; Sigma, St. Louis, MO) [72]; (7) the non-selective $\mathrm{K}_{\mathrm{ATP}}$ channel inhibitor glibenclamide $\left(1 \mu \mathrm{M}\right.$, an effective $\mathrm{K}_{\mathrm{ATP}}$ blocking concentration that does not affect ischemia/reperfuion injury alone; Sigma, St. Louis, MO) [73]; (8) SNAP (1 $\mu \mathrm{M})$ and glibenclamide $(1 \mu \mathrm{M})$; and DMSO (Sigma, St. Louis, MO) control groups.

Either normoxic or SI treatments were followed by $120 \mathrm{~min}$ reoxygenation with growth medium without ascorbic acid and superfusion with $95 \%$ air and $5 \% \mathrm{CO}_{2}$ at $37{ }^{\circ} \mathrm{C}$. 


\subsubsection{Cell Viability Assay}

Cell viability was assessed by a PI assay performed in each group after $120 \mathrm{~min}$ reoxygenation. PI was chosen, as it stains cells with severely impaired membrane integrity and it does not necessitate dissociation of the cells. Briefly, the growth medium was removed, cells were washed with PBS twice and incubated with PI (50 $\mu$ M; Sigma, St. Louis, MO) for 7 minutes. Each experiment included a digitonin (10 $\mu \mathrm{M}$; Sigma, St. Louis, MO) treated positive control well and PI control (mESC-derived cardiomyocytes without treatment and stained for PI for $7 \mathrm{~min}$ ) (Fig.14). Then PI solution was replaced with fresh PBS and fluorescence intensity of each EB was detected by fluorescent plate reader (FluoStar Optima, BMG Labtech). Fluorescence intensity was measured in well scanning mode (scan matrix: 10x10; scan diameter: $10 \mathrm{~mm}$; bottom optic; number of flashes/scan point: 3 ; temp: $37^{\circ} \mathrm{C}$; excitation wavelength: $544 \mathrm{~nm}$; emission wavelength: $610 \mathrm{~nm}$ ). PI intensity reflecting the cell death was evaluated on a standard area (21 scan box) in each well placed to the center of EB. The cardiomyocyte-rich region can be found predominantly near the edge of the embryonic body. Therefore, the evaluation of cardiac myocyte rich regions was performed manually on several plates by detecting eGFP expression driven by the promoter of the early cardiac myocyte marker Nkx2.5. The ratio of cardiac myocyte death was the same as the ratio of cell death of all cells found in the embryonic body. Background fluorescence intensity (dye control) was subtracted from the fluorescence intensity of each well after PI staining, and the average intensity of each group was plotted. The cytoprotective effect of different compounds was compared to simulated ischemic control groups.

\subsubsection{Statistical Analysis}

Results are expressed as mean \pm SEM. One way analysis of variance (ANOVA) followed by Fisher's least significant difference (LSD) post-hoc tests was used to determine differences in mean values between groups. In case comparison of two groups, unpaired t-test was used. Differences were considered significant at $p<0.05$. 


\section{RESULTS}

\subsection{Results of Study 1}

\subsubsection{Effect of ilomastat on cardiac gelatinolytic activity}

In a preliminary series of studies, the in vitro MMP-inhibitory dose range of ilomastat was estimated in rat cardiac tissue homogenate by gelatin zymography. We have found that the $\mathrm{IC}_{50}$ of ilomastat was $0.83 \mathrm{nM}$. Gelatinolytic activity was detectable only at $72 \mathrm{kDa}$ in cardiac homogenate suggesting that only MMP-2 activity was present in the heart tissue at a significant level (Fig.7).

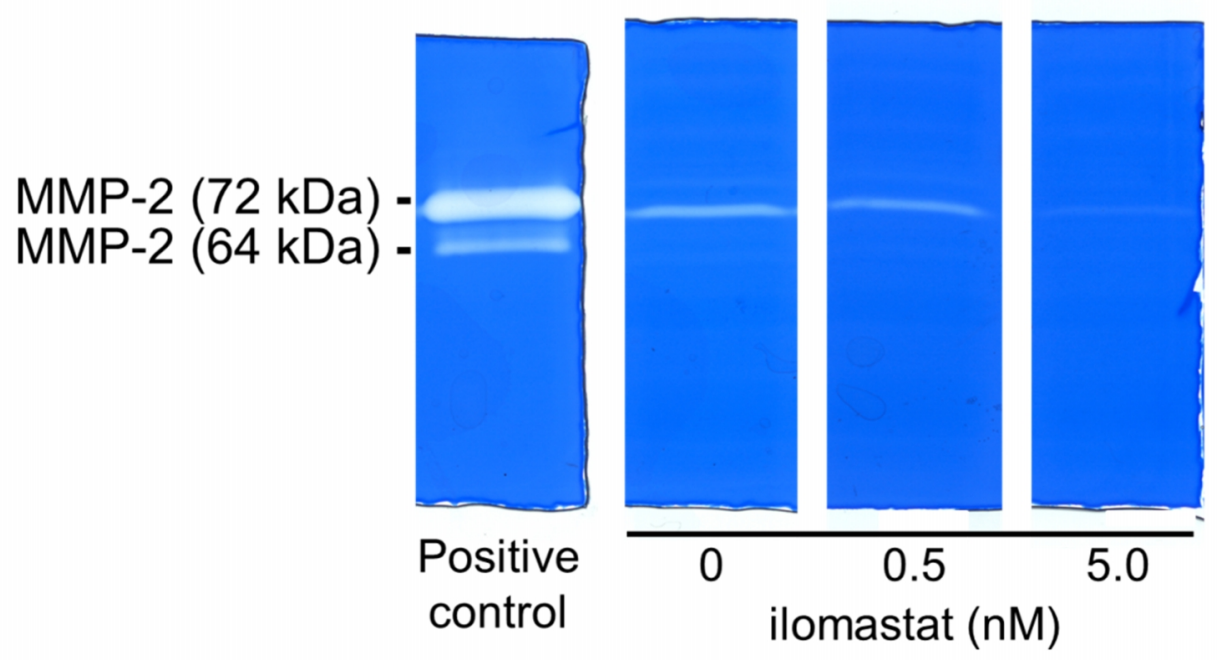

Fig.7: Representative images of MMP-2 activity in rat cardiac tissue homogenate in the presence of $0 ; 0.5$ and $5.0 \mathrm{nM}$ ilomastat.

\subsubsection{Effect of ilomastat on cardiomyocytes injured by ischemia/reoxygenation}

In order to test if a direct cardiocytoprotection by MMP-2 inhibition of ilomastat is involved in its cardioprotective effect, we examined ilomastat-induced cytoprotection in primary neonatal rat cardiomyocytes subjected to normoxia or SI/R (Fig.3). Ilomastat at a concentration range of $0.5 \mathrm{nM}$ up to $5 \mu \mathrm{M}$ did not influence cell viability in normoxic conditions (Table 1). However, ilomastat at $500 \mathrm{nM}$ and $5 \mu \mathrm{M}$ significantly increased cell viability as compared to vehicle treated group (from $8.6 \pm 0.3$ to $9.8 \pm 0.4$ and $9.7 \pm 0.2$, 
respectively, expressed in arbitrary units of fluorescent intensity) in neonatal rat cardiomyocytes exposed to SI/R injury (Fig.8).

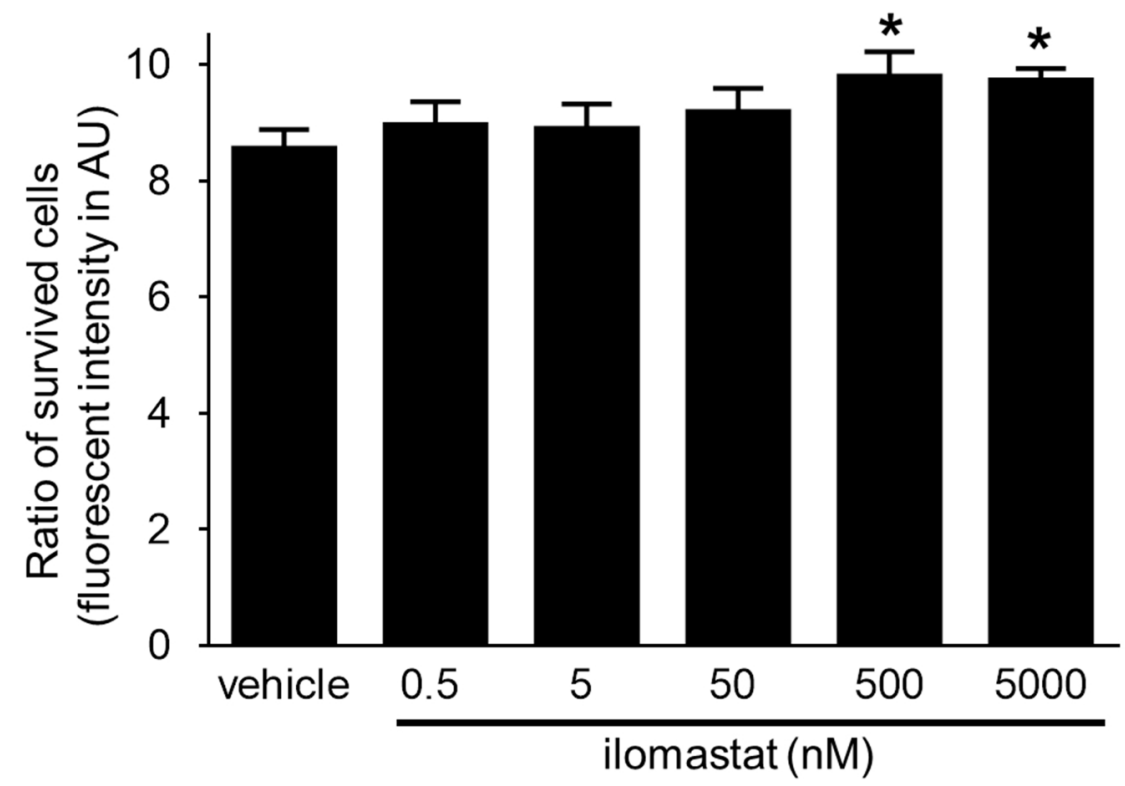

Fig.8: Effect of ilomastat on cell viability of neonatal rat cardiomyocytes after SI/R.

Data are expressed as mean \pm SEM; $\mathrm{n}=6$; one-way ANOVA followed by Fischer LSD posthoc test; * $<<0.05$ compared to vehicle treated group.

\begin{tabular}{lc}
\hline $\begin{array}{l}\text { Table 1: Effect of ilomastat } \\
\text { cardiomyocytes after } 240 \text { min normoxia }\end{array}$ & cell viability of neonatal rat \\
\hline Cell viability & (\% of vehicle control) \\
vehicle & $100 \pm 4$ \\
ilo $0.5 \mathrm{nM}$ & $102 \pm 6$ \\
ilo $5 \mathrm{nM}$ & $92 \pm 5$ \\
ilo $50 \mathrm{nM}$ & $104 \pm 10$ \\
ilo $500 \mathrm{nM}$ & $105 \pm 9$ \\
ilo $5 \mu \mathrm{M}$ & $97 \pm 8.3$ \\
medium control & $115 \pm 7$ \\
\hline \hline
\end{tabular}

Table 1: Effect of ilomastat on cell viability of neonatal rat cardiomyocytes after 240 min normoxia (suitable for the hypoxic period) followed by 120 min reoxygenation. Data are expressed as mean \pm SEM; n=5-6; one-way ANOVA followed by Fischer LSD posthoc test. 


\subsubsection{In situ MMP-2 inhibition by ilomastat in cardiomyocytes injured by ischemia/reoxygenation}

To test the in situ MMP inhibitory efficacy of the cardiocytoprotective concentration of ilomastat, we performed in situ zymography on isolated neonatal rat cardiomyocytes subjected to SI/R (Fig.9).

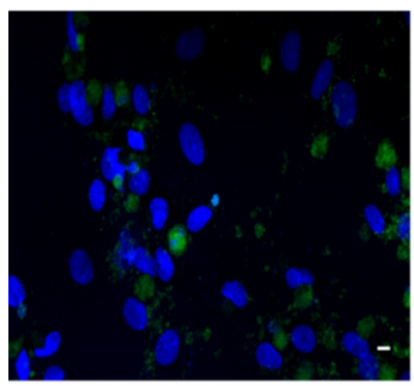

Normoxia + vehicle

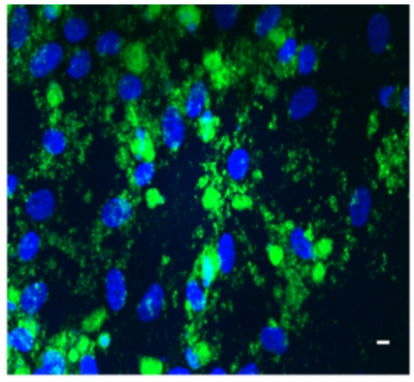

SI+ vehicle

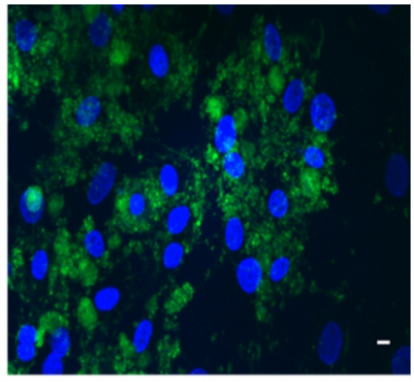

SI + ilo $500 \mathrm{nM}$

Fig.9: Representative fluorescent confocal images from neonatal rat cardiomyocytes subjected to normoxia, SI, or SI in the presence of $500 \mathrm{nM}$ ilomastat. Green color represents MMP-2 activity as measured by in situ zymography FITC signal; blue color shows the nuclei of the cells. Scale bars $=20 \mu \mathrm{m}$.

SI/R injury increased gelatinolytic activity significantly from its control value of $0.48 \pm 0.04 \%$ to $0.93 \pm 0.05 \%$ of area fraction. The cardiocytoprotective concentration of ilomastat $(500 \mathrm{nM}$, see Fig.8) moderately inhibited the in situ gelatinolytic activity approximately by $25 \%$, i.e. from $0.93 \pm 0.05 \%$ to $0.70 \pm 0.04 \%$ of area fraction, during SI/R (Fig. 10 ).

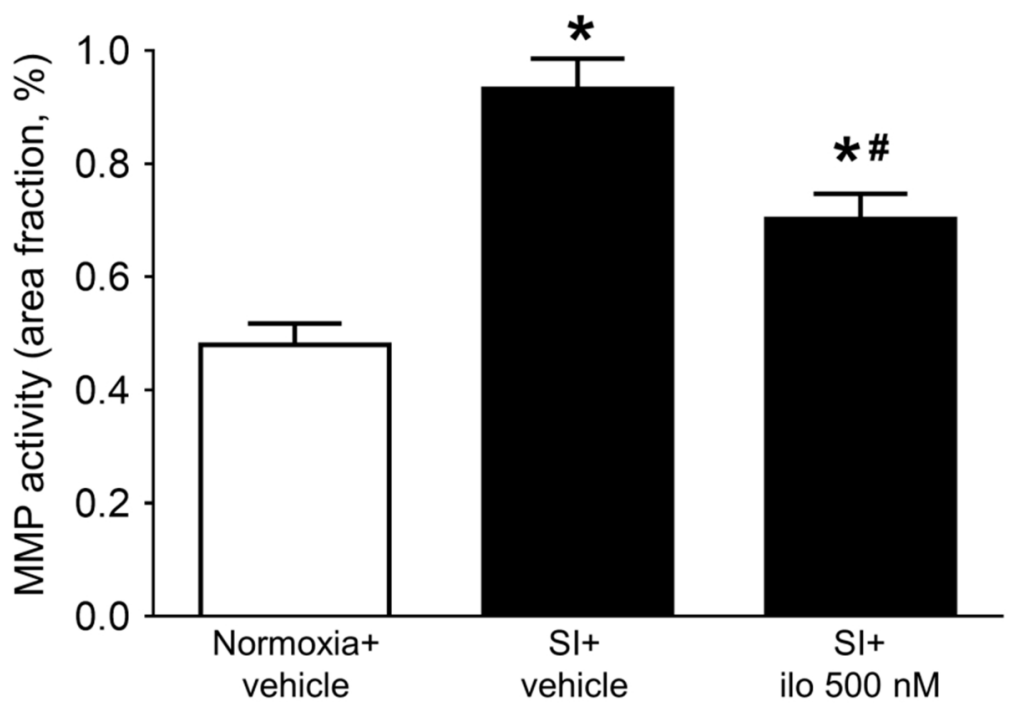

Fig.10: Effect of ilomastat on intracellular gelatinolytic activity in neonatal rat cardiomyocytes after SI/R. Data are expressed as mean $\pm \mathrm{SEM} ; \mathrm{n}=6$; one-way ANOVA followed by Fischer LSD posthoc test; *p<0.001 compared to normoxic vehicle-treated group; $\# \mathrm{p}<0.01$ compared to simulated ischemia/reperfusion, vehicletreated group, 
Moreover, we performed separate experiments to show co-localization of MMP-2 with the fluorescent gelatinolytic signal in isolated neonatal rat cardiomyocytes exposed to SI/R injury. MMP-2 showed over 90\% co-localization rate with gelatinolytic activity in all groups (Fig.11).

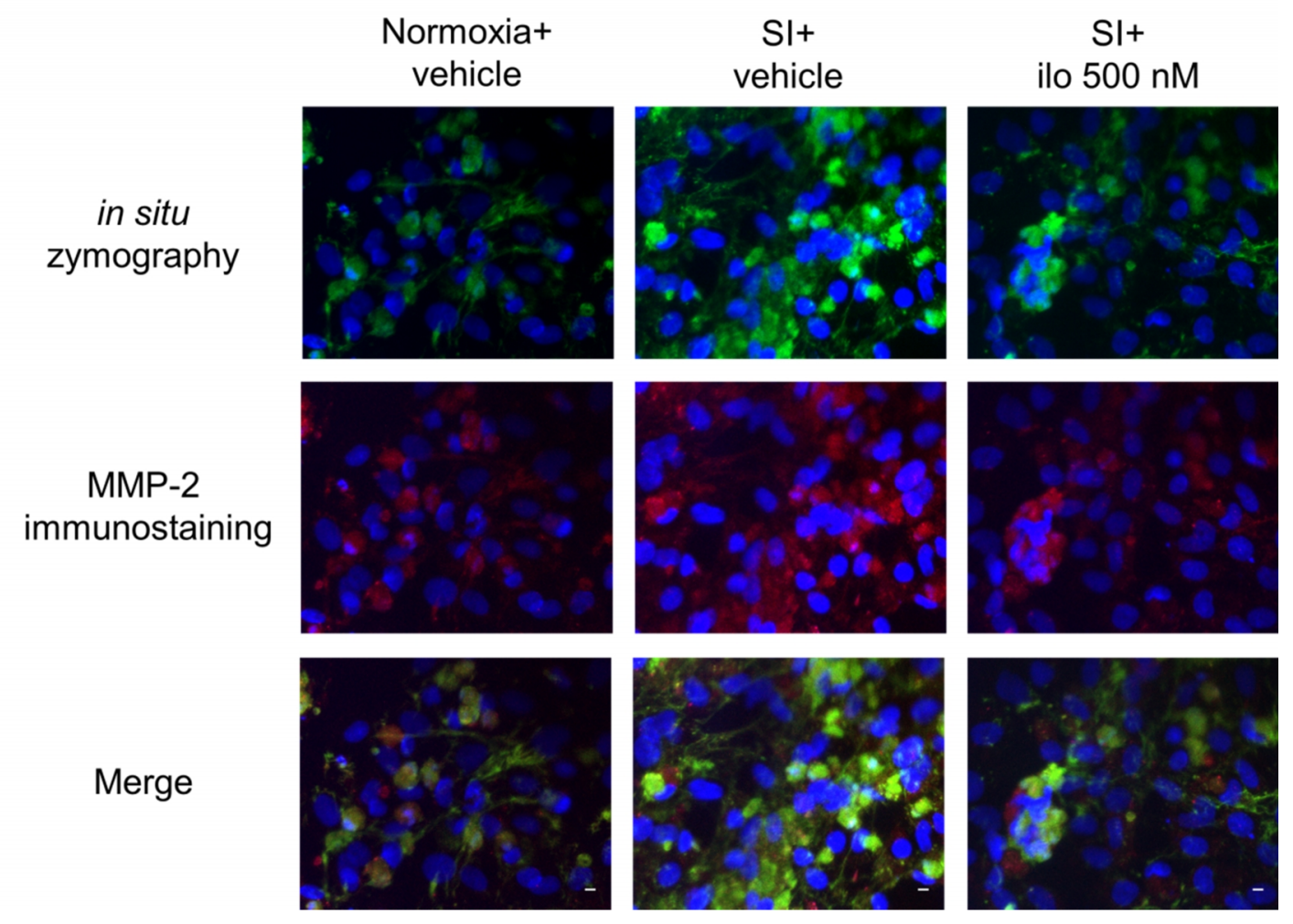

Fig.11: Representative confocal images of cultured neonatal rat cardiomyocytes exposed to normoxia or SI in the presence or absence of ilomastat $(500 \mathrm{nM})$. Green fluorescence: fluorescent signal of gelatin substrate after proteolytic cleavage. Red fluorescence: MMP-2 immunostaining, Blue fluorescence: cell nuclei.

Scale bars $=20 \mu \mathrm{m}$

\subsubsection{Effect of ilomastat on infarct size in vivo}

The cardioprotective effect of ilomastat administered before the onset of ischemia (Fig.4) or before the onset of reperfusion (Fig.5) was studied in an in vivo myocardial infarction model induced by coronary occlusion in rats. When administered before the onset of ischemia, ilomastat at 0.75 and $1.5 \mu \mathrm{mol} / \mathrm{kg}$ doses reduced infarct size significantly as compared to vehicle-treated group (from $66.1 \pm 4.6 \%$ to $45.3 \pm 7.0 \%$ and $46.7 \pm 5.5 \%$ of area at risk, respectively) showing a U-shaped dose-response relationship (Fig.12). When administered before the onset of reperfusion, ilomastat at $6.0 \mu \mathrm{mol} / \mathrm{kg}$ reduced infarct size significantly (from $65.4 \pm 2.5 \%$ to $52.8 \pm 3.7 \%$ of area at risk), however, lower doses were 
ineffective (Fig.13). There were no significant differences in the area at risk among the groups (data not shown). There were no significant differences in the mean arterial blood pressure and heart rate among the groups (Table 2 and Table 3) as well.

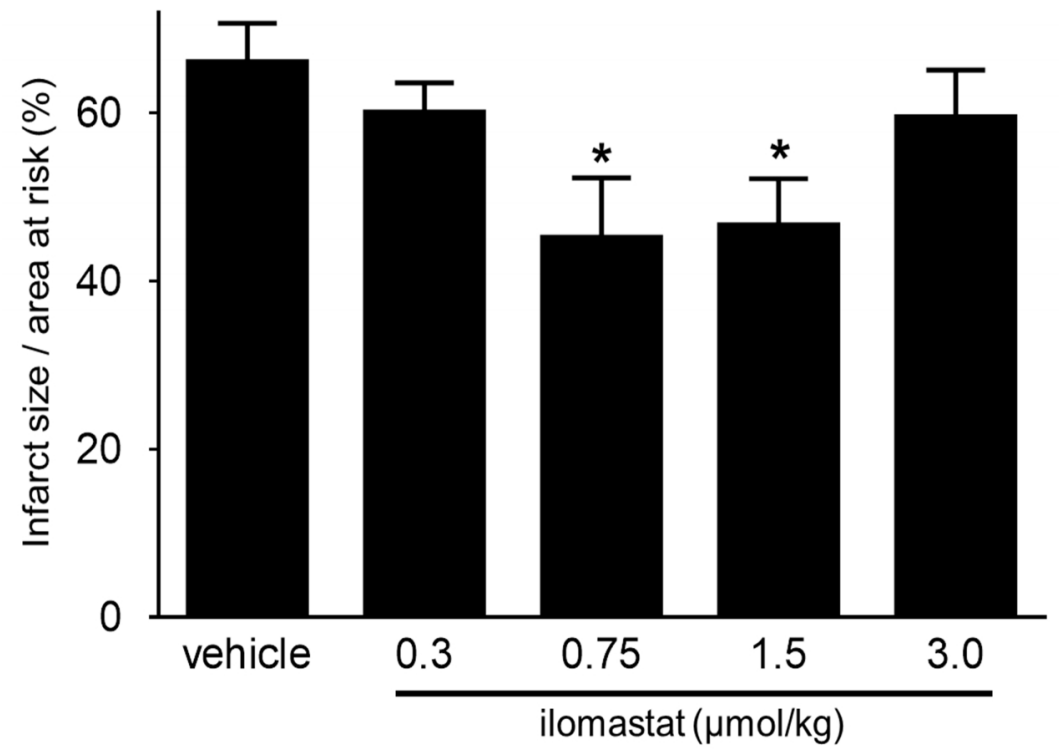

Fig.12: Effect of ilomastat treatment on infarct size when administered before ischemia.

Data are shown as mean $\pm \mathrm{SEM} ; \mathrm{n}=7-8$; one-way ANOVA followed by Fischer LSD posthoc test; ${ }^{*} \mathrm{p}<0.05$ compared to vehicle-treated group.

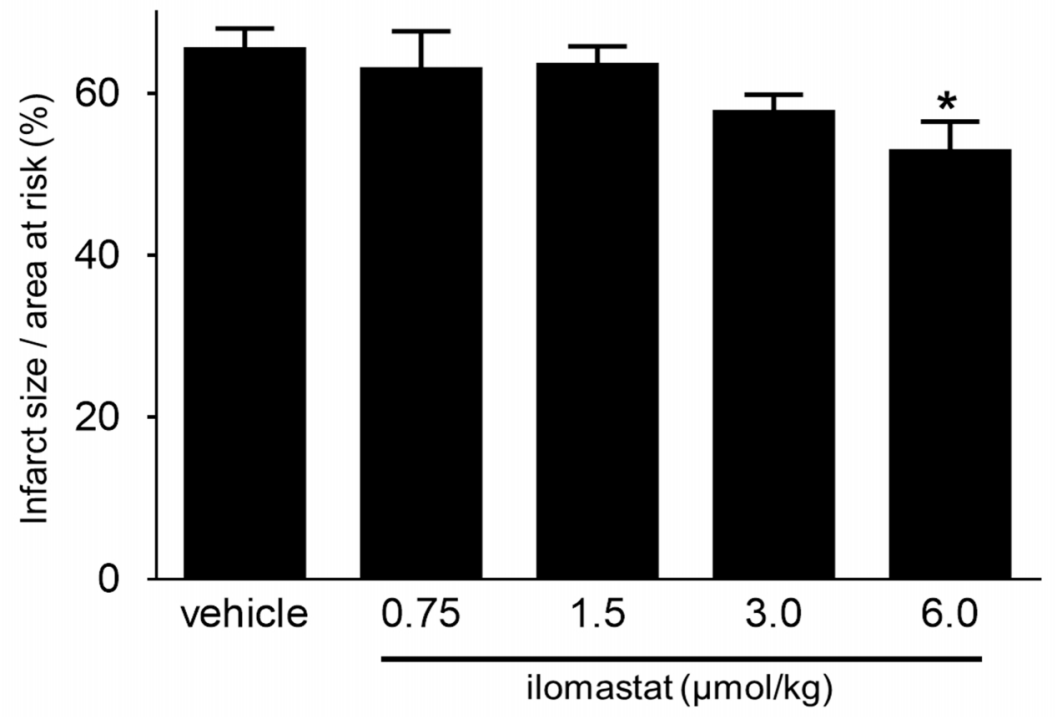

Fig.13: Effect of ilomastat treatment on infarct size when administered before reperfusion.

Data are shown as mean $\pm \mathrm{SEM} ; \mathrm{n}=7-8$; one-way ANOVA followed by Fischer LSD posthoc test; ${ }^{*} \mathrm{p}<0.05$ compared to vehicle-treated group. 
Table 2: Effects of ilomastat treatment on mean arterial blood pressure and heart rate when administered before the onset of ischemia.

\begin{tabular}{lccc}
\hline $\begin{array}{l}\text { Mean arterial blood } \\
\text { pressure (mmHg) } \\
\text { vehicle }\end{array}$ & $\begin{array}{c}\text { Baseline } \\
121.1 \pm 6.7\end{array}$ & $\begin{array}{c}\mathbf{3 0}^{\text {th }} \text { min of } \\
\text { ischemia } \\
82.4 \pm 6.6\end{array}$ & $\begin{array}{c}\mathbf{1 2 0}^{\text {th }} \text { min of } \\
\text { reperfusion } \\
73.1 \pm 1.7\end{array}$ \\
ilo $0.3 \mu \mathrm{mol} / \mathrm{kg}$ & $118.6 \pm 4.4$ & $76.5 \pm 6.1$ & $73.6 \pm 4.8$ \\
ilo $0.75 \mu \mathrm{mol} / \mathrm{kg}$ & $117.5 \pm 2,3$ & $90.5 \pm 3.0$ & $77.6 \pm 7.1$ \\
ilo $1.5 \mu \mathrm{mol} / \mathrm{kg}$ & $118.1 \pm 5.9$ & $75.9 \pm 3.7$ & $58.3 \pm 5.3$ \\
ilo $3.0 \mu \mathrm{mol} / \mathrm{kg}$ & $120.0 \pm 4.7$ & $80.5 \pm 8.5$ & $71.2 \pm 6.0$ \\
\hline \hline Heart $\mathrm{Rate}(\mathrm{beats} / \mathrm{min})$ & & & $373 \pm 9$ \\
vehicle & $408 \pm 7$ & $392 \pm 16$ & $378 \pm 18$ \\
ilo $0.3 \mu \mathrm{mol} / \mathrm{kg}$ & $398 \pm 10$ & $374 \pm 21$ & $390 \pm 16$ \\
ilo $0.75 \mu \mathrm{mol} / \mathrm{kg}$ & $441 \pm 20$ & $422 \pm 11$ & $410 \pm 15$ \\
ilo $1.5 \mu \mathrm{mol} / \mathrm{kg}$ & $400 \pm 14$ & $388 \pm 24$ & $401 \pm 27$ \\
ilo $3.0 \mu \mathrm{mol} / \mathrm{kg}$ & $449 \pm 20$ & $400 \pm 17$ & \\
\hline \hline
\end{tabular}

Table 2: Effects of ilomastat treatment on mean arterial blood pressure and heart rate when administered before the onset of ischemia. Data are expressed as mean \pm SEM; $n=7-8$; one-way ANOVA followed by Fischer LSD posthoc test.

Table 3: Effects of ilomastat treatment on mean arterial blood pressure and heart rate when administered before the onset of reperfusion

\begin{tabular}{lccc}
\hline $\begin{array}{l}\text { Mean arterial blood } \\
\text { pressure (mmHg) }\end{array}$ & $\begin{array}{c}\text { Baseline } \\
\text { vehicle }\end{array}$ & $\begin{array}{c}3 \mathbf{0}^{\text {th }} \text { min of } \\
\text { ischemia } \\
87.3 \pm 5.1\end{array}$ & $\begin{array}{c}\mathbf{1 2 0}^{\text {th }} \text { min of } \\
\text { reperfusion }\end{array}$ \\
ilo $0.75 \mu \mathrm{mol} / \mathrm{kg}$ & $114.1 \pm 4.3$ & $91.3 \pm 7.4$ & $77.7 \pm 5.2$ \\
ilo $1.5 \mu \mathrm{mol} / \mathrm{kg}$ & $111.8 \pm 5.4$ & $86.8 \pm 6.5$ & $83.1 \pm 5.3$ \\
ilo $3.0 \mu \mathrm{mol} / \mathrm{kg}$ & $112.6 \pm 4.3$ & $97.4 \pm 6.7$ & $81.3 \pm 5.3$ \\
ilo $6.0 \mu \mathrm{mol} / \mathrm{kg}$ & $104.1 \pm 6.7$ & $80.2 \pm 9.0$ & $74.4 \pm 6.8$ \\
\hline \hline
\end{tabular}




\section{Heart Rate (beats/min)}

vehicle

ilo $0.75 \mu \mathrm{mol} / \mathrm{kg}$

ilo $1.5 \mu \mathrm{mol} / \mathrm{kg}$

ilo $3.0 \mu \mathrm{mol} / \mathrm{kg}$

ilo $6.0 \mu \mathrm{mol} / \mathrm{kg}$
$408 \pm 14$

$429 \pm 15$

$402 \pm 15$

$423 \pm 15$

$444 \pm 13$
$424 \pm 10$

$424 \pm 14$

$387 \pm 10$

$412 \pm 14$

$417 \pm 17$
$406 \pm 11$

$392 \pm 15$

$396 \pm 11$

$392 \pm 15$

$411 \pm 13$

Table 3: Effects of ilomastat treatment on mean arterial blood pressure and heart rate when administered before the onset of reperfusion. Data are expressed as mean \pm SEM; $n=10-18$; one-way ANOVA followed by Fischer LSD posthoc test. 


\subsection{Results of Study 2}

\subsubsection{Cell Viability after SI/R treatment of mESC-derived cardiomyocytes}

We applied SI/R to mimic in vivo ischemia/reperfusion injury in mESC-derived cardiomyocytes. $150 \mathrm{~min}$ of SI followed by $120 \mathrm{~min}$ reoxygenation caused significantly higher cell death in mESC-derived cardiomyocytes than time-matched controls kept under normoxic conditions (Fig.14).

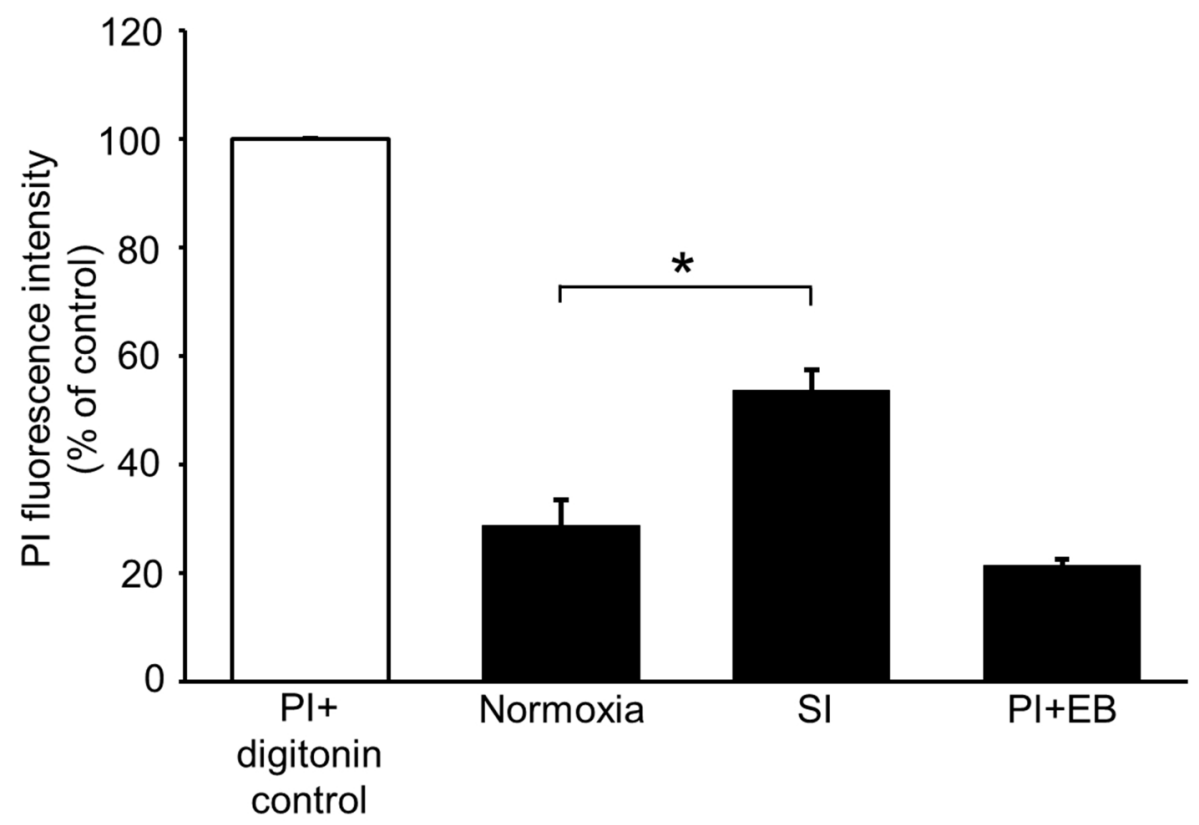

Fig.14: Cell viability of mESC-derived cardiomyocytes subjected to normoxia or SI. Background fluorescence intensity is represented by using non-treated EB + PI in three wells. PI+ digitonin control alone was applied in one well. Data are expressed as mean $\pm \mathrm{SEM}$; $\mathrm{n}=5-6$; unpaired t-test; $* \mathrm{p}<0.05$ compared to normoxic group

Simulated ischemia killed roughly $20-40 \%$ of cells in embryonic body. The cytoprotective action of the NO donor SNAP that activates soluble guanylate cyclase was tested in this model of SI and reoxygenation-induced cell death in mESC-derived cardiomyocytes. Cell death was significantly decreased by SNAP in a concentration-dependent manner $(1 \mu \mathrm{M}$ and $10 \mu \mathrm{M}, v s$. vehicle control, $\mathrm{p}<0.05)$ when applied during SI period (Fig.15). The contribution of endogenous NO production of mESC-derived cardiomyocytes to cell death during SI was tested by administration of the non-selective NOS inhibitor L-NNA at $10 \mu \mathrm{M}$ and $100 \mu \mathrm{M}$ concentration. The presence of L-NNA did not influence cell death after SI (Fig.16). 


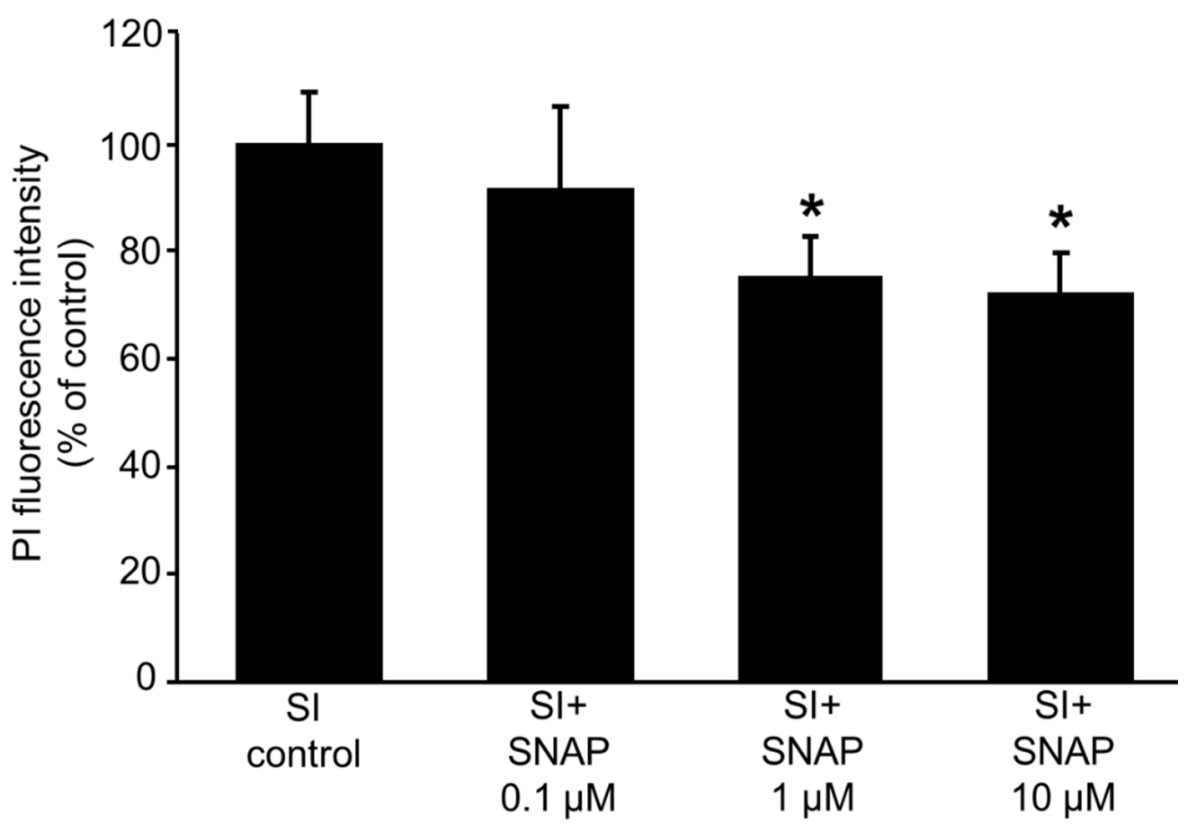

Fig.15: Effect of SNAP on cell viability of mESC-derived cardiomyocytes.

Data are expressed as mean \pm SEM; $n=10-12$; one-way ANOVA followed by Fischer LSD posthoc test; * $\mathrm{p}<0.05$ compared to SI control.

$\mathrm{BNP}$, an activator of particulate guanylate cyclase was also tested under SI condition at $1 \mathrm{nM}$, $10 \mathrm{nM}$ and $100 \mathrm{nM}$ concentrations. However, BNP did not influence cell death significantly (Fig.17).

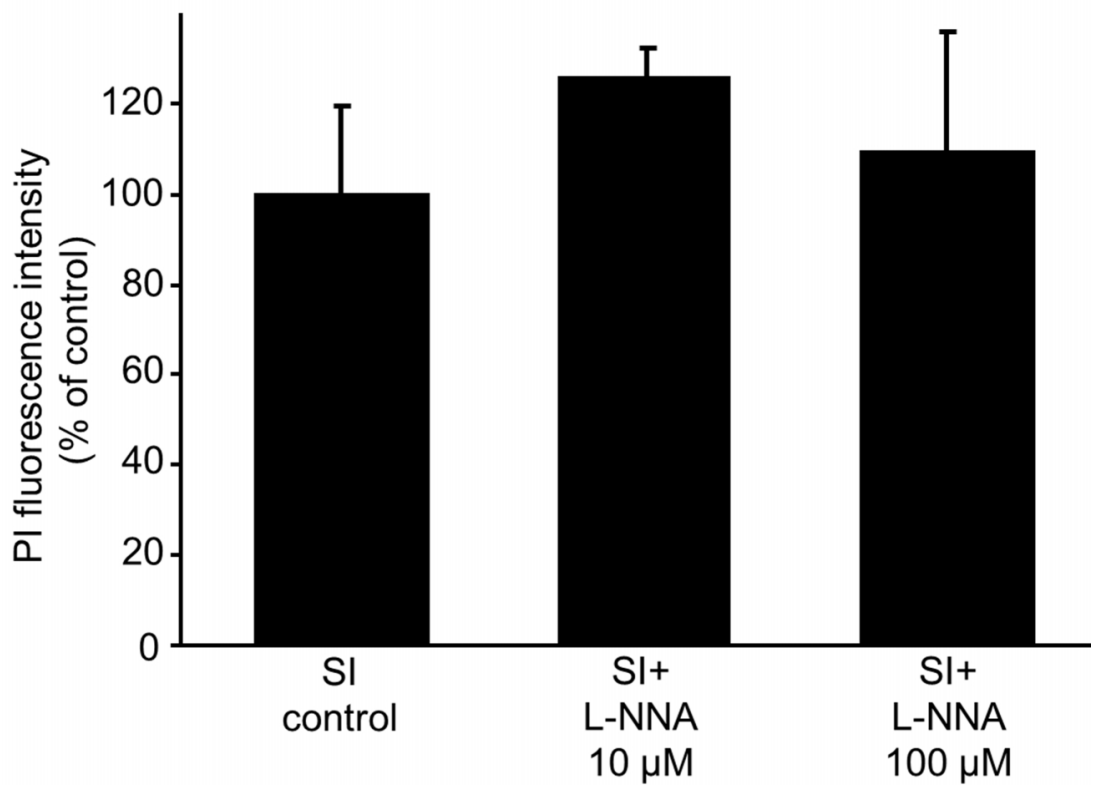

Fig.16: Effect of L-NNA on cell viability of mESC-derived cardiomyocytes.

Data are expressed as mean \pm SEM; $n=10-12$ 


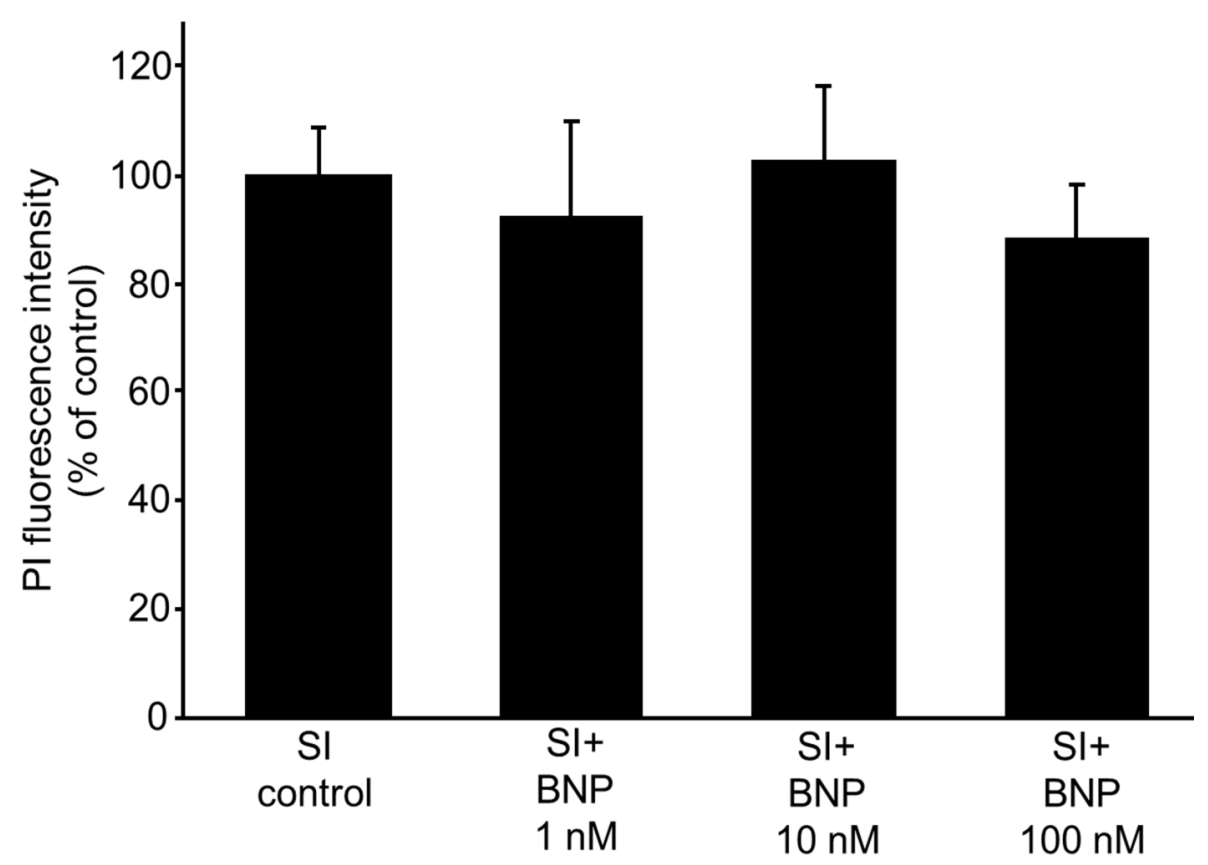

Fig.17: Effect of BNP on cell viability of mESC-derived cardiomyocytes.

Data are expressed as mean \pm SEM; $n=10-12$

In separate experiments, the downstream pathways of SNAP-induced protection of mESCderived cardiomyocytes were studied (Fig.18).

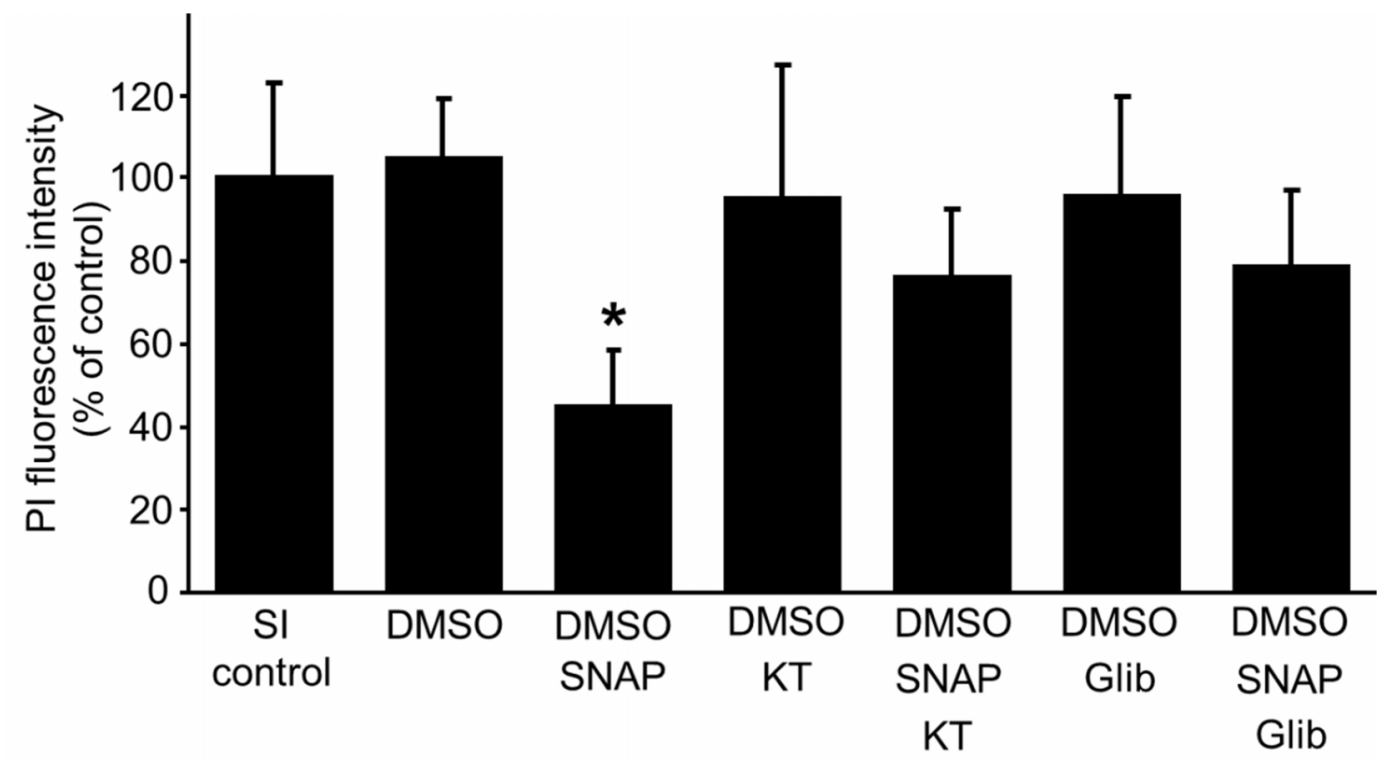

Fig.18: Effect of PKG (KT) and $\mathrm{K}_{\mathrm{ATP}}$ (Glib) inhibitor on cell viability of mESC-derived cardiomyocytes. Data are expressed as mean $\pm \mathrm{SEM} ; \mathrm{n}=10-12$; one-way ANOVA followed by Fischer LSD posthoc test; $* \mathrm{p}<0.05$ compared to SI control. 
The cytoprotective effect of SNAP (at $1 \mu \mathrm{M}$ ) was attenuated either by simultaneous administration of the selective PKG inhibitor KT-5823 (60 nM) or by simultaneous administration of $\mathrm{K}_{\mathrm{ATP}}$ channel inhibitor glibenclamide $(1 \mu \mathrm{M})$. Inhibitors administered alone, or their vehicle DMSO did not influence cell viability (Fig. 18).

In time-matched normoxic control groups, none of the above treatment influenced cell viability significantly (data not shown). 


\section{DISCUSSION}

\subsection{Study 1: MMP-2 inhibition by ilomasat exerts cardioprotection}

In study 1 we have demonstrated that an approximately $25 \%$ inhibition of intracellular MMP-2 activity by the non-selective MMP inhibitor ilomastat confers significant cardiocytoprotection. Moreover, ilomastat reduced infarct size when administered either before the onset of ischemia or before the onset of reperfusion in vivo and revealed its cardioprotective dose-response relationship. This is the first demonstration that the cardioprotective effect of ilomastat may involve a cardiocytoprotective mechanism due to a moderate inhibition of MMP-2.

Endogenous cardioprotection by early and late ischemic preconditioning as well as postconditioning might act via MMP-2 inhibition [34-36,74]; Bell et al. reported that ilomastat protects the heart against reperfusion injury independently from the well-known cardioprotective cellular RISK/mPTP modulating pathways [37]. Since ilomastat is a nonselective MMP inhibitor, therefore, the question has arose, inhibition of which MMP isoenzyme was responsible for the cardioprotective effect of ilomastat. To answer this question, here we performed gelatin zymography from cardiac homogenates isolated from untreated rats and used purified MMP-2 enzyme to identify the MMP-2 specific activity in the zymogram. Gelatinolytic activities at 72 and $64 \mathrm{kDa}$ were detected according to the molecular weights of the two active isoforms of MMP-2. Bands of other molecular weights were not observed on the zymogram which is in line with our previous finding reported by Kupai et al. [31].

Recently, a large number of studies focused on the intracellular actions of MMP-2, that can degrade several newly identified intracellular targets including cardiac troponin I, myosin light chain-1, $\alpha$-actinin (for review see ref. 28). The degradation of myocardial contractile proteins is an early event in myocardial infarction; which may contribute to the induction of proapoptotic cascades in cardiomyocytes and thus leads to cell death and contractile dysfunction [75]. Therefore, here we tested the direct cytoprotective effect of ilomastat in a previously established drug screening platform using isolated neonatal rat cardiomyocytes exposed to SI/R injury [58]. Our results clearly show that ilomastat exerts direct cytoprotective effect via attenuating the intracellularly active MMP-2 activity as proved by in situ zymography whereas, gelatinolytic activity was co-localized with MMP-2 immunostaining. Additionally, we have previously shown that MMP-2 activity can be 
detected in both intact and in ischemia/reperfused rat ventricular samples [35]. Thus, MMP-2 is suspected to be the only MMP isoform with gelatinolytic activity in the rat myocardium. This is in accordance with previous findings by others, who have shown that MMP-2 possesses a predominant expression in both animal and human cardiomyocytes and cardiac tissue $[27,76]$. Therefore, the presenting results suggest that gelatinolytic activity in the heart is originated solely from MMP-2. Nevertheless, it cannot be excluded that inhibition of other non-gelatinolytic proteases may be involved in the cardiocytoprotective effect of ilomastat.

Moreover, here we further tested the magnitude of MMP-2 inhibition necessary for cardioprotection and found that the cardiocytoprotective dose of ilomastat inhibited MMP-2 activity only by $25 \%$. Previously we have demonstrated that cardioprotection by late ischemic preconditioning reduced MMP-2 activity by approximately 20\% [36]. Our present study suggests that a moderate MMP-2 inhibition is sufficient for cardioprotection. Due to the wellknown side effects of MMP inhibitors including tendonitis-like fibromyalgia and musculoskeletal syndrome $[39,77]$, it is of great clinical importance that possibly there is no need for high efficacy MMP inhibitors to protect the heart against ischemia/reperfusion injury.

We further investigated the cardioprotective effect of ilomastat in an in vivo rat heart model of myocardial infarction. Ilomastat reduced infarct size dose-dependently when administered either before ischemia or before reperfusion. We have found a different dose range between this two administration protocols. When administered before the onset of ischemia, the effective doses of ilomastat were 0.75 and $1.5 \mu \mathrm{mol} / \mathrm{kg}$, however, higher doses of ilomastat were not significantly effective. Nevertheless, when ilomastat was administered before the onset of reperfusion, $6 \mu \mathrm{mol} / \mathrm{kg}$ ilomastat was found to decrease infarct size, and lower doses were ineffective. This is the first demonstration that the cardioprotective dose ranges of ilomastat, when administered before ischemia or before reperfusion, were not overlapping in vivo. Our present results are supported by previous studies describing that $\mathrm{Zn}^{2+}$-binding type MMP inhibitors, such as doxycycline and o-phenantroline, improved cardiac mechanical function after ischemia/reperfusion injury via the inhibition of MMP-2 in isolated rat hearts $[25,78,79]$. We have recently shown that the intravenously injected ilomasat (at $1.5 \mu \mathrm{mol} / \mathrm{kg}$, administered before the onset of ischemia) decreased infarct size and had a comparable cardioprotective effect to ischemic late preconditioning [36]. More recently, Bell and colleagues reported cardioprotection in an in vivo mouse heart model of ischemia/reperfusion when ilomasat was administered intravenously at $6 \mu \mathrm{mol} / \mathrm{kg}$ upon releasing coronary occlusion [37]. However, the percentage of in situ MMP-2 inhibition was 
not determined in the abovementioned studies and in the latter study, authors did not examine directly the MMP inhibitory effect of ilomastat.

Taken together, ilomastat at doses with moderate MMP-2 inhibition protects cardiomyocytes thereby reducing infarct size when administered either before the onset of ischemia or before the onset of reperfusion in vivo. Our results show that a moderate MMP-2 inhibition is sufficient for cardioprotection.

\subsection{Study 2: the NO donor SNAP has cytoprotective effect on mESC- derived cardiomyocytes}

In study 2 we established an embryonic stem cell-derived cardiac myocyte-based in vitro drug screening system and showed that the NO-donor SNAP was protective against SI/R-induced cell death. Either a selective inhibitor of PKG or a non-selective inhibitor of $\mathrm{K}_{\mathrm{ATP}}$ channels interfered with this protection. In contrast to SNAP, the particulate guanylate cyclase stimulator BNP had no effect on cell viability during SI. This is the first demonstration that mESC-derived cardiomyocytes are a useful tool for screening cytoprotective agents and their cytoprotective signaling pathways against simulated ischemia/reoxygenation injury.

Currently used cell-based assays using primary neonatal cardiomyocytes have limitations for screening cardioprotective agents, including variability introduced by the isolation procedure and limited proliferation [80]. Adult cardiomyocytes are suitable to study individual cells, especially their electrophysiological properties. However, extracellular matrix proteins are required for their maintenance which may influence viability during SI [81]. The H9c2 cardiomyoblast cell line is a widely used model for in vitro drug screening as well. However, H9c2 cells differ from primary cardiomyocytes, because of lacking spontaneous electric activity and clearly developed sarcomeric structures [82]. Therefore, advantages of ESC-based assays are the well-reproducible production of contracting myocardial cells and that they do not require sacrificing high number of animals.

Therefore, here we validated a mESC-derived cardiomyocyte-based drug-screening platform using the NO donor SNAP. SNAP is a well-known cardioprotective compound. It exerts both early and late preconditioning-like cardioprotective effect in various models [83,84] and

attenuates apoptosis in neonatal cardiomyocytes [85]. Accordingly, in the present study, SNAP showed a concentration-dependent increase in viability of mESC-derived cardiomyocytes after SI/R insult. This finding indicates that $\mathrm{mESC}$-derived cardiomyocytes are useful tools for testing cardioprotective agents and suggests that NO donors may also be 
cytoprotective for stem cell-derived cardiomyocytes implanted into ischemic areas of the myocardium. Moreover NO has also been shown to promote cardiac-committed differentiation of mESCs [86].

It has been well established that NO donors including SNAP exert protective effect against myocardial ischemia/reperfusion injury via activation of soluble guanylate cyclase and increased cGMP signaling (for a review see ref. 87). We have recently shown that SNAP induces cytoprotection via the activation of soluble guanylate cyclase in neonatal cardiomyocytes [58]. However, in our previous studies the efficacy of SNAP-induced cytoprotection was more pronounced in neonatal cardiomyocytes than shown here in mESCderived cardiomyocytes. This difference is probably due to the low expression level of soluble guanylate cyclase and nitric oxide synthase (NOS) at 6-8 days old stage of mESC-derived cardiomyocytes [88]. The latter is in accordance with our present results that the NOS inhibitor L-NNA did not affect cell viability after SI/R injury of mESC-derived cardiomyocytes showing that endogenous NO is not involved in cardiocytoprotection.

To test if activation of particulate guanylate cyclase can increase cell viability similar to SNAP, the effect of BNP was tested. BNP is a potent cardioprotective peptide, as it is able to reduce infarct size in rat heart preparations [71] and to protect neonatal rat cardiomyocytes against SI/R injury [58]. Interestingly, in our present study, cell viability was not influenced by either concentration of BNP in mESC-derived cardiomyocytes. This finding may be due to a low expression of the BNP specific NPR-A receptor during mouse ESC differentiation [89].

We further identified cardioprotective signaling pathways downstream of cGMP in mESC-derived cardiomyocytes. In the cardiomyocytes, at least three classes of protein targets are activated by cGMP, including cGMP-dependent PKG, cGMP-regulated phosphodiesterases, and cyclic nucleotide-gated ion channels [60], In the present study, the involvement of PKG in SNAP-induced protection was tested by the PKG inhibitor KT-5823 during SI, which interferes with PKG at the level of the ATP binding site of its catalytic domain KT-5823 alone did not affect the viability of mESC-derived cardiomyocyte, but interfered with the cytoprotective effect of SNAP, which suggests that the mechanism of SNAP-induced protection involves PKG. Our present findings in mESC-derived cardiomyocytes are consistent with our previous results obtained in neonatal rat cardiomyocytes, in which the PKG inhibitor abolished the protective effect of SNAP [58]. However, it is of interest that Mobley et al. showed that PKG was down-regulated during cardiomyocyte differentiation and inhibition of PKG facilitated cardiac-committed differentiation of mESCs [90]. 
$\mathrm{Xu}$ et al. demonstrated that exogenous NO mediates the production of reactive oxygen species and may act via the activation of cGMP/PKG signaling, triggering cardiocytoprotection by mitochondrial $\mathrm{K}_{\mathrm{ATP}}$ channel opening or by opening the mitochondrial permeability transition pore in adult rat cardiomyocytes $\mathrm{K}_{\mathrm{ATP}}$ channels have a prominent role in the electrical excitability of cardiac-committed mESC-derived cells [91]. Therefore, in the present study, we investigated the involvement of $\mathrm{K}_{\mathrm{ATP}}$ channels in SNAP-induced cytoprotection in mESC-derived cardiomyocytes. The nonselective $\mathrm{K}_{\mathrm{ATP}}$ channel inhibitor glibenclamide alone did not affect mESC-derived cardiomyocyte viability, but abolished the cytoprotective effect of SNAP. This is in line with several earlier reports in other systems $[92,93]$.

Taken together, our present study is the first demonstration that mESC-derived cardiomyocytes exposed to SI/R injury are a useful alternative tool for in vitro screening of potential cardioprotective agents and to study their downstream cellular signaling pathways. The major advantages of ESC-based screening platforms over other cellular assays are the well reproducible production of beating myocardial cells and that it does not require to sacrifice a number of animals. All the above-mentioned findings emphasize the necessity of detailed analyses of signal transduction pathways in ESC-derived cells both in physiological and pathological conditions to establish well-reproducible ESC-derived drug screening platforms and to predict the viability of these cells after implantation into an ischemic region of a tissue. 


\section{CONCLUSIONS AND FURTHER PERSPECTIVES}

Study 1 is the first demonstration that

- the cardioprotective effect of ilomastat occurs via the moderate inhibition of MMP-2.

- ilomastat has direct cytoprotective effect via attenuating the intracellularly active MMP-2 activity as proved by in situ zymography. This finding was proven by the previously established drug screening platform that is suitable for testing cardioprotective compounds.

- ilomastat reduced infarct size when administered either before the onset of ischemia or before the onset of reperfusion in vivo. However, the cardioprotective doses of ilomastat are not overlapped, when administered before ischemia or before reperfusion.

We conclude that MMP-2 inhibition before the onset of reperfusion is a promising target in the treatment of AMI, since it may have high clinical relevance during recanalization therapy via percutaneous coronary intervention. Furthermore, moderate inhibition of MMP-2 might be a useful tool to reduce infarct size and improve clinical outcomes of AMI in patients without the occurrence of severe side effects derived from high efficacy MMP inhibition.

In Study 2, we demonstrated for the firs time that

- the NO-donor SNAP is protective against SI/R-induced cell death of mESC-derived cardiomyocytes. Moreover, we proved that the activation of cGMP-PKG signaling cascade is involved in this protection.

- $\mathrm{mESC}$-derived cardiomyocytes exposed to SI/R injury can be a useful tool for predicting the viability of ESC-derived cardiomyocytes after implantation into the ischemic myocardium.

- this mESC-derived cardiomyocyte-based platform can be used for in vitro testing of potential cardioprotective drugs and to study their downstream signaling pathways.

In conclusion, stem-cell-derived cardiomyocytes may be a useful source for cardiac repair after AMI. The major limitation that needs to be overcome towards clinical translation is the low survival rate of cells after implantation. Therefore, the improvement of cell replacement therapy is one of the most important aims of our further investigations. 


\section{ACKNOWLEDGEMENT}

These works were supported by the following grants of the Hungarian Ministry of Health and the European Union: (ETT 476/2009), the National Development Agency (NKFP_06_A1-MMP_2006); HURO/0901/137/2.2.2 - HU-RO TRANS-MED; TÁMOP4.2.1/B-09/1/KONV-2010-0005; TÁMOP-4.2.2/B-10/1-2010-0012 and TÁMOP-4.2.2.A11/1/KONV-2012-0035; NKFP 07 1-ES2HEART-HU (OM-00202/2007); TÁMOP-4.2.208/1/2008-0013, TÁMOP-4.2.1/B-09/1/KONV-2010-0005, TÁMOP-4.2.2/B-10/1-20100012; NKTH-OTKA FP7 "Mobility" HUMAN-MB08C-80205 (for M.K.P.); the EU FP7 (InduHeart, PEOPLE-IRG-2008-234390; PartnErS, PIAP-GA-2008-218205; InduStem PIAPGA-2008-230675), COST BM1005, OTKA-PD106001. S.R. and N.K. were supported by the Office of the Higher Education Commission, Thailand (CHE-PhD-SW-2005-100 and CHEPhD-SW-RG-2007, respectively). T. Csont and A. Görbe hold a Bolyai János Fellowship of the Hungarian Academy of Sciences, P. Ferdinandy holds a Szentágothai Fellowship (TÁMOP-4.2.4.A/ 2-11/1-2012-0001) and J Pálóczi holds an Apáczai Fellowship (TÁMOP4.2.4.A/ 2-11/1-2012-0001) of the National Excellence Program of Hungary. Z. Varga was supported by the National Program of Excellence (TÁMOP 4.2.4.A/1-11-1-2012-0001).

I would like to thank Professor László Dux for providing possibility to work at the Biochemistry Department.

I would like to give the expression of my sincere gratitude to my supervisors, Dr. Anikó Görbe and Dr. Péter Bencsik for their excellent leadership and supervision. I would also like to thank for their support, patience and encouragement during my $\mathrm{PhD}$ studies.

I would like to thank Professor Peter Ferdinandy, for his valuable guidance and for providing a remarkable insight into my projects. Apart from excellent scientific advice, he greatly helped me improve my analytical thinking, reasoning and presentation skills.

I am thankful to Judit Pipis, Zsuzsanna Lajtos, Judit Kovács, Szilvia Török and Nóra Bagi for their skillful assistance.

I would like to give my special thanks to all of my present and past colleagues, students and friends. Finally, I take this opportunity to acknowledge the support from my lovely family: Niki and Máté. 


\section{REFERENCES}

1. Nichols M, Townsend N, Scarborough P, Rayner M. European cardiovascular disease statistics. 2012.

2. Az ST-elevacioval jaro akut myocardialis infarktus- finanszirozasi protokoll. Available from: http://site.oep.hu/steam/downloads/finprot_20141119/Az_STelevacioval_jaro_akut_myocardialis_infarktus_-_finanszirozasi_protokoll.pdf

3. Pfeffer MA, Braunwald E. Ventricular remodeling after myocardial infarction. Experimental observations and clinical implications. Circulation. 1990;81:1161-72.

4. Prasad SB, See V, Brown P, McKay T, Narayan A, Kovoor P, et al. Impact of duration of ischemia on left ventricular diastolic properties following reperfusion for acute myocardial infarction. Am J Cardiol. 2011;108:348-54.

5. Zhu X, Liu B, Zhou S, Chen Y-R, Deng Y, Zweier JL, et al. Ischemic preconditioning prevents in vivo hyperoxygenation in postischemic myocardium with preservation of mitochondrial oxygen consumption. Am J Physiol - Heart Circ Physiol. 2007;293:H1442-50.

6. Hassink RJ, Brutel de la Rivière A, Mummery CL, Doevendans PA. Transplantation of cells for cardiac repair. J Am Coll Cardiol. 2003;41:711-7.

7. Caspi O, Huber I, Kehat I, Habib M, Arbel G, Gepstein A, et al. Transplantation of Human Embryonic Stem Cell-Derived Cardiomyocytes Improves Myocardial Performance in Infarcted Rat Hearts. J Am Coll Cardiol. 2007;50:1884-93.

8. Singla DK. Embryonic Stem Cells in Cardiac Repair and Regeneration. Antioxid Redox Signal. 2009;11:1857-63.

9. Lundy SD, Zhu W-Z, Regnier M, Laflamme MA. Structural and Functional Maturation of Cardiomyocytes Derived from Human Pluripotent Stem Cells. Stem Cells Dev. 2013;22:1991-2002.

10. Hearse DJ, Bolli R. Reperfusion induced injury: manifestations, mechanisms, and clinical relevance. Cardiovasc Res. 1992;26:101-8.

11. Tani M, Neely JR. Na+ accumulation increases Ca2+ overload and impairs function in anoxic rat heart. J Mol Cell Cardiol. 1990;22:57-72.

12. Seal JB, Gewertz BL. Vascular dysfunction in ischemia-reperfusion injury. Ann Vasc Surg. 2005;19:572-84.

13. Ong S-B, Samangouei P, Kalkhoran SB, Hausenloy DJ. The mitochondrial permeability transition pore and its role in myocardial ischemia reperfusion injury. J Mol Cell Cardiol. 2015;78:23-34.

14. Turer AT, Hill JA. Pathogenesis of Myocardial Ischemia-Reperfusion Injury and Rationale for Therapy. Am J Cardiol. 2010;106:360-8. 
15. Spinale FG. Matrix Metalloproteinases Regulation and Dysregulation in the Failing Heart. Circ Res. 2002;90:520-30.

16. Inserte J, Barba I, Hernando V, Garcia-Dorado D. Delayed recovery of intracellular acidosis during reperfusion prevents calpain activation and determines protection in postconditioned myocardium. Cardiovasc Res. 2009;81:116-22.

17. Gross J, Lapiere CM. COLLAGENOLYTIC ACTIVITY IN AMPHIBIAN TISSUES: A TISSUE CULTURE ASSAY*. Proc Natl Acad Sci U S A. 1962;48:1014-22.

18. Yu S, Yehia G, Wang J, Stypulkowski E, Sakamori R, Jiang P, et al. Global ablation of the mouse Rab1la gene impairs early embryogenesis and matrix metalloproteinase secretion. J Biol Chem. 2014;289:32030-43.

19. Ma Y-L, Lin S-W, Fang H-C, Chou K-J, Bee Y-S, Chu T-H, et al. A novel polynaphthol compound ST104P suppresses angiogenesis by attenuating matrix metalloproteinase-2 expression in endothelial cells. Int J Mol Sci. 2014;15:16611-27.

20. Gomez-Rodriguez V, Orbe J, Martinez-Aguilar E, Rodriguez JA, Fernandez-Alonso L, Serneels J, et al. Functional MMP-10 is required for efficient tissue repair after experimental hind limb ischemia. FASEB J Off Publ Fed Am Soc Exp Biol. 2015;29:960-72.

21. Yu G, Herazo-Maya JD, Nukui T, Romkes M, Parwani A, Juan-Guardela BM, et al. Matrix metalloproteinase-19 promotes metastatic behavior in vitro and is associated with increased mortality in non-small cell lung cancer. Am J Respir Crit Care Med. 2014;190:780-90.

22. Singh A, Rajasekaran N, Hartenstein B, Szabowski S, Gajda M, Angel P, et al. Collagenase-3 (MMP-13) deficiency protects C57BL/6 mice from antibody-induced arthritis. Arthritis Res Ther. 2013;15:R222.

23. Koelink PJ, Overbeek SA, Braber S, Morgan ME, Henricks PAJ, Abdul Roda M, et al. Collagen degradation and neutrophilic infiltration: a vicious circle in inflammatory bowel disease. Gut. 2014;63:578-87.

24. Lee SW, Song KE, Shin DS, Ahn SM, Ha ES, Kim DJ, et al. Alterations in peripheral blood levels of TIMP-1, MMP-2, and MMP-9 in patients with type-2 diabetes. Diabetes Res Clin Pract. 2005;69:175-9.

25. Cheung P-Y, Sawicki G, Wozniak M, Wang W, Radomski MW, Schulz R. Matrix Metalloproteinase-2 Contributes to Ischemia-Reperfusion Injury in the Heart. Circulation. 2000;101:1833-9.

26. Wang W, Sawicki G, Schulz R. Peroxynitrite-induced myocardial injury is mediated through matrix metalloproteinase-2. Cardiovasc Res. 2002;53:165-74.

27. Wang W, Schulze CJ, Suarez-Pinzon WL, Dyck JRB, Sawicki G, Schulz R. Intracellular Action of Matrix Metalloproteinase-2 Accounts for Acute Myocardial Ischemia and Reperfusion Injury. Circulation. 2002;106:1543-9. 
28. DeCoux A, Lindsey ML, Villarreal F, Garcia RA, Schulz R. Myocardial matrix metalloproteinase-2: inside out and upside down. J Mol Cell Cardiol. 2014;77:64-72.

29. Okamoto T, Akaike T, Sawa T, Miyamoto Y, Vliet A van der, Maeda H. Activation of Matrix Metalloproteinases by Peroxynitrite-induced Protein S-Glutathiolation via Disulfide S-Oxide Formation. J Biol Chem. 2001;276:29596-602.

30. Siwik DA, Pagano PJ, Colucci WS. Oxidative stress regulates collagen synthesis and matrix metalloproteinase activity in cardiac fibroblasts. Am J Physiol - Cell Physiol. 2001;280:C53-60.

31. Kupai K, Szucs G, Cseh S, Hajdu I, Csonka C, Csont T, et al. Matrix metalloproteinase activity assays: Importance of zymography. J Pharmacol Toxicol Methods. 2010;61:205-9.

32. Jacob-Ferreira AL, Kondo MY, Baral PK, James MNG, Holt A, Fan X, et al. Phosphorylation status of $72 \mathrm{kDa}$ MMP-2 determines its structure and activity in response to peroxynitrite. PloS One. 2013;8:e71794.

33. Hughes BG, Schulz R. Targeting MMP-2 to treat ischemic heart injury. Basic Res Cardiol. 2014;109:424.

34. Lalu MM, Csonka C, Giricz Z, Csont T, Schulz R, Ferdinandy P. Preconditioning decreases ischemia/reperfusion-induced release and activation of matrix metalloproteinase-2. Biochem Biophys Res Commun. 2002;296:937-41.

35. Giricz Z, Lalu MM, Csonka C, Bencsik P, Schulz R, Ferdinandy P. Hyperlipidemia attenuates the infarct size-limiting effect of ischemic preconditioning: role of matrix metalloproteinase-2 inhibition. J Pharmacol Exp Ther. 2006;316:154-61.

36. Bencsik P, Kupai K, Giricz Z, Görbe A, Pipis J, Murlasits Z, et al. Role of iNOS and peroxynitrite-matrix metalloproteinase-2 signaling in myocardial late preconditioning in rats. Am J Physiol Heart Circ Physiol. 2010;299:H512-8.

37. Bell RM, Kunuthur SP, Hendry C, Bruce-Hickman D, Davidson S, Yellon DM. Matrix metalloproteinase inhibition protects CyPD knockout mice independently of RISK/mPTP signalling: a parallel pathway to protection. Basic Res Cardiol. 2013;108:1-12.

38. Dorman G, Kocsis-Szommer K, Spadoni C, Ferdinandy P. MMP Inhibitors in Cardiac Diseases: An Update. Recent Patents Cardiovasc Drug Discov. 2007;2:186-94.

39. Dormán DG, Cseh S, Hajdú I, Barna L, Kónya D, Kupai K, et al. Matrix Metalloproteinase Inhibitors. Drugs. 2012;70:949-64.

40. Bagai A, Dangas GD, Stone GW, Granger CB. Reperfusion strategies in acute coronary syndromes. Circ Res. 2014;114:1918-28.

41. Dai W, Hale SL, Kloner RA. Stem cell transplantation for the treatment of myocardial infarction. Transpl Immunol. 2005;15:91-7. 
42. Takahashi K, Yamanaka S. Induction of Pluripotent Stem Cells from Mouse Embryonic and Adult Fibroblast Cultures by Defined Factors. Cell. 2006;126:663-76.

43. Kawamura M, Miyagawa S, Miki K, Saito A, Fukushima S, Higuchi T, et al. Feasibility, Safety, and Therapeutic Efficacy of Human Induced Pluripotent Stem Cell-Derived Cardiomyocyte Sheets in a Porcine Ischemic Cardiomyopathy Model. Circulation. 2012;126:S29-37.

44. Zwi-Dantsis L, Gepstein L. Induced pluripotent stem cells for cardiac repair. Cell Mol Life Sci. 2012;69:3285-99.

45. Dai W, Field LJ, Rubart M, Reuter S, Hale SL, Zweigerdt R, et al. Survival and maturation of human embryonic stem cell-derived cardiomyocytes in rat hearts. J Mol Cell Cardiol. 2007;43:504-16.

46. Yoshida Y, Yamanaka S. Recent Stem Cell Advances: Induced Pluripotent Stem Cells for Disease Modeling and Stem Cell-Based Regeneration. Circulation. 2010;122:80-7.

47. Okano H, Nakamura M, Yoshida K, Okada Y, Tsuji O, Nori S, et al. Steps Toward Safe Cell Therapy Using Induced Pluripotent Stem Cells. Circ Res. 2013;112:523-33.

48. Qiao H, Surti S, Choi SR, Raju K, Zhang H, Ponde DE, et al. Death and Proliferation Time Course of Stem Cells Transplanted in the Myocardium. Mol Imaging Biol. 2009;11:408-14.

49. Luo J, Weaver MS, Cao B, Dennis JE, Van Biber B, Laflamme MA, et al. Cobalt protoporphyrin pretreatment protects human embryonic stem cell-derived cardiomyocytes from hypoxia/reoxygenation injury in vitro and increases graft size and vascularization in vivo. Stem Cells Transl Med. 2014;3:734-44.

50. Hsieh A, Feric NT, Radisic M. Combined hypoxia and sodium nitrite pretreatment for cardiomyocyte protection in vitro. Biotechnol Prog. 2015; in press.

51. Murphy E, Kohr M, Menazza S, Nguyen T, Evangelista A, Sun J, et al. Signaling by Snitrosylation in the heart. J Mol Cell Cardiol. 2014;73:18-25.

52. Fago A, Jensen FB. Hypoxia Tolerance, Nitric Oxide, and Nitrite: Lessons From Extreme Animals. Physiology. 2015;30:116-26.

53. Burley DS, Ferdinandy P, Baxter GF. Cyclic GMP and protein kinase-G in myocardial ischaemia-reperfusion: opportunities and obstacles for survival signaling. $\mathrm{Br} \mathrm{J}$ Pharmacol. 2007;152:855-69.

54. Bencsik P, Kupai K, Giricz Z, Görbe A, Huliák I, Fürst S, et al. Cardiac capsaicinsensitive sensory nerves regulate myocardial relaxation via S-nitrosylation of SERCA: role of peroxynitrite. Br J Pharmacol. 2008;153:488-96.

55. Otani $\mathrm{H}$. The role of nitric oxide in myocardial repair and remodeling. Antioxid Redox Signal. 2009;11:1913-28.

56. Sun J, Murphy E. Protein S-Nitrosylation and Cardioprotection. Circ Res. 2010;106:285-96. 
57. Schulz R, Ferdinandy P. Does nitric oxide signaling differ in pre- and post-conditioning? Importance of S-nitrosylation vs. protein kinase G activation. Free Radic Biol Med. 2013;54:113-5.

58. Gorbe A, Giricz Z, Szunyog A, Csont T, Burley DS, Baxter GF, et al. Role of cGMPPKG signaling in the protection of neonatal rat cardiac myocytes subjected to simulated ischemia/reoxygenation. Basic Res Cardiol. 2010;105:643-50.

59. Bell RM, Yellon DM. The contribution of endothelial nitric oxide synthase to early ischaemic preconditioning: the lowering of the preconditioning threshold. An investigation in eNOS knockout mice. Cardiovasc Res. 2001;52:274-80.

60. Burley DS, Baxter PGF. B-type natriuretic peptide at early reperfusion limits infarct size in the rat isolated heart. Basic Res Cardiol. 2007;102:529-41.

61. Bugaisky LB, Zak R. Differentiation of adult rat cardiac myocytes in cell culture. Circ Res. 1989;64:493-500.

62. Woodcock EA, Matkovich SJ. Cardiomyocytes structure, function and associated pathologies. Int J Biochem Cell Biol. 2005;37:1746-51.

63. Csont T, Görbe A, Bereczki E, Szunyog A, Aypar E, Tóth ME, et al. Biglycan protects cardiomyocytes against hypoxia/reoxygenation injury: role of nitric oxide. J Mol Cell Cardiol. 2010;48:649-52.

64. Li X, Heinzel FR, Boengler K, Schulz R, Heusch G. Role of connexin 43 in ischemic preconditioning does not involve intercellular communication through gap junctions. $\mathrm{J}$ Mol Cell Cardiol. 2004;36:161-3.

65. Galis ZS, Sukhova GK, Libby P. Microscopic localization of active proteases by in situ zymography: detection of matrix metalloproteinase activity in vascular tissue. FASEB J. 1995;9:974-80.

66. Galardy RE, Cassabonne ME, Giese C, Gilbert JH, Lapierre F, Lopez H, et al. Low molecular weight inhibitors in corneal ulceration. Ann N Y Acad Sci. 1994;732:315-23.

67. Csonka C, Szilvássy Z, Fülöp F, Páli T, Blasig IE, Tosaki A, et al. Classic preconditioning decreases the harmful accumulation of nitric oxide during ischemia and reperfusion in rat hearts. Circulation. 1999;100:2260-6.

68. Csonka C, Kupai K, Kocsis GF, Novák G, Fekete V, Bencsik P, et al. Measurement of myocardial infarct size in preclinical studies. J Pharmacol Toxicol Methods. 2010;61:163-70.

69. Belteki G, Gertsenstein M, Ow DW, Nagy A. Site-specific cassette exchange and germline transmission with mouse ES cells expressing $\varphi \mathrm{C} 31$ integrase. Nat Biotechnol. $2003 ; 21: 321-4$.

70. Mummery CL, Ward D, Passier R. Differentiation of human embryonic stem cells to cardiomyocytes by coculture with endoderm in serum-free medium. Curr Protoc Stem Cell Biol. 2007; Chapter 1:Unit 1F.2. 
71. D’Souza SP, Yellon DM, Martin C, Schulz R, Heusch G, Onody A, et al. B-type natriuretic peptide limits infarct size in rat isolated hearts via KATP channel opening. Am J Physiol - Heart Circ Physiol. 2003;284:H1592-600.

72. Milkiewicz M, Kelland C, Colgan S, Haas TL. Nitric oxide and p38 MAP kinase mediate shear stress-dependent inhibition of MMP-2 production in microvascular endothelial cells. J Cell Physiol. 2006;208:229-37.

73. Ferdinandy P, Szilvássy Z, Droy-Lefaix MT, Tarrade T, Koltai M. KATP channel modulation in working rat hearts with coronary occlusion: effects of cromakalim, cicletanine, and glibenclamide. Cardiovasc Res. 1995;30:781-7.

74. Donato M, D'Annunzio V, Buchholz B, Miksztowicz V, Carrión CL, Valdez LB, et al. Role of matrix metalloproteinase-2 in the cardioprotective effect of ischaemic postconditioning. Exp Physiol. 2010;95:274-81.

75. Kandasamy AD, Chow AK, Ali MAM, Schulz R. Matrix metalloproteinase-2 and myocardial oxidative stress injury: beyond the matrix. Cardiovasc Res. 2010;85:413-23.

76. Tyagi SC, Kumar SG, Banks J, Fortson W. Co-expression of tissue inhibitor and matrix metalloproteinase in myocardium. J Mol Cell Cardiol. 1995;27:2177-89.

77. Sang Q-XA, Jin Y, Newcomer RG, Monroe SC, Fang X, Hurst DR, et al. Matrix metalloproteinase inhibitors as prospective agents for the prevention and treatment of cardiovascular and neoplastic diseases. Curr Top Med Chem. 2006;6:289-316.

78. Castro MM, Rizzi E, Prado CM, Rossi MA, Tanus-Santos JE, Gerlach RF. Imbalance between matrix metalloproteinases and tissue inhibitor of metalloproteinases in hypertensive vascular remodeling. Matrix Biol. 2010;29:194-201.

79. Fert-Bober J, Leon H, Sawicka J, Basran RS, Devon RM, Schulz R, et al. Inhibiting matrix metalloproteinase-2 reduces protein release into coronary effluent from isolated rat hearts during ischemia-reperfusion. Basic Res Cardiol. 2008;103:431-43.

80. Walsh KB, Rich TC, Coffman ZJ. Development of a high-throughput assay for monitoring cAMP levels in cardiac ventricular myocytes. J Cardiovasc Pharmacol. 2009;53:223-30.

81. Xu C, Police S, Rao N, Carpenter MK. Characterization and Enrichment of Cardiomyocytes Derived From Human Embryonic Stem Cells. Circ Res. 2002;91:5018.

82. Ozsvári B, Puskás LG, Nagy LI, Kanizsai I, Gyuris M, Madácsi R, et al. A cellmicroelectronic sensing technique for the screening of cytoprotective compounds. Int $\mathrm{J}$ Mol Med. 2010;25:525-30.

83. Nakano A, Liu GS, Heusch G, Downey JM, Cohen MV. Exogenous Nitric Oxide Can Trigger a Preconditioned State Through a Free Radical Mechanism, But Endogenous Nitric Oxide Is Not a Trigger of Classical Ischemic Preconditioning. J Mol Cell Cardiol. 2000;32:1159-67. 
84. Takano H, Tang XL, Qiu Y, Guo Y, French BA, Bolli R. Nitric oxide donors induce late preconditioning against myocardial stunning and infarction in conscious rabbits via an antioxidant-sensitive mechanism. Circ Res. 1998;83:73-84.

85. Maejima $\mathrm{Y}$, Adachi $\mathrm{S}$, Ito $\mathrm{H}$, Nobori $\mathrm{K}$, Tamamori-Adachi $\mathrm{M}$, Isobe M. Nitric oxide inhibits ischemia/reperfusion-induced myocardial apoptosis by modulating cyclin Aassociated kinase activity. Cardiovasc Res. 2003;59:308-20.

86. Kanno S, Kim PKM, Sallam K, Lei J, Billiar TR, Shears LL. Nitric oxide facilitates cardiomyogenesis in mouse embryonic stem cells. Proc Natl Acad Sci U S A. 2004;101:12277-81.

87. Ferdinandy P, Schulz R. Nitric oxide, superoxide, and peroxynitrite in myocardial ischaemia-reperfusion injury and preconditioning. Br J Pharmacol. 2003;138:532-43.

88. Krumenacker JS, Katsuki S, Kots A, Murad F. Differential expression of genes involved in cGMP-dependent nitric oxide signaling in murine embryonic stem (ES) cells and ES cell-derived cardiomyocytes. Nitric Oxide Biol Chem Off J Nitric Oxide Soc. 2006;14:1-11.

89. Abdelalim EM, Tooyama I. BNP Signaling Is Crucial For Embryonic Stem Cell Proliferation. PLoS ONE. 2009;4:e5341.

90. Mobley S, Shookhof JM, Foshay K, Park M, Gallicano GI. PKG and PKC Are DownRegulated during Cardiomyocyte Differentiation from Embryonic Stem Cells: Manipulation of These Pathways Enhances Cardiomyocyte Production. Stem Cells Int. 2010;2010:701212.

91. $\mathrm{Xu} \mathrm{Z}$, Ji X, Boysen PG. Exogenous nitric oxide generates ROS and induces cardioprotection: involvement of PKG, mitochondrial KATP channels, and ERK. Am J Physiol - Heart Circ Physiol. 2004;286:H1433-40.

92. Gryshchenko O, Fischer IR, Dittrich M, Viatchenko-Karpinski S, Soest J, Böhm-Pinger $\mathrm{MM}$, et al. Role of ATP-dependent $\mathrm{K}(+)$ channels in the electrical excitability of early embryonic stem cell-derived cardiomyocytes. J Cell Sci. 1999;112:2903-12.

93. Baharvand H, Hajheidari M, Zonouzi R, Ashtiani SK, Hosseinkhani S, Salekdeh GH. Comparative proteomic analysis of mouse embryonic stem cells and neonatal-derived cardiomyocytes. Biochem Biophys Res Commun. 2006;349:1041-9. 


\section{ANNEX}




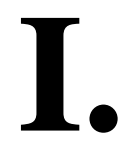




\title{
Moderate inhibition of myocardial matrix metalloproteinase-2 by ilomastat is cardioprotective
}

\author{
Péter Bencsik ${ }^{\mathrm{a}, c, 1}$, János Pálóczi a,1 ${ }^{\mathrm{a}}$, Gabriella F. Kocsis ${ }^{\mathrm{a}}$, Judit Pipis ${ }^{\mathrm{a}}$, István Belecz ${ }^{\mathrm{b}}$, \\ Zoltán V. Varga ${ }^{a}$, Csaba Csonka ${ }^{a, c}$, Anikó Görbe ${ }^{a, c}$, Tamás Csont ${ }^{a, c}$, Péter Ferdinandy ${ }^{c, d, *}$ \\ a Cardiovascular Research Group, Department of Biochemistry, University of Szeged, Szeged, Hungary \\ ${ }^{\mathrm{b}}$ Department of Medical Biology, Faculty of Medicine, University of Szeged, Szeged, Hungary \\ c Pharmahungary Group, Szeged, Hungary \\ d Department of Pharmacology and Pharmacotherapy, Semmelweis University, Budapest, Hungary
}

\section{A R T I C L E I N F O}

\section{Article history:}

Received 24 September 2013

Received in revised form

17 December 2013

Accepted 18 December 2013

\section{Keywords:}

Matrix metalloproteinase

Ilomastat

Ischemia/reperfusion injury

Coronary occlusion

In situ zymography

Cardiomyocyte

\begin{abstract}
A B S T R A C T
Pharmacological inhibition of matrix metalloproteinase-2 (MMP-2) is a promising target for acute cardioprotection against ischemia/reperfusion injury. Therefore, here we investigated if the MMP inhibitor ilomastat administered either before ischemia or before reperfusion is able to reduce infarct size via inhibition of MMP-2, the most abundant MMP in the rat heart.

Infarct-size limiting effect of ilomastat $(0.3-6.0 \mu \mathrm{mol} / \mathrm{kg})$ was tested in an in vivo rat model of myocardial infarction induced by $30 \mathrm{~min}$ coronary occlusion/120 min reperfusion. Ilomastat at 0.75 and $1.5 \mu \mathrm{mol} / \mathrm{kg}$ decreased infarct size significantly as compared to the vehicle-treated (dimethyl sulfoxide) group (from $66.1 \pm 4.6 \%$ to $45.3 \pm 7.0 \%$ and $46.7 \pm 5.5 \%$ of area at risk, $p<0.0 .5$, respectively), when administered $5 \mathrm{~min}$ before the onset of ischemia. Ilomastat at $6.0 \mu \mathrm{mol} / \mathrm{kg}$ significantly reduced infarct size from its control value of $65.4 \pm 2.5 \%$ to $52.8 \pm 3.7 \%$ of area at risk $(p<0.05)$, when administered $5 \mathrm{~min}$ before the onset of reperfusion. Area at risk was not significantly affected by ilomastat treatments. To further assess the cytoprotective effect of ilomastat, primary cardiomyocytes isolated from neonatal rats were subjected to $240 \mathrm{~min}$ simulated ischemia followed by $120 \mathrm{~min}$ simulated reperfusion in the presence of ilomastat ( $5 \mathrm{nM}-5 \mu \mathrm{M})$. Ilomastat at $500 \mathrm{nM}$ and $5 \mu \mathrm{M}$ significantly increased cell viability when compared to vehicle treated group. To assess the in situ MMP-2 inhibitory effect of ilomastat, in separate experiments in situ zymography was performed in cardiomyocytes. The cytoprotective concentration of ilomastat ( $500 \mathrm{nM})$ showed a moderate (approximately 25\%) inhibition of intracellular MMP-2 in ischemic/reperfused cardiomyocytes. In these cells, MMP-2 immunostaining showed a 90\% colocalization with the in situ gelatinolytic activity.

We conclude that the MMP inhibitor ilomastat reduces infarct size when administered either before the onset of ischemia or before the onset of reperfusion in vivo. Furthermore, this is the first demonstration that a moderate inhibition of intracellular MMP-2 is sufficient to confer cardiocytoprotection.
\end{abstract}

(c) 2013 Elsevier Ltd. All rights reserved.

\section{Introduction}

Acute myocardial infarction and its complications are the leading cause of death in the industrialized countries. The treatment of acute ischemic heart disease has entered a new era through early reperfusion therapy, however, irreversible cell injury leading to

Abbreviations: DMSO, dimethyl sulfoxide; ILO, ilomastat; LAD, left anterior descending coronary artery; MMP, matrix metalloproteinase; PBS, phosphate buffer solution; PI, propidium iodine.

* Corresponding author at: Pharmahungary Group, Dóm tér 9, H-6720 Szeged, Hungary.

E-mail address: peter.ferdinandy@pharmahungary.com (P. Ferdinandy).

1 These authors contributed equally to this work. apoptosis and necrosis may be precipitated by reperfusion, which may contribute to the development of infarction [1,2]. Therefore, to protect the heart from acute ischemic and reperfusion injury, i.e. to reduce infarct size is of great clinical relevance.

The pathomechanism of myocardial ischemia and reperfusion injury is not completely revealed. Since the original observation by the research group of Richard Schulz, the involvement of matrix metalloproteinases (MMP) in acute myocardial ischemia/reperfusion injury has been well-established [3-9]. MMPs are zinc dependent, neutral endopeptidases involved in several physiological processes, such as embryogenesis, angiogenesis and re-building of extracellular matrix (ECM). Gelatinase types of MMPs, MMP-2 and -9, are implicated in numerous cardiovascular diseases including ischemia/reperfusion injury [10]. Recently, the presence of MMP-2 has been shown in the cytosol of intact 
cardiomyocytes [11]. Moreover, several cardiac contractile proteins, such as titin and troponins, were shown to be potential targets of acute intracellular MMP-2 activation during ischemia/reperfusion [12]. Therefore, MMP-2 became a major target for drug development in acute cardiovascular pathologies including myocardial infarction $[13,14]$.

We have previously reported that MMP-2 activity was moderately decreased during ischemic preconditioning [6] and that exogenous inhibition of MMPs by ilomastat, a non-selective MMP inhibitor, diminished ischemia-induced MMP-2 activity in isolated rat hearts [5]. Furthermore, we have described that the activities of MMP-2 and MMP-9 were decreased significantly in an in vivo rat model of ischemic late preconditioning [3]. Moreover, we and others have shown that ilomastat reduces infarct size in rats and mice $([3,15]$, for review see Refs. $[10,16])$. Nevertheless, the dose-response relationships of ilomastat administered before the onset of ischemia as well as before the onset of reperfusion are still unknown. Moreover, there is no proof if ilomastat-induced cardioprotection is due to MMP-2 inhibition. Furthermore, it is also not known, what extent of intracellular MMP-2 inhibition is needed for effective cardioprotection.

Therefore, in the present study, we aimed to investigate the dose-response relationships of ilomastat administered before the onset of ischemia as well as before the onset of reperfusion in an in vivo rat model of myocardial infarction. Furthermore, to test if ilomastat-induced cardioprotection is due to (and what extent of) MMP-2 inhibition, we performed gelatin zymography and in situ zymography followed by immunostaining of MMP-2 in cardiomyocytes subjected to simulated ischemia/reperfusion.

\section{Materials and methods}

\subsection{Animals}

Animal handling and the investigation was in conjunction with Guide for the Care and Use of Laboratory Animals published by the U.S. National Institutes of Health (National Institutes of Health publication 85-23, revised 1996), and it was approved by a local animal ethics committee.

Male Wistar rats (Charles-River, Germany) weighing 280-370 g were used in the experiments housed in individually ventilated cages. Animals were fed with standard murine chow and unlimited access to water was ensured prior to the surgical intervention. For the cell culture experiments, neonatal Wistar rats were purchased from the local live-stock of the University of Szeged.

\subsection{In vivo studies}

\subsubsection{Surgical procedure of coronary occlusion}

Rats were anesthetized by intraperitoneal injection of $60 \mathrm{mg} / \mathrm{kg}$ sodium pentobarbital (Euthasol, Produlab Pharma b.v., Raamsdonksveer, The Netherlands). Animals were mechanically ventilated (Model 683, Harvard Apparatus, Holliston, MA) with room air in a volume of $6.2 \mathrm{ml} / \mathrm{kg}$ and a frequency of $55 \pm 5$ breath $/ \mathrm{min}$ according to body weight. Rats were placed in supine position on a heating pad to maintain body core temperature in physiological range $\left(37.0 \pm 1.0^{\circ} \mathrm{C}\right)$. Right carotid artery was cannulated to measure mean arterial blood pressure by a pressure transducer (Experimetria Inc., Budapest, Hungary). Mean arterial blood pressure and body surface electrocardiogram (ECG) was monitored throughout the experiments (Haemosys, Experimetria Inc., Budapest, Hungary). Right jugular vein was also cannulated for fluid substitution and drug administration. Left anterior descending coronary artery (LAD) occlusion was induced by left thoracotomy. A 5-0 Prolene suture (Ethicon, Johnson \& Johnson, Budapest,
A

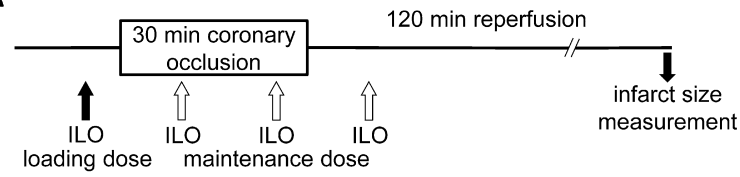

B

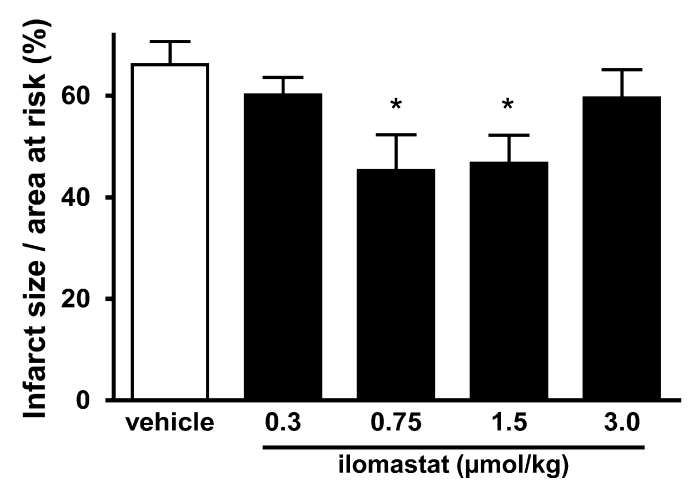

Fig. 1. Panel $A$ : In vivo experimental protocol: rats were subjected to $30 \mathrm{~min}$ ischemia/120 min reperfusion to measure infarct size. Ilomastat at $0.3,0.75,1.5$ and $3.0 \mu \mathrm{mol} / \mathrm{kg}$ or vehicle (DMSO) was administered intravenously (upward closed arrow) at 5 min before the onset of ischemia. To maintain serum level of ilomastat, repeated boluses with half dose of the first bolus were administered in every $15 \mathrm{~min}$, three times: at the 10th and 25th min of ischemia and at the 10th min of reperfusion (upward open arrows). Panel $B$ : Effect of ilomastat treatment on infarct size when administered before ischemia. ${ }^{*} p<0.05$ compared to vehicle-treated group, $n=7-8$, data are shown as mean \pm S.E.M.

Hungary) was placed around LAD artery and a small plastic knob, which was threaded through the ligature and placed in contact with the heart, was used for making occlusion for $30 \mathrm{~min}$. Appearance of ischemia was confirmed by ST segment elevation and arrhythmias. After 30-min ischemia, hearts were reperfused for $120 \mathrm{~min}$ by releasing the ligature. Restoration of blood flow was confirmed by arrhythmias observed in the first minutes of reperfusion.

\subsubsection{Experimental groups}

In first series of in vivo experiments, ilomastat was administered before the onset and during the 30-min ischemia. Animals were divided into five groups. Dimethyl sulfoxide (DMSO; $11.6 \mathrm{w} / \mathrm{v} \%$ solution diluted with physiological saline) as vehicle or $0.3,0.75$, 1.5 , and $3.0 \mu \mathrm{mol} / \mathrm{kg}$ ilomastat were administered intravenously in slow bolus 5 min before ischemia (Fig. 1A). To maintain serum level of ilomastat, additional 3 boluses of vehicle $(5.8 \mathrm{w} / \mathrm{v} \%$ DMSO solution) or ilomastat with half dose $(0.15,0.375,0.75$; and $1.5 \mu \mathrm{mol} / \mathrm{kg}$, respectively), were given at the 10 th, 25 th min of ischemia and at the 10 th min of reperfusion. We estimated the maintaining doses of ilomastat according to its half-life based on pharmacokinetic data described previously in rodents after a single intravenous bolus injection [17].

In the second series of in vivo experiments DMSO $(11.6 \mathrm{w} / \mathrm{v} \%$ solution) or ilomastat $(0.75,1.5,3.0$, and $6.0 \mu \mathrm{mol} / \mathrm{kg})$ bolus was injected at the 25 th min of ischemia. Maintaining boluses $(5.8 \mathrm{w} / \mathrm{v} \%$ DMSO or $0.375,0.75,1.5$, and $3.0 \mu \mathrm{mol} / \mathrm{kg}$, respectively) were administered at the 10th, 25 th and 40 th min of reperfusion (Fig. 2A) to maintain constant ilomastat concentration in blood during the early phase of reperfusion.

\subsubsection{Determination of infarct size}

After $120 \mathrm{~min}$ of reperfusion hearts were isolated for infarct size measurements. Hearts were perfused in Langendorff perfusion system with $37^{\circ} \mathrm{C}$ Krebs-Henseleit buffer (composition given in Ref. [18]) to remove blood from the coronary vessels. After 5 min of perfusion, risk area was re-occluded, and hearts were perfused with $4 \mathrm{ml}$ of $0.1 \%$ Evans blue dye through the ascending aorta. 


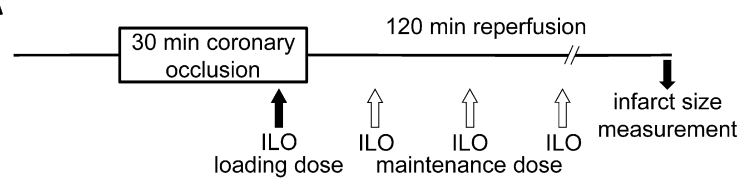

B

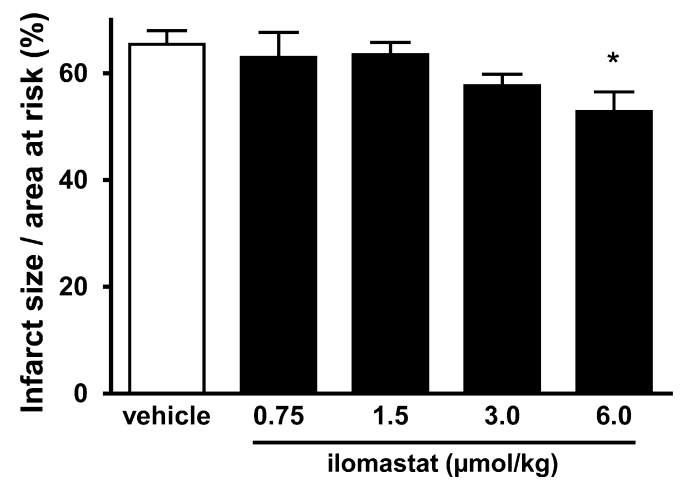

Fig. 2. Panel A: In vivo experimental protocol: rats were subjected to $30 \mathrm{~min}$ ischemia/120 min reperfusion to measure infarct size. Ilomastat at $0.75,1.5,3.0$, and $6.0 \mu \mathrm{mol} / \mathrm{kg}$ or vehicle (DMSO) was administered intravenously (upward closed arrow) at $5 \mathrm{~min}$ before the onset of reperfusion. To maintain serum level of ilomastat, repeated boluses with half dose of the first bolus were administered in every 15 min, three times: at the 10th, 25th and the 40th min of reperfusion (upward open arrows). Panel $B$ : Effect of ilomastat treatment on infarct size when administered before reperfusion. ${ }^{*} p<0.05$ compared to vehicle-treated group, $n=7-8$, data are shown as mean \pm S.E.M.

Following Evans staining, hearts were cut into 5 transversal slices and incubated in 1\% triphenyl-tetrazolium-chloride for $10 \mathrm{~min}$ at $37^{\circ} \mathrm{C}$ followed by formalin fixation for $10 \mathrm{~min}$. Planimetric evaluation was carried out to determine infarct size using InfarctSize ${ }^{\mathrm{TM}}$ software, (Pharmahungary, Szeged, Hungary; [19]).

\subsection{In vitro studies}

\subsubsection{Inhibition of gelatinase activity by ilomastat}

To determine the source of the gelatinolytic activity and its inhibition by ilomastat, gelatin zymography was performed on cardiac tissue homogenate of a non-treated control rat. Gelatinolytic activities of MMP-2 were examined as previously described in detail [20]. Briefly, $8 \%$ polyacrylamide gels were copolymerized with gelatin $(2 \mathrm{mg} / \mathrm{ml}$, type A from porcine skin, Sigma-Aldrich, Budapest, Hungary), and $50 \mu \mathrm{g}$ of protein per lane was loaded. After electrophoresis $(90 \mathrm{~V}, 1.5 \mathrm{~h})$, gels were washed firstly with renaturation buffer (Bio-Rad, Hercules, CA; containing 2.5\% Triton X-100) for $3 \times 15$ min then incubated in development buffer (Bio-Rad, Hercules, CA) for 20 min to eliminate Triton-X-100. Gels were sliced according to the lanes and the slices were incubated separately for $20 \mathrm{~h}$ at $37^{\circ} \mathrm{C}$ at $\mathrm{pH} 7.4$ in development buffer in the presence of vehicle and/or different concentrations of ilomastat $(0.5 \mathrm{nM}$ and $5.0 \mathrm{nM}$ ). Recombinant, human MMP-2 was used as positive control. Gels were then stained with $0.05 \%$ Coomassie brilliant blue (G-250, Sigma-Aldrich, Budapest, Hungary). Gelatinolytic activities were detected as transparent bands against the dark-blue background. Band intensities were quantified (Quantity One software, Bio-Rad, Hercules, CA) and expressed in arbitrary units. The gelatin zymography protocol does not contain any component or step, which may inhibit proteases including other MMPs.

\subsubsection{Simulated ischemia/reperfusion in cardiomyocytes}

Neonatal rat cardiomyocytes were cultured in 48-well plates. Neonatal cardiomyocytes were chosen for the present study, as they can be harvested on culture dishes without coating. The lack of coating is important in the present study, as coating materials (e.g. laminin, collagen, etc.) could influence the action of matrix metalloproteinases [21,22]. Cell isolation and culturing method was described previously in detail $[23,24]$. Briefly, neonatal rats were sacrificed by cervical dislocation and hearts were placed into ice cold PBS solution. Ventricles were digested in $0.25 \%$ trypsin (Invitrogen, Life Technologies Hungary Ltd., Budapest, Hungary) solution and cell suspension was centrifuged at $400 \times g$, for $15 \mathrm{~min}$ at $4{ }^{\circ} \mathrm{C}$. Cell pellet was re-suspended in Dulbecco's Modified Eagle Medium (Sigma-Aldrich, Budapest, Hungary) supplemented with L-glutamine (Sigma-Aldrich, Budapest, Hungary), Antibiotic-antimycotic solution (Sigma-Aldrich, Budapest, Hungary) and 10\% fetal bovine serum (Gibco, Life Technologies Hungary Ltd., Budapest, Hungary). Cells were counted in a hemocytometer, and seeded into 48 -well plates at a density of $5 \times 10^{4}$ cell/well. After $24 \mathrm{~h}$, the growth medium was replaced with differentiation medium containing $1 \%$ fetal bovine serum. Cardiomyocytes were kept under normoxic conditions $\left(37^{\circ} \mathrm{C}\right.$, in $95 \%$ air and $5 \% \mathrm{CO}_{2}$ gas mixture) for three days prior to simulated ischemia/reperfusion experiments. We used a combination of hypoxic chamber and hypoxic solution to simulate tissue ischemia. In the simulated ischemic group, the medium of the cultures were replaced with a hypoxic solution (composition given in Ref. [25]) and plates were kept in a hypoxic chamber (gassed with $95 \% \mathrm{~N}_{2}$ and $5 \% \mathrm{CO}_{2}$ at $37^{\circ} \mathrm{C}$ ) for $240 \mathrm{~min}$ in the presence or absence of ilomastat ( $5 \mathrm{nM}, 50 \mathrm{nM}, 500 \mathrm{nM}$ and $5 \mu \mathrm{M}$ ). The vehicle group was treated with $0.2 \%$ DMSO. During simulated reperfusion cells were covered with differentiation medium (containing $1 \%$ fetal bovine serum) and kept in a normoxic incubator for $120 \mathrm{~min}$.

\subsubsection{Cell viability assay}

Cell viability was assessed by a calcein and propidium iodine (PI) assay performed in each group after $2 \mathrm{~h}$ simulated reperfusion [26]. Briefly, the growth medium was removed, cells were washed with PBS twice and incubated with calcein $(1 \mu \mathrm{M})$ for $30 \mathrm{~min}$. Then calcein solution was replaced with fresh PBS and fluorescence intensity of each well was detected by fluorescent plate reader (FluoStar Optima, BMG Labtech, Auro-Science Consulting Ltd., Budapest, Hungary). Then PI $(50 \mu \mathrm{M})$ and digitonin $(100 \mu \mathrm{M})$ (Sigma-Aldrich, St. Louis, MO) were added to PBS and cells were incubated for $7 \mathrm{~min}$. Then PI solution was replaced with fresh PBS and fluorescent intensity was detected with same settings.

\subsubsection{In situ zymography and MMP-2 co-localization}

To detect in situ MMP-2 activity, neonatal rat cardiomyocytes were cultured in 24-well tissue culture plate at the density of $10^{5}$ cells/well for 3 days. The medium of cells was replaced with hypoxic solution supplemented with $\mathrm{DQ}^{\mathrm{TM}}$ gelatin (Invitrogen, Life Technologies Hungary Ltd., Budapest, Hungary) at $40 \mu \mathrm{g} / \mathrm{ml}$ concentration. Cells were then subjected to $240 \mathrm{~min}$ simulated ischemia in the presence of ilomastat (at $500 \mathrm{nM}$ concentration) or its vehicle. Other series of cells were covered with normoxic solution and kept in normoxic incubator for $240 \mathrm{~min}$. Subsequently, all groups were subjected to reoxygenation: the hypoxic, or normoxic solution of the cells was replaced with differentiation medium supplemented with DQ gelatin and cells were placed into a normoxic incubator for $120 \mathrm{~min}$. Finally cells were washed with PBS, and fixed in 3.7\% paraformaldehyde dissolved in PBS for $15 \mathrm{~min}$. MMP2 fluorescent immunostaining using anti-proMMP-2 antibody (Chemicon, MAB3308; Merck Ltd., Budapest, Hungary; secondary antibody: rhodamine-labeled goat anti-mouse antibody; Abcam, AB5885, Cambridge, UK) was assessed to detect co-localization of MMP-2 with gelatinolytic activity. Nuclei of the cells were stained with Hoechst 33342 (Invitrogen, Life Technologies Hungary Ltd., Budapest, Hungary). After the subsequent washing steps, cells were covered with fluorescent mounting medium (Dako, Frank Diagnosztika Ltd., Budapest, Hungary), and fluorescence was 


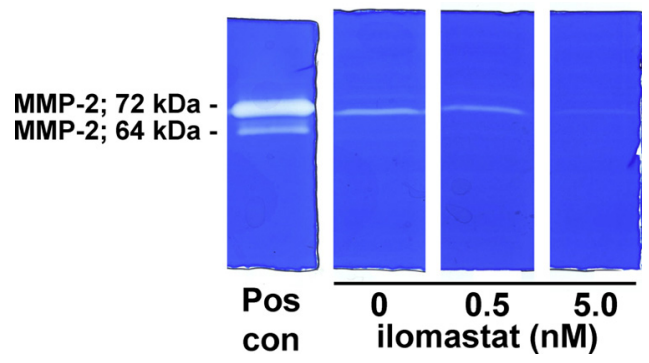

Fig. 3. Representative images of MMP-2 activity in gelatin zymograms in the presence of $0,0.5$ and $5.0 \mathrm{nM}$ ilomastat.

detected with a confocal laser microscope in sequential scanning mode (Olympus Fluoview 1000, Olympus Hungary Ltd., Budapest, Hungary). Assessment of the gelatinolytic activity was carried out by quantifying different parameters of fluorescent particles from 10 fields selected randomly on each coverslip. Four coverslips were analyzed in each group. The number, total area, and area fraction of fluorescent signal, and the analyses of co-localization were quantified on images by Image 1.45 software (National Institutes of Health, Bethesda, MD).

\subsection{Statistical analysis}

Statistical analysis was performed using Sigmaplot 11.0 software. All data were given as mean \pm standard error of the mean (S.E.M.). One-way analysis of variance followed by Fisher-LSD post hoc tests were performed to show differences among groups. $p$ values of $\leq 0.05$ were accepted as statistically significant difference compared to vehicle control.

\section{Results}

\subsection{Effect of ilomastat on infarct size in vivo}

The cardioprotective effect of ilomastat administered before the onset of ischemia (Fig. 1) or before the onset of reperfusion (Fig. 2) was studied in an in vivo myocardial infarction model induced by coronary occlusion in rats. When administered before the onset of ischemia, ilomastat at 0.75 and $1.5 \mu \mathrm{mol} / \mathrm{kg}$ doses reduced infarct size significantly as compared to vehicle-treated group (from $66.1 \pm 4.6 \%$ to $45.3 \pm 7.0 \%$ and $46.7 \pm 5.5 \%$ of area at risk, respectively) showing a U-shaped dose-response relationship (Fig. 1B). When administered before the onset of reperfusion, ilomastat at $6.0 \mu \mathrm{mol} / \mathrm{kg}$ reduced infarct size significantly (from $65.4 \pm 2.5 \%$ to $52.8 \pm 3.7 \%$ of area at risk), however, lower doses were ineffective (Fig. 2B). There was no significant difference in the area at risk among the groups (data not shown). There was no significant difference in the mean arterial blood pressure and heart rate among the groups (Tables 1 and 2 are shown in data supplement).

\subsection{Effect of ilomastat on cardiac gelatinolytic activity}

In a preliminary series of studies, the in vitro MMP-inhibitory dose range of ilomastat was estimated in rat cardiac tissue homogenate by gelatin zymography. We have found that the IC50 of ilomastat was $0.83 \mathrm{nM}$. Gelatinolytic activity was detectable only at $72 \mathrm{kDa}$ in cardiac homogenate suggesting that only MMP-2 activity was present in the heart tissue at a significant level (Fig. 3).

\subsection{Effect of ilomastat on ischemia/reperfused cardiomyocytes}

In order to test if a direct cardiocytoprotection by MMP2 inhibition of ilomastat is involved in its cardioprotective
A

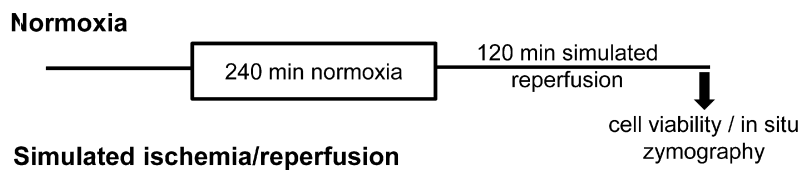

Simulated ischemia/reperfusion zymography

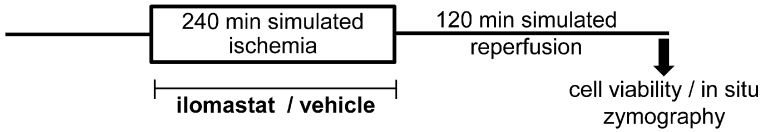

B

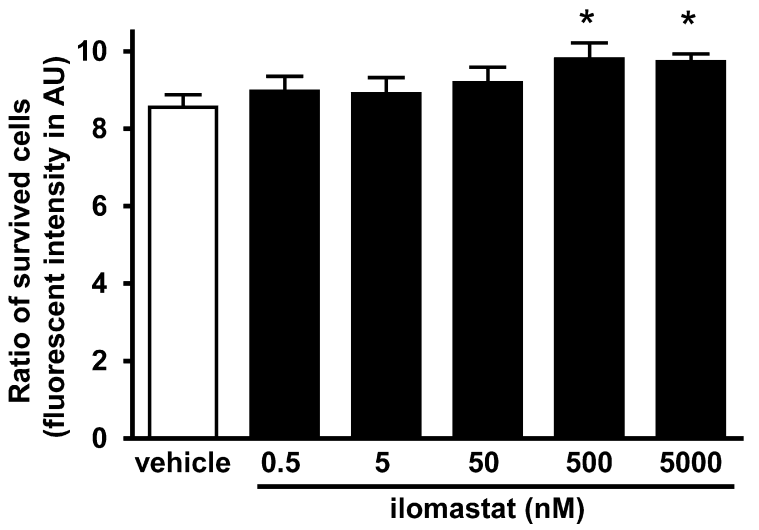

Fig. 4. Panel A: Experimental protocol of cell culture studies. Simulated ischemia/reperfusion was induced in the presence of vehicle (DMSO) or ilomastat. Viability assays and in situ zymography were performed after the end of simulated reperfusion. Normoxic time-matched control groups were kept under normoxic solution in normoxic conditions. Panel B: Effect of ilomastat on cell viability in neonatal rat cardiomyocytes after simulated ischemia/reperfusion. ${ }^{*} p<0.05$ compared to vehicle treated group, $n=6$; data are shown as mean \pm S.E.M.

effect, we examined ilomastat-induced cytoprotection in isolated neonatal rat cardiomyocytes subjected to normoxia or simulated ischemia/reperfusion (Fig. 4A). Ilomastat at a dose range of $0.5 \mathrm{nM}$ up to $5 \mu \mathrm{M}$ did not influence cell viability in normoxic conditions (Table 3, supplementary material). However, ilomastat at $500 \mathrm{nM}$ and $5 \mu \mathrm{M}$ significantly increased cell viability as compared to vehicle treated group (from $8.6 \pm 0.3$ to $9.8 \pm 0.4$ and $9.7 \pm 0.2$, respectively, expressed in arbitrary units of fluorescent intensity) in cardiomyocytes subjected to simulated ischemia/reperfusion (Fig. 4B).

\subsection{In situ MMP-2 inhibition by ilomastat in ischemia/reperfused cardiomyocytes}

To test the in situ MMP inhibitory efficacy of the cardiocytoprotective concentration of ilomastat, we performed in situ zymography on isolated rat cardiomyocytes subjected to simulated ischemia/reperfusion (Fig. 5). Simulated ischemia/reperfusion increased gelatinolytic activity significantly from its control value of $0.48 \pm 0.04 \%$ to $0.93 \pm 0.05 \%$ of area fraction. The cardiocytoprotective concentration of ilomastat ( $500 \mathrm{nM}$, see Fig. 4B) moderately inhibited the in situ gelatinolytic activity approximately by $25 \%$, i.e. from $0.93 \pm 0.05 \%$ to $0.70 \pm 0.04 \%$ of area fraction, during simulated ischemia/reperfusion (Fig. 5/D). Moreover, we performed separate experiments to show co-localization of MMP-2 with the fluorescent gelatinolytic signal in isolated rat cardiomyocytes subjected to simulated ischemia/reperfusion. MMP-2 showed over $90 \%$ co-localization rate with gelatinolytic activity in all groups (Fig. 6).

\section{Discussion}

Here we have demonstrated that ilomastat, a non-selective MMP inhibitor, reduced infarct size when administered either before the onset of ischemia or before the onset of reperfusion 


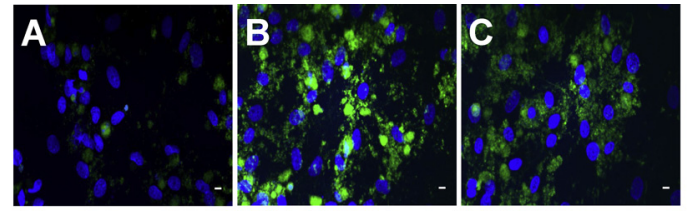

D

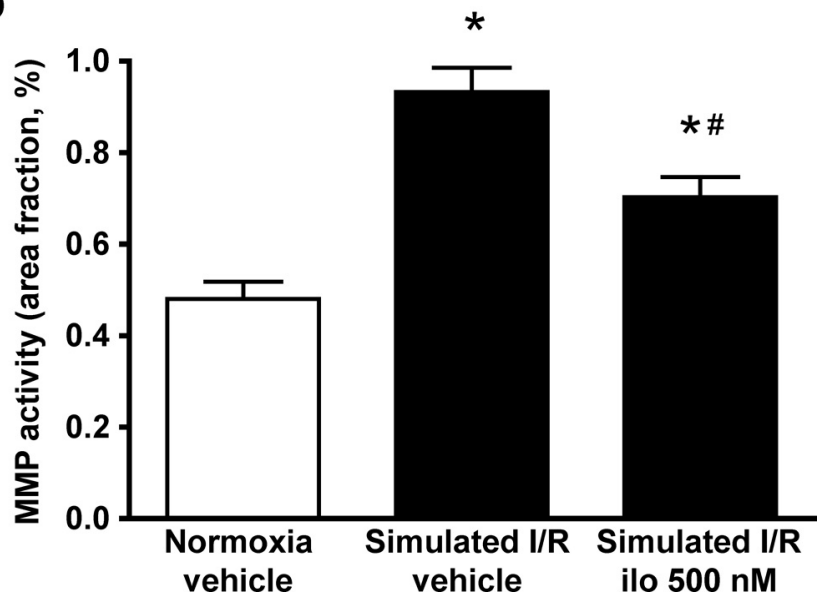

Fig. 5. Effect of the cardiocytoprotective concentration of ilomastat ( $500 \mathrm{nM})$ on in situ MMP-2 activity in neonatal rat cardiomyocytes subjected to simulated ischemia/reperfusion. Panel $A-C$ : Representative fluorescent confocal images from neonatal rat cardiomyocytes subjected to normoxia $(A)$, simulated ischemia/reperfusion (B), or simulated ischemia/reperfusion in the presence of $500 \mathrm{nM}$ ilomastat (C). Green color represents MMP-2 activity as measured by in situ zymography FITC signal; blue color represents the nuclei of the cells. Scale bars $=20 \mu \mathrm{m}$. Panel $D$ shows area fraction of fluorescent images. ${ }^{*} p<0.001$ compared to normoxic vehicle-treated group, ${ }^{\#} p<0.01$ compared to simulated ischemia/reperfusion, vehicle-treated group, $n=6$; data are shown as mean \pm S.E.M. (For interpretation of the references to color in this figure legend, the reader is referred to the web version of this article.)

in vivo and revealed its cardioprotective dose-response relationship. Moreover, we have shown that an approximately $25 \%$ inhibition of intracellular MMP-2 activity by ilomastat confers significant cardiocytoprotection. This is the first demonstration that
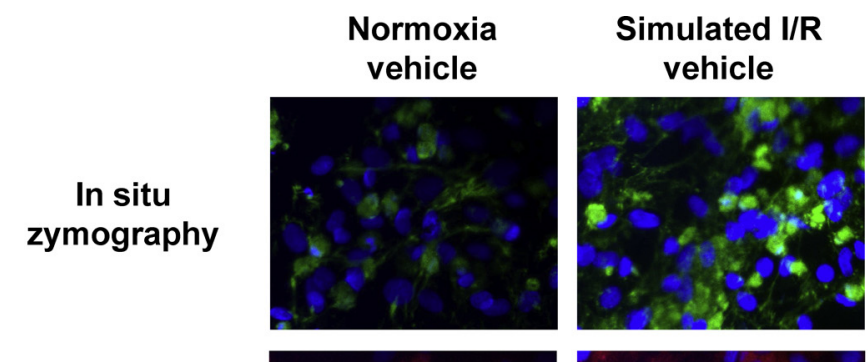

the cardioprotective effect of ilomastat may involve a cardiocytoprotective mechanism due to a moderate inhibition of MMP-2.

In our present study, ilomastat reduced infarct size dosedependently when administered either before ischemia or before reperfusion. We have found a slightly different dose range between the 2 administration patterns. When administered before the onset of ischemia, the effective doses of ilomastat were 0.75 and $1.5 \mu \mathrm{mol} / \mathrm{kg}$, however, higher doses of ilomastat were not significantly effective. Nevertheless, when ilomastat was administered before the onset of reperfusion, $6 \mu \mathrm{mol} / \mathrm{kg}$ ilomastat was found to decrease infarct size, and lower doses were ineffective. This is the first demonstration that the cardioprotective dose ranges of ilomastat, when administered before ischemia or before reperfusion, were not overlapping in vivo. Our present results are supported by previous studies describing that $\mathrm{Zn}^{2+}$-binding type MMP inhibitors, such as doxycycline and o-phenantroline, improved cardiac mechanical function after ischemia/reperfusion injury via the inhibition of MMP-2 in isolated rat hearts $[4,27,28]$. We have previously shown that iv. injection of $1.5 \mu \mathrm{mol} / \mathrm{kg}$ ilomastat before a $30-\mathrm{min}$ ischemia decreased infarct size comparable to ischemic late preconditioning in an in vivo rat model of coronary occlusion [3]. Recently, Bell and colleagues reported cardioprotection in a mouse model of ischemia/reperfusion when administered iv. $6 \mu \mathrm{mol} / \mathrm{kg}$ ilomastat at the release of coronary occlusion [15]. However, in the abovementioned studies the percentage of in situ MMP-2 inhibition was not determined and in the latter study, authors did not examine directly the MMP inhibitory effect of ilomastat.

Ilomastat is a non-selective MMP inhibitor, therefore, the question has arose, inhibition of which MMP isoenzyme was responsible for the cardioprotective effect of ilomastat. To answer this question, here we performed gelatin zymography from cardiac homogenates isolated from untreated rats and used purified MMP-2 enzyme to identify the MMP-2 specific activity in the zymogram. Gelatinolytic activities at 72 and $64 \mathrm{kDa}$ were detectable according to the molecular weights of the two active isoforms of MMP-2. Bands of other molecular weights were not present on the zymogram. Furthermore, here we proved that gelatinolytic activity was co-localized with MMP-2 protein in cardiomyocytes. These results show that gelatinolytic activity in the heart is derived solely from MMP-2

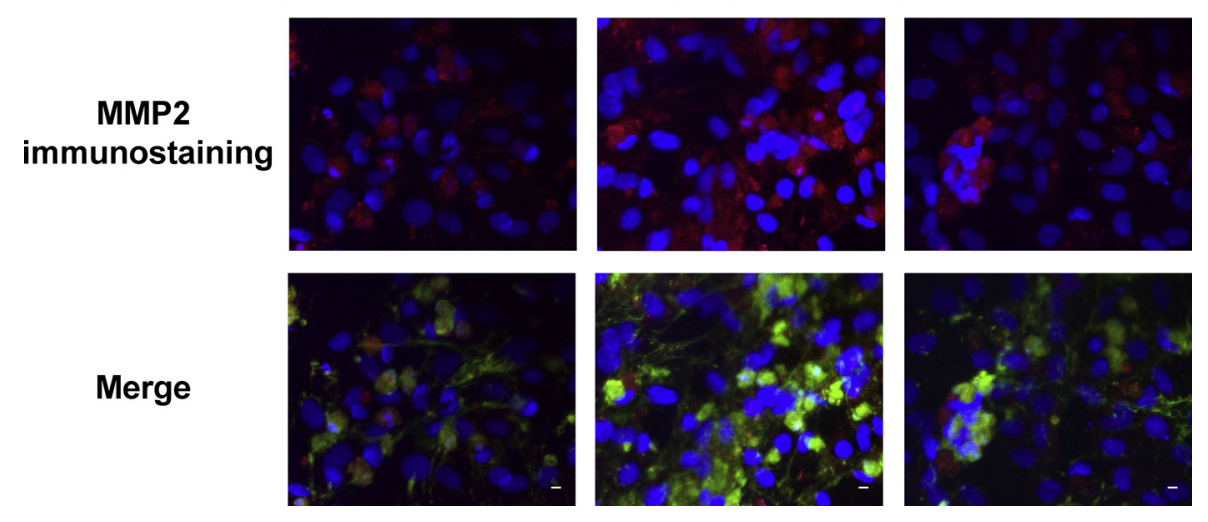

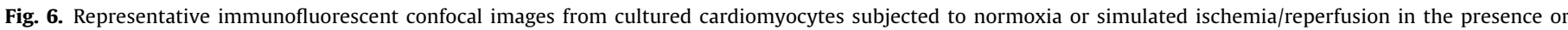

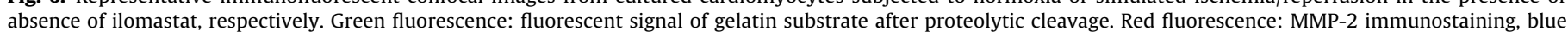
fluorescence: cell nuclei. Scale bars $=20 \mu \mathrm{m}$. (For interpretation of the references to color in this figure legend, the reader is referred to the web version of this article.) 
activity. Accordingly, we have previously shown that MMP-2 activity can be detected both in intact and in ischemia/reperfused rat ventricular samples [5], thus, MMP-2 is suspected to be the only MMP isoform with gelatinolytic activity in the rat myocardium. This is in accordance with previous findings by others, who have shown that MMP-2 possesses a predominant expression in both animal and human cardiomyocytes and cardiac tissue [29,30]. Nevertheless, it cannot be excluded that inhibition of other non-gelatinolytic proteases may be involved in the cardiocytoprotective effect of ilomastat.

Here we further tested the magnitude of MMP-2 inhibition necessary for cardioprotection and found that the cardiocytoprotective dose of ilomastat inhibited MMP-2 activity only by $25 \%$. Our previous findings showing that cardioprotection by late ischemic preconditioning reduced MMP-2 activity by approximately $20 \%$ strongly supports our present results [3]. Our present study suggests that a moderate MMP-2 inhibition is sufficient for cardioprotection. Due to the well-known side effects of MMP inhibitors including tendonitis-like fibromyalgia and musculoskeletal syndrome (for review see Ref. [14,31]), it is of great clinical importance that possibly there is no need for high efficacy MMP inhibitors to protect the heart against ischemia/reperfusion injury.

The cardioprotective cellular mechanism in which MMP-2 inhibition might be involved is not known and has not been investigated in the present study. Although endogenous cardioprotection by early and late ischemic preconditioning as well as postconditioning involve an MMP-2 inhibition-dependent mechanism $[3,5,6,32]$ the exact mechanism by which MMP inhibition results in cardioprotection is not known. Bell et al. reported that ilomastat protects the heart against reperfusion injury independently from the well-known cardioprotective Reperfusion Injury Salvage Kinase/mitochondrial permeability transition pore opening pathways [15]. Recently, a large number of studies focused on the intracellular actions of MMP-2, which can degrade several newly identified intracellular targets including troponin I, myosin light chain-1, $\alpha$-actinin (for review see Ref. [11]) and titin [12]. The degradation of myocardial contractile proteins may contribute to the induction of proapoptotic signals in cardiomyocytes and thus leads to cell death and contractile dysfunction (for review see Ref. [33]).

We conclude that ilomastat at doses with moderate MMP-2 inhibition protects cardiomyocytes thereby reducing infarct size when administered either before the onset of ischemia or before the onset of reperfusion in vivo. Our results show that a moderate MMP-2 inhibition is sufficient for cardioprotection.

\section{Acknowledgements}

This work was supported by the following grants of the Hungarian Ministry of Health and the European Union: (ETT 476/2009), the National Development Agency (NKFP_06_A1-MMP_2006), HURO/0901/137/2.2.2-HU-RO TRANS-MED, TÁMOP-4.2.1/B09/1/KONV-2010-0005, TÁMOP-4.2.2/B-10/1-2010-0012 and TÁMOP-4.2.2.A-11/1/KONV-2012-0035. T. Csont and A. Görbe hold a Bolyai János Fellowship of the Hungarian Academy of Sciences, and P. Ferdinandy holds a Szentágothai Fellowship, and J Pálóczi holds an Apáczai Fellowship (TÁMOP-4.2.4.A/ 2-11/1-2012-0001) of the National Excellence Program of Hungary.

\section{Appendix A. Supplementary data}

Supplementary data associated with this article can be found, in the online version, at http://dx.doi.org/10.1016/j.phrs.2013.12.007.

\section{References}

[1] Ferdinandy P, Schulz R, Baxter GF. Interaction of cardiovascular risk factors with myocardial ischemia/reperfusion injury, preconditioning, and postconditioning. Pharmacol Rev 2007;59:418-58.

[2] Ovize M, Baxter GF, Di Lisa F, Ferdinandy P, Garcia-Dorado D, Hausenloy DJ, et al. Postconditioning and protection from reperfusion injury: where do we stand? Position paper from the Working Group of Cellular Biology of the Heart of the European Society of Cardiology. Cardiovasc Res 2010;87:406-23.

[3] Bencsik P, Kupai K, Giricz Z, Gorbe A, Pipis J, Murlasits Z, et al. Role of iNOS and peroxynitrite-matrix metalloproteinase-2 signaling in myocardial late preconditioning in rats. Am J Physiol Heart Circ Physiol 2010;299:512-8.

[4] Cheung PY, Sawicki G, Wozniak M, Wang W, Radomski MW, Schulz R. Matrix metalloproteinase-2 contributes to ischemia-reperfusion injury in the heart. Circulation 2000;101:1833-9.

[5] Giricz Z, Lalu MM, Csonka C, Bencsik P, Schulz R, Ferdinandy P. Hyperlipidemia attenuates the infarct size-limiting effect of ischemic preconditioning: role of matrix metalloproteinase-2 inhibition. J Pharmacol Exp Ther 2006;316:154-61.

[6] Lalu MM, Csonka C, Giricz Z, Csont T, Schulz R, Ferdinandy P. Preconditioning decreases ischemia/reperfusion-induced release and activation of matrix metalloproteinase-2. Biochem Biophys Res Commun 2002;296: 937-41.

[7] Lalu MM, Pasini E, Schulze CJ, Ferrari-Vivaldi M, Ferrari-Vivaldi G, Bachetti T, et al. Ischaemia-reperfusion injury activates matrix metalloproteinases in the human heart. Eur Heart J 2005;26:27-35.

[8] Sariahmetoglu M, Skrzypiec-Spring M, Youssef N, Jacob-Ferreira AL, Sawicka J. Holmes C, et al. Phosphorylation status of matrix metalloproteinase 2 in myocardial ischaemia-reperfusion injury. Heart 2012;98:656-62.

[9] Schulze CJ, Wang W, Suarez-Pinzon WL, Sawicka J, Sawicki G, Schulz R. Imbalance between tissue inhibitor of metalloproteinase-4 and matrix metalloproteinases during acute myocardial ischemia-reperfusion injury. Circulation 2003; 107:2487-92.

[10] Chow AK, Cena J, Schulz R. Acute actions and novel targets of matrix metalloproteinases in the heart and vasculature. Br J Pharmacol 2007;152: 189-205.

[11] Schulz R. Intracellular targets of matrix metalloproteinase-2 in cardiac disease: rationale and therapeutic approaches. Annu Rev Pharmacol Toxicol 2007; 47:211-42.

[12] Ali MA, Cho WJ, Hudson B, Kassiri Z, Granzier H, Schulz R. Titin is a target of matrix metalloproteinase-2: implications in myocardial ischemia/reperfusion injury. Circulation 2010:122:2039-47.

[13] Dorman G, Kocsis-Szommer K, Spadoni C, Ferdinandy P. MMP inhibitors in cardiac diseases: an update. Recent Pat Cardiovasc Drug Discov 2007;2: 186-94.

[14] Dorman G, Cseh S, Hajdu I, Barna L, Konya D, Kupai K, et al. Matrix metalloproteinase inhibitors: a critical appraisal of design principles and proposed therapeutic utility. Drugs 2010;70:949-64.

[15] Bell RM, Kunuthur SP, Hendry C, Bruce-Hickman D, Davidson S, Yellon DM. Matrix metalloproteinase inhibition protects CyPD knockout mice independently of RISK/mPTP signalling: a parallel pathway to protection. Basic Res Cardiol 2013;108:0331.

[16] Bell RM, Yellon DM. Conditioning the whole heart - not just the cardiomyocyte. J Mol Cell Cardiol 2012;53:24-32

[17] Galardy RE, Cassabonne ME, Giese C, Gilbert JH, Lapierre F, Lopez H, et al. Low molecular weight inhibitors in corneal ulceration. Ann N Y Acad Sci $1994 ; 732: 315-23$

[18] Csonka C, Szilvassy Z, Fulop F, Pali T, Blasig IE, Tosaki A, et al. Classic preconditioning decreases the harmful accumulation of nitric oxide during ischemia and reperfusion in rat hearts. Circulation 1999;100:2260-6.

[19] Csonka C, Kupai K, Kocsis GF, Novak G, Fekete V, Bencsik P, et al. Measurement of myocardial infarct size in preclinical studies. J Pharmacol Toxicol Methods 2010;61:163-70

[20] Kupai K, Szucs G, Cseh S, Hajdu I, Csonka C, Csont T, et al. Matrix metalloproteinase activity assays: importance of zymography. J Pharmacol Toxicol Methods 2010;61:205-9.

[21] Bugaisky LB, Zak R. Differentiation of adult rat cardiac myocytes in cell culture. Circ Res 1989;64:493-500.

[22] Woodcock EA, Matkovich SJ. Cardiomyocytes structure, function and associated pathologies. Int J Biochem Cell Biol 2005;37:1746-51.

[23] Csont T, Gorbe A, Bereczki E, Szunyog A, Aypar E, Toth ME, et al. Biglycan protects cardiomyocytes against hypoxia/reoxygenation injury: role of nitric oxide. J Mol Cell Cardiol 2010;48:649-52.

[24] Gorbe A, Giricz Z, Szunyog A, Csont T, Burley DS, Baxter GF, et al. Role of cGMPPKG signaling in the protection of neonatal rat cardiac myocytes subjected to simulated ischemia/reoxygenation. Basic Res Cardiol 2010;105:643-50.

[25] Li X, Heinzel FR, Boengler K, Schulz R, Heusch G. Role of connexin 43 in ischemic preconditioning does not involve intercellular communication through gap junctions. J Mol Cell Cardiol 2004;36:161-3.

[26] Gorbe A, Varga ZV, Paloczi J, Rungarunlert S, Klincumhom N, Pirity MK, et al. Cytoprotection by the NO-donor SNAP against ischemia/reoxygenation injury in mouse embryonic stem cell-derived cardiomyocytes. Mol Biotechnol 2013 [Epub. ahead of print].

[27] Castro MM, Kandasamy AD, Youssef N, Schulz R. Matrix metalloproteinase inhibitor properties of tetracyclines: therapeutic potential in cardiovascular diseases. Pharmacol Res 2011;64:551-60 
[28] Fert-Bober J, Leon H, Sawicka J, Basran RS, Devon RM, Schulz R, et al. Inhibiting matrix metalloproteinase-2 reduces protein release into coronary effluent from isolated rat hearts during ischemia-reperfusion. Basic Res Cardiol 2008;103:431-43.

[29] Tyagi SC, Kumar SG, Banks J, Fortson W. Co-expression of tissue inhibitor and matrix metalloproteinase in myocardium. J Mol Cell Cardiol 1995;27: 2177-89.

[30] Wang W, Schulze CJ, Suarez-Pinzon WL, Dyck JR, Sawicki G, Schulz R. Intracellular action of matrix metalloproteinase-2 accounts for acute myocardial ischemia and reperfusion injury. Circulation 2002;106:1543-9.
[31] Sang QX, Jin Y, Newcomer RG, Monroe SC, Fang X, Hurst DR, et al. Matrix metalloproteinase inhibitors as prospective agents for the prevention and treatment of cardiovascular and neoplastic diseases. Curr Top Med Chem 2006;6:289-316.

[32] Wang ZF, Wang NP, Harmouche S, Philip T, Pang XF, Bai F, et al. Postconditioning promotes the cardiac repair through balancing collagen degradation and synthesis after myocardial infarction in rats. Basic Res Cardiol 2013;108:318.

[33] Kandasamy AD, Chow AK, Ali MA, Schulz R. Matrix metalloproteinase-2 and myocardial oxidative stress injury: beyond the matrix. Cardiovasc Res 2010;85:413-23. 


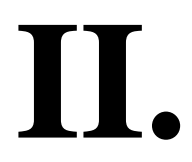




\title{
Cytoprotection by the NO-Donor SNAP Against Ischemia/ Reoxygenation Injury in Mouse Embryonic Stem Cell-Derived Cardiomyocytes
}

\author{
A. Görbe $\cdot$ Z. V. Varga $\cdot$ J. Pálóczi $\cdot$ S. Rungarunlert $\cdot$ N. Klincumhom $\cdot$ \\ M. K. Pirity $\cdot$ R. Madonna $\cdot$ T. Eschenhagen $\cdot$ A. Dinnyés $\cdot$ T. Csont • \\ P. Ferdinandy
}

Published online: 28 September 2013

(c) Springer Science+Business Media New York 2013

\begin{abstract}
Embryonic stem cell (ESC)-derived cardiomyocytes are a promising cell source for the screening for potential cytoprotective molecules against ischemia/reperfusion injury, however, little is known on their behavior in hypoxia/reoxygenation conditions. Here we tested the cytoprotective effect of the NO-donor SNAP and its downstream cellular pathway. Mouse ESC-derived cardiomyocytes were subjected to 150 -min simulated ischemia (SI) followed by 120-min reoxygenation or corresponding non-ischemic
\end{abstract}

A. Görbe and Z. V. Varga have contributed equally to this study.

A. Görbe $(\bowtie)$ · Z. V. Varga · J. Pálóczi · T. Csont

Cardiovascular Research Group, Department of Biochemistry,

University of Szeged, Dóm tér 9, 6720 Szeged, Hungary

e-mail: gorbe.aniko@med.u-szeged.hu;

aniko.gorbe@pharmahungary.com

URL: www.cardiovasc.com; www.pharmahungary.com

A. Görbe · T. Csont · P. Ferdinandy

Pharmahungary Group, Szeged, Hungary

Z. V. Varga $\cdot$ P. Ferdinandy

Department of Pharmacology and Pharmacotherapy,

Semmelweis University, Budapest, Hungary

S. Rungarunlert · N. Klincumhom

Department of Obstetrics, Gynaecology and Reproduction,

Faculty of Veterinary Science, Chulalongkorn University,

Bangkok, Thailand

S. Rungarunlert · A. Dinnyés

Molecular Animal Biotechnology Laboratory, Szent István

University, Gödöllő, Hungary

Present Address:

S. Rungarunlert

Department of Preclinic and Applied Animal Science, Faculty of Veterinary Science, Mahidol University, Nakhon Pathom 73710,

Thailand conditions. The following treatments were applied during SI or normoxia: the NO-donor $S$-Nitroso- $N$-acetyl-D,L-penicillamine (SNAP), the protein kinase $\mathrm{G}$ (PKG) inhibitor, the $\mathrm{K}_{\mathrm{ATP}}$ channel blocker glibenclamide, the particulate guanylate cyclase activator brain type natriuretic peptide (BNP), and a non-specific NO synthase inhibitor ( $N$-Nitro-L-arginine, L-NNA) alone or in different combinations. Viability of cells was assayed by propidium iodide staining. SNAP attenuated SI-induced cell death in a concentration-dependent manner, and this protection was attenuated by inhibition of either PKG or $\mathrm{K}_{\mathrm{ATP}}$ channels. However, SI-induced cell death was not

N. Klincumhom · M. K. Pirity · A. Dinnyés

Biotalentum Ltd., Gödöllö, Hungary

Present Address:

N. Klincumhom

Siriraj Center of Excellence for Stem Cell Research, Faculty of Medicine Siriraj Hospital, Mahidol University, Bangkok 10700, Thailand

Present Address:

M. K. Pirity

Institute of Genetics, Biological Research Centre, Hungarian Academy of Sciences, Szeged, Hungary

R. Madonna

Texas Heart Institute, Houston, TX, USA

R. Madonna

University of Chieti, Chieti, Italy

T. Eschenhagen

Department of Experimental Pharmacology and Toxicology, Cardiovascular Research Center Hamburg, University Medical Center Hamburg Eppendorf, Hamburg, Germany 
affected by BNP or by L-NNA. We conclude that SNAP protects $\mathrm{mESC}$-derived cardiomyocytes against SI/R injury and that soluble guanylate-cyclase, $\mathrm{PKG}$, and $\mathrm{K}_{\mathrm{ATP}}$ channels play a role in the downstream pathway of SNAP-induced cytoprotection. The present mESC-derived cardiomyocytebased screening platform is a useful tool for discovery of cytoprotective molecules.

Keywords Stem cell · Nitric oxide - Ischemia/ reoxygenation - Signal-transduction ·

Cardioprotection

\section{Introduction}

Ischemic heart disease is the leading cause of death in the industrialized world, therefore, development of cardioprotective therapies are of great importance.

In vitro cardiac myocyte-based drug screening platforms at the early stage of the development of cardioprotective agents are widely used. However, currently used assays based on cardiomyoblast cell lines (H9c2) as well as primary neonatal and adult cardiac myocytes [1] have limitations including limited proliferation capacity, uncontrolled stress during cell isolation and dissociation of cultured cells, low-throughput nature, and poor predictability of the assays toward in vivo efficacy [2]. Embryonic stem cells (ESC) are capable of unlimited proliferation in vitro and differentiation into cardiac myocytes [3], therefore, ESCs provide a promising source of cardiac myocytes for in vitro drug screening $[4,5]$. ESCs may also become tools for regeneration therapy [6], however, several limitations were reported including ethical, immunological, and tumorigenicity problems, which restrict their clinical application [7]. Moreover, transplanted cells undergo a significant rate of cell death shortly after transplantation, approaching $90 \%$ within the first 24-h after transplantation [8]. One reason is may be the unfavorable microenvironment grafted cells face when injected into host cardiac muscle. In most studies, wellnourished and oxygenated stem cells are transplanted into poorly perfused tissue, where they are exposed to increased oxidative stress and local inflammation [9]. Characterization of these cells in a high throughput ischemia/reoxygenation test system would be important, since little is known about the ischemic tolerance and signal transduction pathways involved in protection of ESC-derived cardiomyocytes.

It has been previously shown that nitric oxide (NO) has a direct cytoprotective effect in case of simulated ischemia (SI) in cardiomyocytes [10]. Furthermore, administration of the NOdonor $S$-Nitroso- $N$-acetyl-D,L-penicillamine (SNAP, $2 \mathrm{mM}$ ) has been shown to mimic preconditioning protection in mouse hearts [11]. NO-mediated cytoprotection may act via different signaling pathways. Intracellular elevation of cyclic guanosine monophosphate (cGMP) by NO or natriuretic peptides has been proposed to influence cellular responses to ischemia and to contribute to cardioprotection. However, the contribution of $\mathrm{NO}$ and its downstream signaling pathway in the protection of ESC-derived cardiomyocytes has not been studied yet. Opening of sarcolemmal and mitochondrial ATP-sensitive potassium $\left(\mathrm{K}_{\mathrm{ATP}}\right)$ channels can be activated by exogenous $\mathrm{NO}$ and these channels have been demonstrated to mediate cardioprotection [12]. However, the importance of this pathway in mouse ESC (mESC)-derived cardiomyocytes is not known.

The aim of the present study was to test an mESC-derived cardiomyocyte-based drug screening platform by investigating whether the cytoprotective NO-donor SNAP is able to protect these cells against SI/reoxygenation injury. We also investigated the downstream pathways of the protection in this platform.

\section{Methods}

\section{Mouse ESC Culture}

Undifferentiated mESCs (Nkx2.5/EGFP transgenic C57BL/6 mouse ES cell line; $\mathrm{Tg}^{\mathrm{Nkx2.5/EGFP}} \mathrm{C} 57 \mathrm{BL} / 6$; passages $10-12$ ) were cultured on feeder layers of mitomycin $\mathrm{C}$-inactivated mouse embryonic fibroblasts (MEFs) which were obtained from 13.5 days postcoitus mouse embryos, as described earlier by Belteki [13]. mESCs were maintained in ES medium consisting of Dulbecco's Modified Eagle's Medium (DMEM), $15 \%$ (v/v) fetal bovine serum (FBS, Sera Laboratories International, West Sussex, RH17 5PB, UK) supplemented with 1,000 U/mL mouse leukemia inhibitory factor (LIF, ESGRO, Chemicon International, Budapest, Hungary), $0.1 \mathrm{mM}$ nonessential amino acids (NEAA), $0.1 \mathrm{mM} \beta$-mercaptoethanol ( $\beta$-ME), and $50 \mathrm{U} / \mathrm{mL}$ penicillin $/ 50 \mu \mathrm{g} / \mathrm{mL}$ streptomycin. mESCs were cultured on feeder layers for at least two passages after thawing and subsequently were cultured without feeder cells on $0.1 \%$ gelatin-coated tissue culture plates in the presence of LIF (2,000 U/mL). Medium was changed daily for standards maintenance. mESCs were usually passaged every 1-2 days prior reaching $70 \%$ confluences.

\section{Embryoid Body (EB) Formation and Cardiomyocyte Differentiation}

mESCs were dissociated from monolayer culture with $0.05 \%$ trypsin-EDTA into a single cell suspension. EBs were produced by the hanging drop (HD) method [14]; in brief, mESCs were seeded as $4 \times 10^{4}$ cells $/ \mathrm{mL}$ (resulting in 800 cells/drop) suspension in differentiation medium (regular DMEM without LIF). 2 days later, the EBs were transferred and plated into 24-well plates on gelatin-coated coverslips. $0.1 \mathrm{mg} / \mathrm{mL}$ ascorbic acid was supplemented to induce cardiac differentiation. mESC-derived cardiomyocytes were used at 6-8-day-old stage for SI/reoxygenation 
experiments. At this stage, the ratio of Nkx2.5-eGFP positive cells, an early marker for cardiac differentiation, exhibited $52.5 \pm 10 \%$ EGFP positivity $(n=30)$. The cells were fluorescently imaged and analyzed by using Digital Image Processing Software (AxioVision 4.8.1, Carl Zeiss MicroImaging GmbH, Germany).

\section{Experimental Groups}

For cell viability experiments, mESC-derived cardiomyocytes were tested under normoxic condition or were subjected to SI (Fig. 1). The normoxic mESC-derived cardiomyocytes were kept under normoxic conditions, i.e., the growth medium was changed to a normoxic solution (in $\mathrm{mM}$ : $\mathrm{NaCl} 125, \mathrm{KCl}$ 5.4, $\mathrm{NaH}_{2} \mathrm{PO}_{4} 1.2, \mathrm{MgCl}_{2}$ 0.5, HEPES 20, glucose 15, taurine 5, $\mathrm{CaCl}_{2} 1$, creatine 2.5, BSA 0.1\%, pH 7.4, $310 \mathrm{mOsm} / \mathrm{l}$ ) [15] and the cells were incubated under $95 \%$ air and $5 \% \mathrm{CO}_{2}$ at $37{ }^{\circ} \mathrm{C}$ for $2.5 \mathrm{~h}$. In the second series of experiments, mESCderived cardiomyocytes were subjected to SI by incubating the cells in hypoxic solution (in $\mathrm{mM}: \mathrm{NaCl} 119, \mathrm{KCl} 5.4$, $\mathrm{MgSO}_{4}$ 1.3, $\mathrm{NaH}_{2} \mathrm{PO}_{4}$ 1.2, HEPES 5, $\mathrm{MgCl}_{2}$ 0.5, $\mathrm{CaCl}_{2}$ 0.9, Na-lactate 20, BSA $0.1 \%, 310 \mathrm{mOsm} / \mathrm{l}, \mathrm{pH}=6.4$ ) [15] and placing the plates in a humidified $37^{\circ} \mathrm{C}$ hypoxic chamber exposed to a constant flow of a mixture of $95 \% \mathrm{~N}_{2}$ and $5 \%$ $\mathrm{CO}_{2}$ for $2.5 \mathrm{~h}$. The cells were then subjected to the following treatments during SI or normoxic protocol: (1) untreated control; (2) SNAP $\left(10^{-7}, 10^{-6}, 10^{-5} \mathrm{M}\right)$ (10) (Sigma, St. Louis, MO, USA); (3) selective protein kinase G (PKG) inhibitor KT-5823 $\left(6 \times 10^{-8} \mathrm{M}\right)$, an effective concentration that does not affect cell viability alone (10) (Sigma, St. Louis, MO, USA); (4) SNAP $\left(10^{-6} \mathrm{M}\right.$, a concentration found here protective) in combination with KT-5823 $\left(6 \times 10^{-8} \mathrm{M}\right)$; (5) brain type natriuretic peptide-32 (BNP, $\left.10^{-9}, 10^{-8}, 10^{-7} \mathrm{M}\right)$ [16] (American Peptides, Sunnyvale, CA, USA); (6) nitric oxide synthase (NOS) inhibitor $N$-Nitro-L-arginine (L-NNA, $10^{-4}, 10^{-5}$ M) [17] (Sigma, St. Louis, MO, USA); (7) non- selective $\mathrm{K}_{\mathrm{ATP}}$ channel inhibitor glibenclamide $\left(10^{-6} \mathrm{M}\right.$, an effective $\mathrm{K}_{\mathrm{ATP}}$ blocking concentration that does not affect ischemia/reperfusion injury alone) [18] (Sigma, St. Louis, MO, USA); (8) SNAP $\left(10^{-6} \mathrm{M}\right)$ and glibenclamide $\left(10^{-6} \mathrm{M}\right)$; and dimethyl-sulfoxide (DMSO) (Sigma, St. Louis, MO, USA) control groups.

Either normoxic or SI treatments were followed by $2 \mathrm{~h}$ reoxygenation with growth medium without ascorbic acid and superfusion with $95 \%$ air and $5 \% \mathrm{CO}_{2}$ at $37{ }^{\circ} \mathrm{C}$.

\section{Cell Viability Assay}

Cell viability was assessed by a propidium iodide (PI) assay performed in each group after $2 \mathrm{~h}$ reoxygenation. PI (Sigma, St. Louis, MO, USA) was chosen, as it stains cells with severely impaired membrane integrity and it does not necessitate dissociation of the cells. Briefly, the growth medium was removed, cells were washed with PBS twice and incubated with PI $(50 \mu \mathrm{M})$ for $7 \mathrm{~min}$. Each experiment included a digitonin $\left(10^{-4} \mathrm{M}\right)$ (Sigma, St. Louis, MO, USA) treated positive control well and PI control (mESC-derived cardiomyocytes without treatment and stained for PI for $7 \mathrm{~min}$ ) (Fig. 2). Then PI solution was replaced with fresh PBS and fluorescence intensity of each EB was detected by fluorescent plate reader (FluoStar Optima, BMG Labtech). Fluorescence intensity was measured in well scanning mode (scan matrix: $10 \times 10$; scan diameter: $10 \mathrm{~mm}$; bottom optic; no of flashes/scan point: 3 ; temp. $37^{\circ} \mathrm{C}$; excitation wavelength: $544 \mathrm{~nm}$; emission wavelength: $610 \mathrm{~nm}$ ). PI intensity reflecting the cell death was evaluated on a standard area (21 scan box) in each well placed to the center of EB. The cardiac myocyte-rich region can be found predominantly near the edge of the embryonic body. Therefore, the evaluation of cardiac myocyte rich regions was performed manually on several plates by detecting GFP expression driven by the promoter of the early cardiac myocyte marker Nkx2.5. The ratio of cardiac myocyte death was
Fig. 1 Experimental protocol of SI and reoxygenation in mESC-derived cardiomyocytes

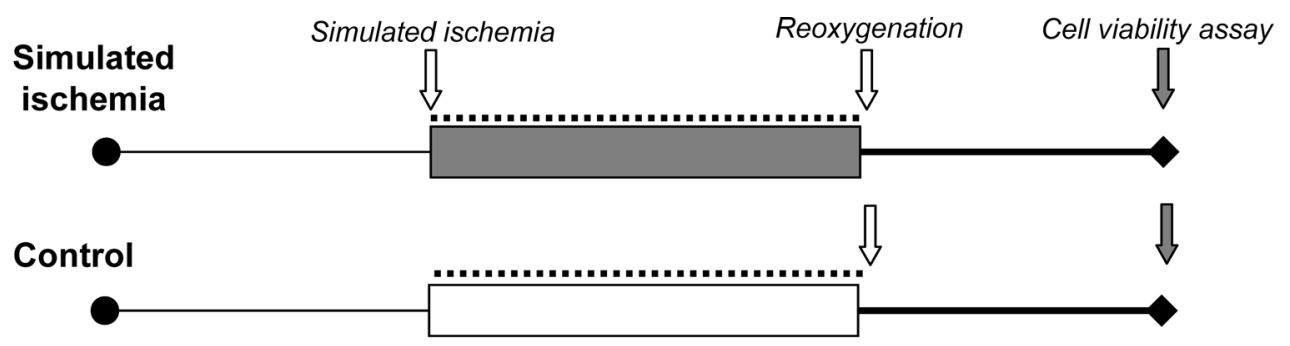

EBs maintained in growth medium

EBs kept in growth medium without ascorbic acid for 2 hours

EBs under normoxic condition for 2.5 hours (normoxia+normoxic solution)

EBs under simulated ischemic condition for 2.5 hours (hypoxia+hypoxic solution)
Drug

administration 


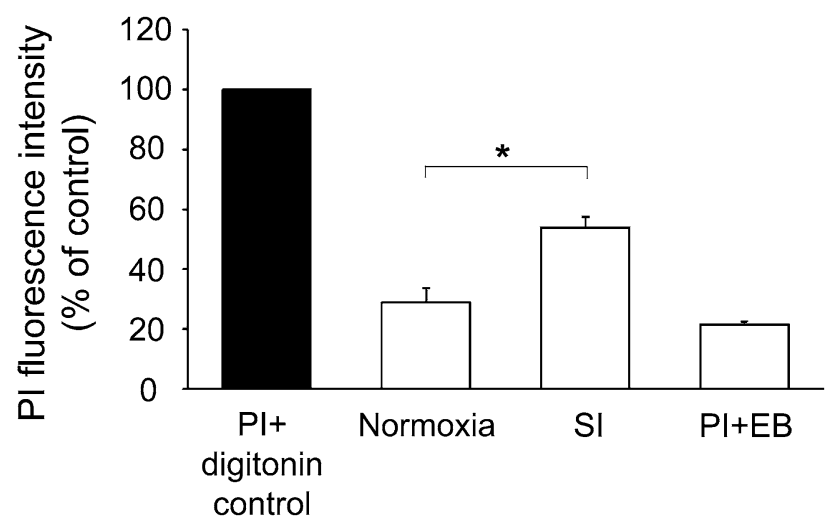

Fig. 2 Cell viability of mESC-derived cardiomyocytes subjected to normoxia or SI: representative results obtained from one plate. Background fluorescence intensity is represented by using non-treated $\mathrm{EB}+\mathrm{PI}$ in three wells. $\mathrm{Pi}+$ digitonin control alone was applied in one well. Data are mean \pm SEM. ${ }^{*} p<0.05$ normoxia versus SI; $t$ test, $n=5-6$ in both groups

the same as the ratio of cell death of all cells found in the embryonic body. Background fluorescence intensity (dye control) was subtracted from the fluorescence intensity of each well after PI staining, and the average intensity of each group was plotted. The cytoprotective effect of different compounds was compared to simulated ischemic control groups.

\section{Statistical Analysis}

Results are expressed as mean \pm SEM. One way analysis of variance (ANOVA) followed by Fisher's least significant difference (LSD) post-hoc tests was used to determine differences in mean values between groups. In case comparison of two groups, unpaired $t$ test was used. Differences were considered significant at $p<0.05$.

\section{Results}

\section{Cell Viability After SI/Reoxygenation}

We applied SI/reoxygenation to mimic ischemia/reperfusion injury in mESC-derived cardiomyocytes. Two and half hours of SI followed by reoxygenation caused significantly higher cell death in mESC-derived cardiomyocytes than time-matched controls kept under normoxic conditions (Fig. 2). SI killed roughly $20-40 \%$ of cells in embryonic body.

The cytoprotective action of the NO donor SNAP that activates soluble guanylate cyclase was tested in this model of SI and reoxygenation-induced cell death in mESCderived cardiomyocytes. Cell death was significantly decreased by SNAP in a concentration-dependent manner $\left(10^{-6}\right.$ and $\left.10^{-5} \mathrm{M}, p<0.05\right)$ when applied during SI period (Figs. 3, 4). The contribution of endogenous NO production of mESC-derived cardiomyocytes to cell death during SI was tested by administration of the non-selective NOS inhibitor L-NNA at $10^{-5}$ and $10^{-4} \mathrm{M}$ concentration. The presence of L-NNA did not influence cell death after SI (Fig. 5).

$\mathrm{BNP}$, an activator of particulate GC, was also tested under SI condition at $10^{-9}, 10^{-8}$, and $10^{-7} \mathrm{M}$ concentrations. However, BNP did not influence cell death significantly (Fig. 6).

In separate experiments, the downstream pathways of SNAP-induced protection of mESC-derived cardiomyocytes were studied. The cytoprotective effect of SNAP (at $10^{-6} \mathrm{M}$ )

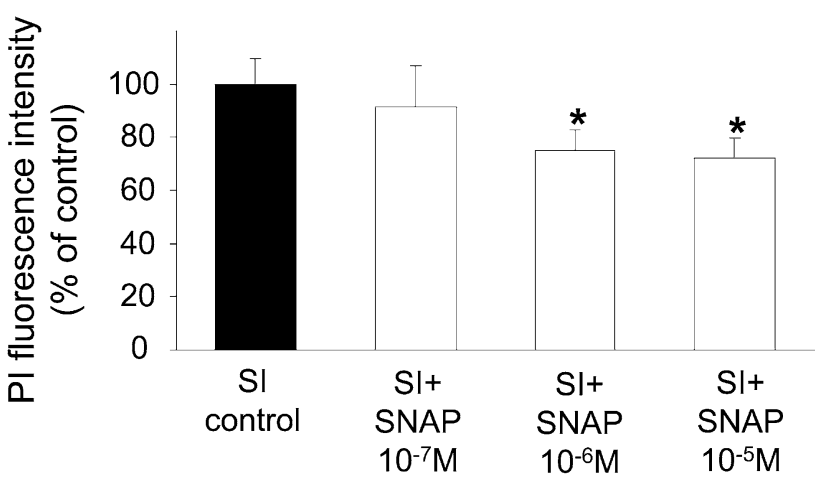

Fig. 4 Effect of SNAP on cell viability of mESC-derived cardiomyocytes. Cell viability of mESC-derived cardiomyocytes subjected to SI. SNAP administration was applied during SI. Data are mean \pm SEM. $*^{*} p<0.05$ versus SI control; one-way ANOVA followed by Fischer LSD post-hoc test, $n=10-12$ in each group
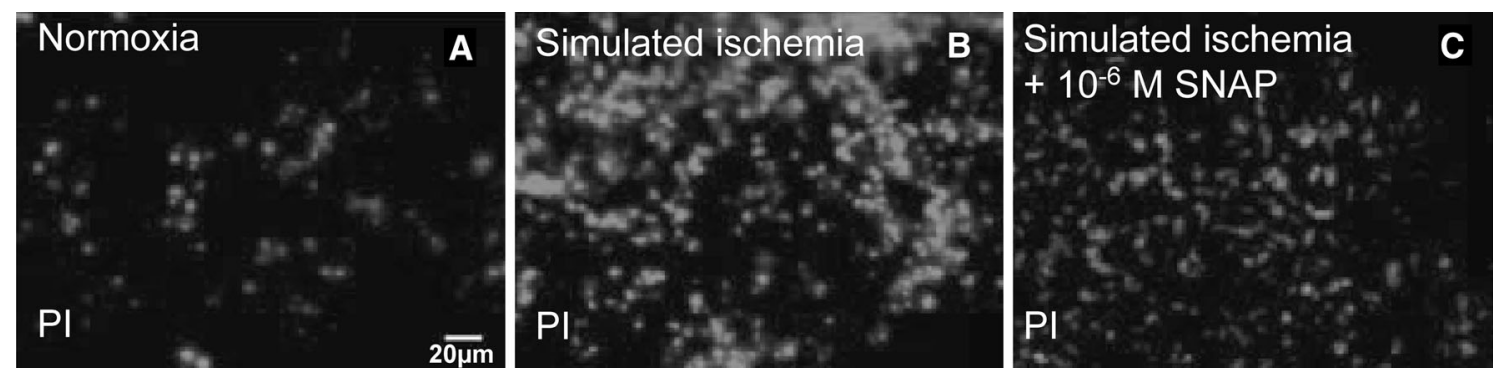

Fig. 3 Cell viability indicated by PI staining on mESC-derived cardiomyocytes. Representative fluorescent images of normoxic (a), SI (b), and SI+SNAP $\left(10^{-6} \mathrm{M}\right)(\mathbf{c})$ treated groups showing the amount of dead cells (increased nuclear fluorescence) in mESC-derived cardiomyocytes 


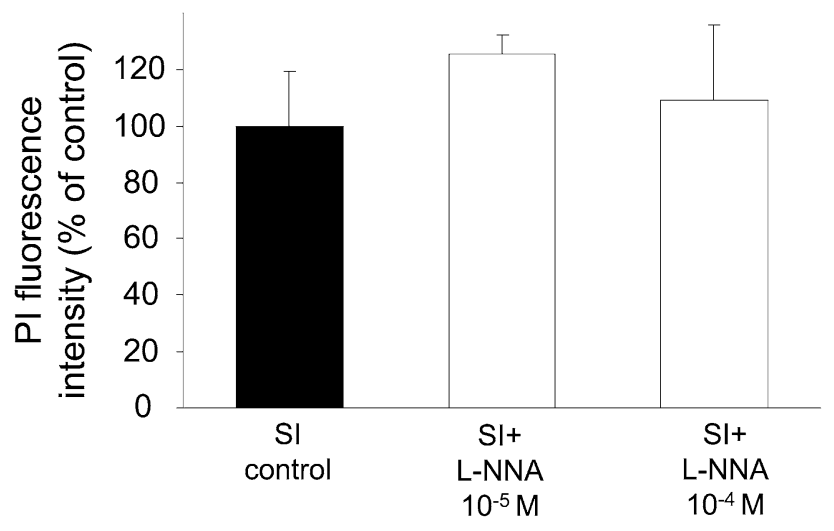

Fig. 5 Effect of L-NNA on cell viability of mESC-derived cardiomyocytes. Cell viability of mESC-derived cardiomyocytes subjected to SI. L-NNA was applied during SI. Data are mean \pm SEM; $n=10-12$ in each groups

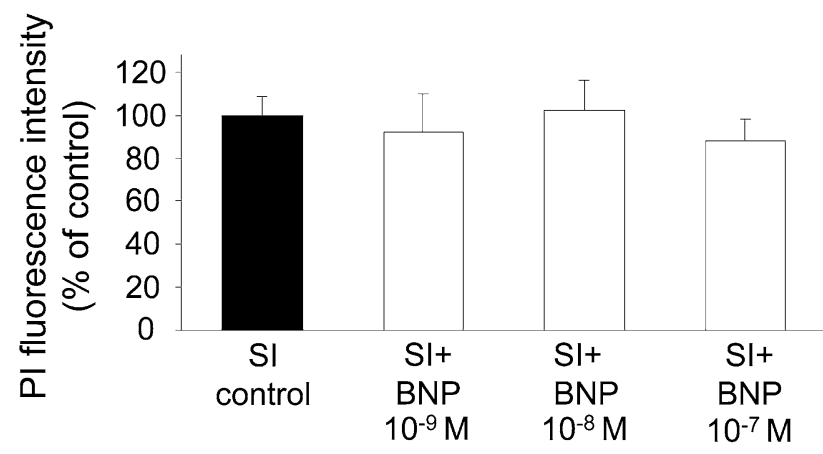

Fig. 6 Effect of BNP on cell viability of mESC-derived cardiomyocytes. Cell viability of mESC-derived cardiomyocytes subjected to SI. BNP was applied during SI. Data are mean \pm SEM, $n=10-12$ in each groups

was attenuated either by simultaneous administration of the selective PKG inhibitor KT-5823 $\left(6 \times 10^{-8} \mathrm{M}\right)$ or by simultaneous administration of $\mathrm{K}_{\mathrm{ATP}}$ channel inhibitor glibenclamide $\left(10^{-6} \mathrm{M}\right)$. Inhibitors administered alone, or their vehicle DMSO did not influence cell viability (Fig. 7).

In time-matched normoxic control groups, none of the above treatment influenced cell viability significantly (data not shown).

\section{Discussion}

In the present study we established an ESC-derived cardiac myocyte-based in vitro drug screening system and showed that the NO-donor SNAP was protective against SI/ reoxygenation-induced cell death. Either a selective inhibitor of PKG or a non-selective inhibitor of $\mathrm{K}_{\mathrm{ATP}}$ channels interfered with this protection. In contrast to

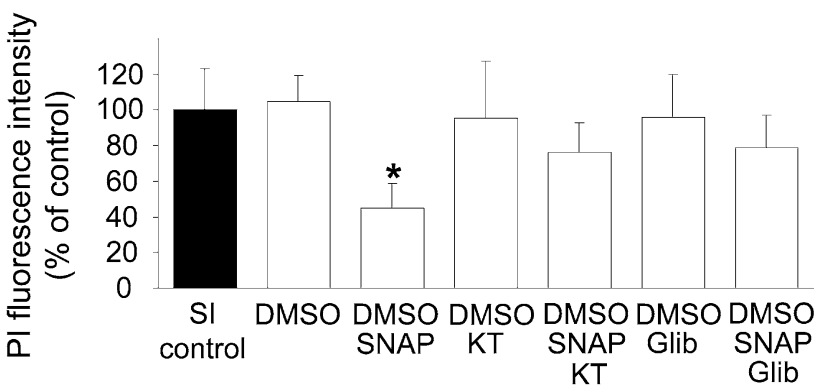

Fig. 7 Effect of PKG (KT) and $\mathrm{K}_{\mathrm{ATP}}$ (Glib) inhibitor on cell viability of mESC-derived cardiomyocytes. Cell viability of mESC-derived cardiomyocytes subjected to SI. Drugs were applied during SI. Data are mean $\pm \mathrm{SEM} ; * p<0.05$ versus SI control; one-way ANOVA followed by Fischer LSD post-hoc test, $n=10-12$ in each groups

SNAP, the particulate guanylyl cyclase stimulator BNP had no effect on cell viability during SI. This is the first demonstration that mESC-derived cardiomyocytes are a useful tool for screening cytoprotective agents and their cytoprotective signaling pathways against ischemia/reperfusion injury.

Currently used cell-based assays based on primary neonatal cells have limitations for screening cardioprotective agents, including variability introduced by the isolation procedure and limited proliferation [19]. Adult cardiomyocytes are suitable to study individual cells, especially their electrophysiological properties. In addition, extracellular matrix proteins are required for their maintenance which may influence viability during SI [2]. The cardiomyoblast cell line (H9c2) is widely used for in vitro drug screening. However, H9c2 cells differ from primary cardiomyocytes, e.g., they are lacking spontaneous electric activity and clearly developed sarcomeric structures [20]. Therefore, advantages of ESC-based assays are the well reproducible production of contracting myocardial cells and that they do not require sacrificing a number of animals.

Therefore, here we validated a mESC-derived cardiomyocyte-based drug-screening platform using the NO donor SNAP. SNAP is a well-known cardioprotective compound. It exerts both early and late preconditioning-like cardioprotective effect in various models [21, 22] and attenuates apoptosis in neonatal cardiomyocytes [23]. Accordingly, in the present study, SNAP showed a concentration-dependent increase in viability of mESC-derived cardiomyocytes after SI/reoxygenation. This finding indicates that mESC-derived cardiac myocytes are useful tools for testing cardioprotective agents and suggests that $\mathrm{NO}$ donors may also be cytoprotective for stem cells implanted into ischemic areas of the myocardium. It is of interest that NO has been also shown to promote ESC differentiation and cardiomyogenesis in mESCs [24]. 
It has been well established that NO donors including SNAP exert protective effect against myocardial ischemiareperfusion injury via activation of soluble guanylate cyclase and increased cGMP signaling (see for a review [25]). We have recently shown that SNAP induces cytoprotection via the activation of soluble guanylate cyclase in neonatal cardiomyocytes [10]. However, in our previous studies the efficacy of SNAP-induced cytoprotection was more pronounced in neonatal cardiomyocytes than shown here in mESC-derived cardiomyocytes. This difference is probably due to the low expression level of soluble guanylyl cyclase and NOS at 6-8-days-old stage of mESCderived cardiomyocytes [26]. The latter is in line with our present results that the NOS inhibitor L-NNA did not affect cell viability after SI/reoxygenation injury of mESCderived cardiomyocytes, showing that endogenous $\mathrm{NO}$ is not involved in cardiocytoprotection.

To test if activation of particulate guanylate cyclase can increase cell viability similar to SNAP, the effect of BNP was tested. BNP is a potent cardioprotective peptide, as it is able to reduce infarct size in rat hearts [16] and to protect neonatal rat cardiomyocytes against SI/reoxygenation injury [10]. Interestingly, in our present study, cell viability was not influenced by either concentration of BNP in mESC-derived cardiomyocytes. This finding may be due to a low expression of the BNP specific NPR-A receptor during mouse ESC differentiation [27].

We further identified cardioprotective signaling pathways downstream of cGMP in mESC-derived cardiomyocytes. In the cardiovascular system, at least three classes of protein targets are activated by cGMP, i.e., cGMP-dependent PKG, cGMP-regulated phosphodiesterases, and cyclic nucleotide-gated ion channel. In the present study, the involvement of PKG in SNAP-induced protection was tested by the PKG inhibitor KT-5823 during SI, which interferes with PKG at the level of the ATP binding site of its catalytic domain. KT-5823 alone did not affect the mESC-derived cardiomyocyte viability, but interfered with the cytoprotective effect of SNAP, which suggests that the mechanism of SNAP-induced protection involves PKG. Our present findings in mESC-derived cardiomyocytes are consistent with our previous results obtained in neonatal rat cardiomyocytes, in which the PKG inhibitor abolished the protective effect of SNAP [10]. However, it is of interest that Mobley et al. [28] showed that PKG was down-regulated during cardiomyocyte differentiation and inhibition of PKG produced significantly more differentiated mESCderived cardiomyocytes.

$\mathrm{Xu}$ et al. [29] demonstrated that exogenous NO mediates the production of reactive oxygen species and may act via activation cGMP/PKG signaling, triggering cardiocytoprotection by mitochondrial $\mathrm{K}_{\mathrm{ATP}}$ channel opening or by opening mitochondrial permeability transition pores in adult rat cardiomyocytes $\mathrm{K}_{\mathrm{ATP}}$ channels have a prominent role in the electrical excitability of early stage of mESCderived cardiomyocytes. Therefore, in the present study, we investigated the involvement of $\mathrm{K}_{\mathrm{ATP}}$ channels in SNAPinduced cytoprotection of mESC-derived cardiomyocytes. The nonselective $\mathrm{K}_{\mathrm{ATP}}$ channel inhibitor glibenclamide alone did not affect mESC-derived cardiomyocyte viability, but abolished the cytoprotective effect of SNAP. This is in line with several earlier reports in other systems [30, 31].

\section{Conclusions}

Although the genotypic and phenotypic features of primary and ESC-derived cardiac myocytes are very similar [31], here we have shown that these cell types show differences under different test conditions, such as, e.g., hypoxia and reoxygenation. These findings emphasize the necessity for detailed analyses of signal transduction pathways in ESCderived cells both in physiological and pathological conditions to establish well-reproducible ESC-derived drug screening platforms and to predict the viability of these cells after implantation into an ischemic region of an organ.

Our present study is the first demonstration that mESCderived cardiomyocytes subjected to SI/reoxygenation injury are a useful alternative tool for in vitro screening for potential cardioprotective agents and to study their downstream cellular signaling pathways. The major advantages of ESC-based screening platforms over other cellular assays are the well reproducible production of beating myocardial cells and that it does not require sacrificing a number of animals.

Acknowledgments This work was supported primarily by a Grant from NKFP 07 1-ES2HEART-HU (OM-00202/2007) and some other Grants: National Development Agency-New Hungary Development Plan (TÁMOP-4.2.2-08/1/2008-0013, TÁMOP-4.2.1/B-09/1/KONV2010-0005, TÁMOP-4.2.2/B-10/1-2010-0012); NKTH-OTKA FP7 "Mobility" HUMAN-MB08C-80205 (for M. K. Pirity); the EU FP7 (InduHeart, PEOPLE-IRG-2008-234390; PartnErS, PIAP-GA-2008218205; InduStem PIAP-GA-2008-230675), COST BM1005, OTKAPD106001, 17586-4/2013/TUDPOL. S. Rungarunlert and N. Klincumhom were supported by the Office of the Higher Education Commission, Thailand (CHE-PhD-SW-2005-100 and CHE-PhD-SWRG-2007, respectively). Z. V. Varga was supported by the National Program of Excellence (TÁMOP 4.2.4.A/1-11-1-2012-0001). A. Görbe and T. Csont holds a "János Bolyai Fellowship" from the Hungarian Academy of Sciences.

Conflict of interest None.

\section{References}

1. Hansen, A., Eder, A., Bonstrup, M., Flato, M., Mewe, M., Schaaf, S., et al. (2010). Development of a drug screening platform based on engineered heart tissue. Circulation Research, 107(1), 35-44. 
2. Woodcock, E. A., \& Matkovich, S. J. (2005). Cardiomyocytes structure, function and associated pathologies. International Journal of Biochemistry \& Cell Biology, 37(9), 1746-1751.

3. Xu, C., Police, S., Rao, N., \& Carpenter, M. K. (2002). Characterization and enrichment of cardiomyocytes derived from human embryonic stem cells. Circulation Research, 91(6), 501-508.

4. Harding, S. E., Ali, N. N., Brito-Martins, M., \& Gorelik, J. (2007). The human embryonic stem cell-derived cardiomyocyte as a pharmacological model. Pharmacology \& Therapeutics, 113(2), 341-353.

5. Liang, H., Matzkies, M., Schunkert, H., Tang, M., Bonnemeier, H., Hescheler, J., et al. (2010). Human and murine embryonic stem cell-derived cardiomyocytes serve together as a valuable model for drug safety screening. Cellular Physiology and Biochemistry, 25(4-5), 459-466.

6. Zimmermann, W. H., \& Eschenhagen, T. (2007). Embryonic stem cells for cardiac muscle engineering. Trends in Cardiovascular Medicine, 17(4), 134-140.

7. Wollert, K. C. (2005). Clinical applications of stem cells for the heart. Circulation Research, 96(2), 151-163.

8. Qiao, H., Zhang, H., Zheng, Y., Ponde, D. E., Shen, D., Gao, F., et al. (2009). Embryonic stem cell grafting in normal and infarcted myocardium: Serial assessment with MR imaging and PET dual detection. Radiology, 250(3), 821-829.

9. Suzuki, K. (2004). Dynamics and mediators of acute graft attrition after myoblast transplantation to the heart. FASEB Journal, 18(10), 1153-1155.

10. Gorbe, A. (2010). Role of cGMP-PKG signaling in the protection of neonatal rat cardiac myocytes subjected to simulated ischemia/ reoxygenation. Basic Research in Cardiology, 105(5), 643-650.

11. Bell, R. M. (2001). The contribution of endothelial nitric oxide synthase to early ischaemic preconditioning: The lowering of the preconditioning threshold. An investigation in eNOS knockout mice. Cardiovascular Research, 52(2), 274-280.

12. Csont, T. (1999). Direct myocardial anti-ischaemic effect of GTN in both nitrate-tolerant and nontolerant rats: A cyclic GMPindependent activation of KATP. British Journal of Pharmacology, 128(7), 1427-1434.

13. Belteki, G. (2003). Site-specific cassette exchange and germline transmission with mouse ES cells expressing phiC31 integrase. Nature Biotechnology, 21(3), 321-324.

14. Mummery, C. L. (2007). Differentiation of human embryonic stem cells to cardiomyocytes by coculture with endoderm in serum-free medium. Current Protocols in Stem Cell Biology. doi:10.1002/9780470151808.sc01f02s2.

15. Li, X. (2004). Role of connexin 43 in ischemic preconditioning does not involve intercellular communication through gap junctions. Journal of Molecular and Cellular Cardiology, 36(1), $161-163$.

16. D'Souza, S. P. (2003). B-type natriuretic peptide limits infarct size in rat isolated hearts via KATP channel opening. American Journal of Physiology, 284(5), H1592-H1600.

17. Milkiewicz, M. (2006). Nitric oxide and p38 MAP kinase mediate shear stress-dependent inhibition of MMP-2 production in microvascular endothelial cells. Journal of Cellular Physiology, 208(1), 229-237.

18. Ferdinandy, P. (1995). KATP channel modulation in working rat hearts with coronary occlusion: Effects of cromakalim, cicletanine, and glibenclamide. Cardiovascular Research, 30(5), 781-787.

19. Walsh, K. B., Rich, T. C., \& Coffman, Z. J. (2009). Development of a high-throughput assay for monitoring cAMP levels in cardiac ventricular myocytes. Journal of Cardiovascular Pharmacology, 53(3), 223-230.

20. Ozsvari, B., Puskas, L. G., Nagy, L. I., Kanizsai, I., Gyuris, M., Madacsi, R., et al. (2010). A cell-microelectronic sensing technique for the screening of cytoprotective compounds. International Journal of Molecular Medicine, 25(4), 525-530.

21. Nakano, A., Liu, G. S., Heusch, G., Downey, J. M., \& Cohen, M. V. (2000). Exogenous nitric oxide can trigger a preconditioned state through a free radical mechanism, but endogenous nitric oxide is not a trigger of classical ischemic preconditioning. Journal of Molecular and Cellular Cardiology, 32(7), $1159-1167$.

22. Takano, H., Tang, X. L., Qiu, Y., Guo, Y., French, B. A., \& Bolli, R. (1998). Nitric oxide donors induce late preconditioning against myocardial stunning and infarction in conscious rabbits via an antioxidant-sensitive mechanism. Circulation Research, 83(1), $73-84$.

23. Maejima, Y., Adachi, S., Ito, H., Nobori, K., Tamamori-Adachi, M., \& Isobe, M. (2003). Nitric oxide inhibits ischemia/reperfusion-induced myocardial apoptosis by modulating cyclin A-associated kinase activity. Cardiovascular Research, 59(2), 308-320.

24. Kanno, S. (2004). Nitric oxide facilitates cardiomyogenesis in mouse embryonic stem cells. Proceedings of the National Academy of Sciences of the United States of America, 101(33), 12277-12281.

25. Ferdinandy, P. (2003). Nitric oxide, superoxide, and peroxynitrite in myocardial ischaemia-reperfusion injury and preconditioning. British Journal of Pharmacology, 138(4), 532-543.

26. Krumenacker, J. S. (2006). Differential expression of genes involved in cGMP-dependent nitric oxide signaling in murine embryonic stem (ES) cells and ES cell-derived cardiomyocytes. Nitric Oxide, 14(1), 1-11.

27. Abdelalim, E. M., \& Tooyama, I. (2009). BNP signaling is crucial for embryonic stem cell proliferation. PLoS One, 4(4), e5341.

28. Mobley, S. (2010). PKG and PKC are down-regulated during cardiomyocyte differentiation from embryonic stem cells: Manipulation of these pathways enhances cardiomyocyte production. Stem Cells International. doi:10.4061/2010/701212.

29. Xu, Z. (2004). Exogenous nitric oxide generates ROS and induces cardioprotection: Involvement of PKG, mitochondrial KATP channels, and ERK. American Journal of Physiology, 286(4), H1433-H1440.

30. Gryshchenko, O. (1999). Role of ATP-dependent K(+) channels in the electrical excitability of early embryonic stem cell-derived cardiomyocytes. Journal of Cell Science, 112(17), 2903-2912.

31. Baharvand, H., Hajheidari, M., Zonouzi, R., Ashtiani, S. K., Hosseinkhani, S., \& Salekdeh, G. H. (2006). Comparative proteomic analysis of mouse embryonic stem cells and neonatalderived cardiomyocytes. Biochemical and Biophysical Research Communications, 349(3), 1041-1049. 